Final Report

\title{
Development of Solar Grade Silicon (SoG-Si) Feedstock by Recycling SoG-Si Wastes
}

\author{
DOE award ED-EE0000575
}

DE-PS36-09G099003 (CFDA number: 81.087): Photovoltaic Supply Chain and Cross-Cutting Technologies:

Topic 1: Proof of Concept/Feasibility Assessment

Focus area 3: PV manufacturing processes and metrologies: Materials recycling

\author{
Lifeng Zhang, Assistant Professor \\ Anping Dong, Postdoctoral Research Associate \\ Lucas Nana Wiredu Damoah, Ph.D. Student \\ Department of Materials Science \& Engineering \\ Missouri University of Science and Technology (Missouri S\&T) \\ 223 McNutt Hall, Rolla, MO 65409-0340 \\ Phone: 573-341-4776, \\ Email: zhanglife@mst.edu
}




\section{Table of Contents}

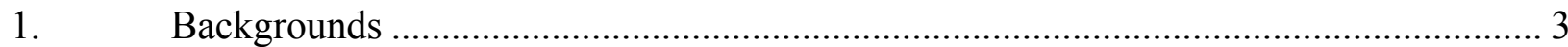

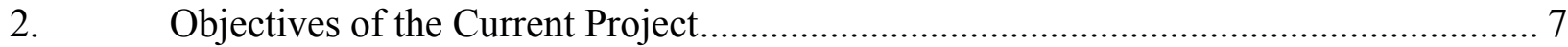

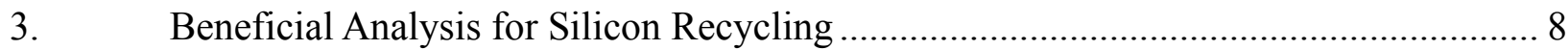

4. Recovery of Siliocn from SoG Silicon Slurry Wastes ................................................ 9

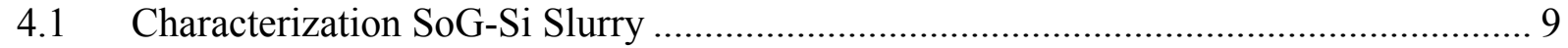

4.2 The Effects of Acid Treatment on Silicon Slurry.................................................... 10

4.2.1 Original silicon slurry without acid treatment .................................................... 10

4.2.2 Original silicon slurry with acid treatment ………................................................ 11

4.2.3 Summary of original silicon slurry analysis …….................................................. 11

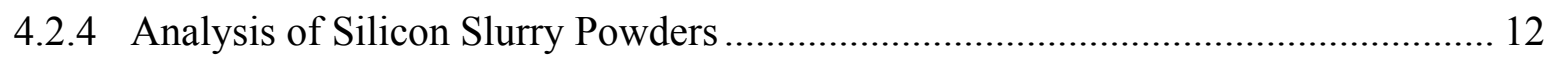

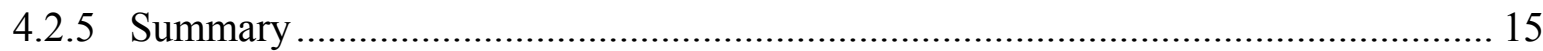

4.3 Recovery of Silicon from Waste Silicon Slurry by High Temperature Remelting ....... 16

4.3.1 Using a Mo-heated High Temperature Furnace ................................................. 16

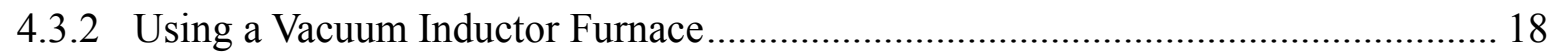

4.3.3 Using High Frequency Electromagnetic Heating .............................................. 19

4.4. Recovery of Silicon from Waste Silicon Slurry by Centrifugation Separation ............ 21

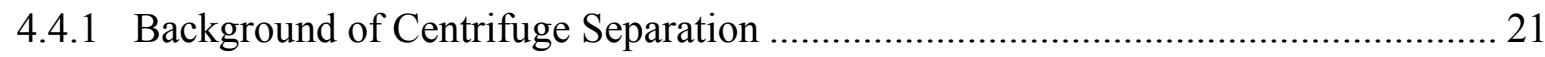

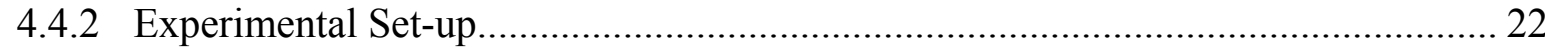

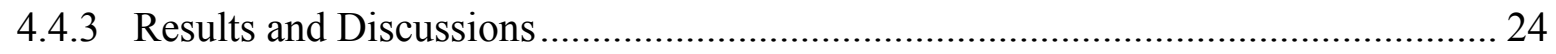

5. Removal of Non-metallic Inclusions from the Silicon Using EM Separation............... 25

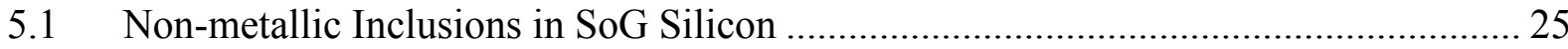

5.1.1 Inclusions in Top Surface of Unpolished Top-cut Scraps ....................................... 25

5.1.2 Inclusions inside Top-cut Scraps from Company X (Sample X).............................. 27

5.1.3 Inclusions inside Top-cut Scraps from Company Y (Sample Y) …………………... 31

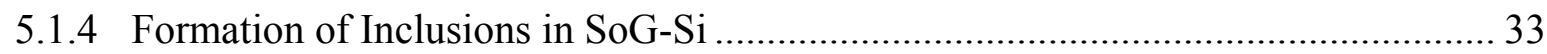

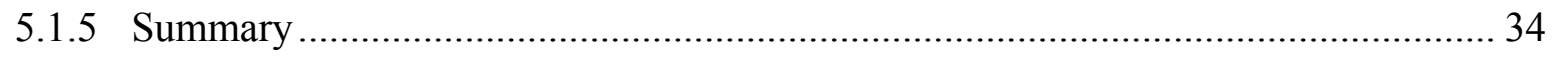

5.2 Recycling of SoG Silicon Top-Cut Scraps using Electromagnetic Purification ........... 34

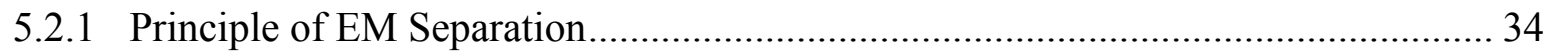

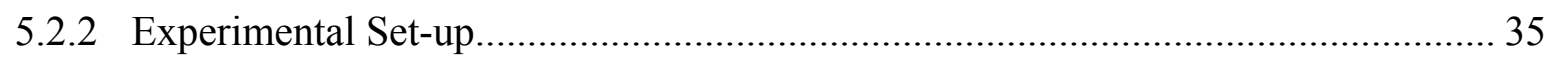

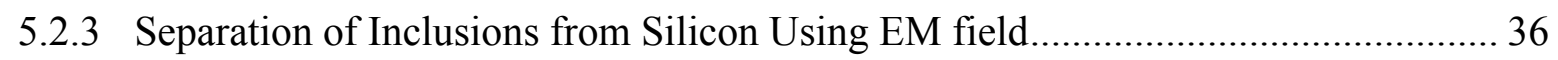

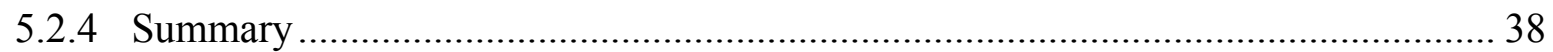

6. Tentative Design for the Recycling of Silicon from Silicon Wastes............................. 38

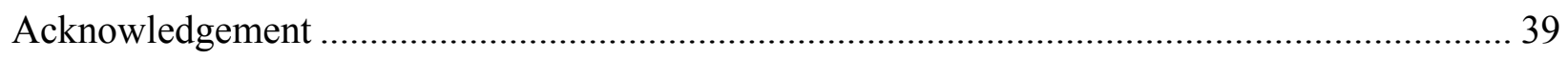

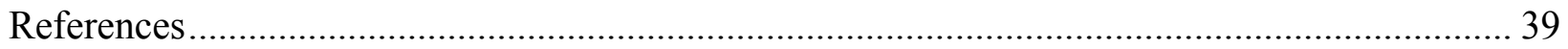




\section{Backgrounds}

With energy sources depleting and costs rising, alternatives have to be looked into to meet the needs of the energy ${ }^{[1]}$. The amount of energy to supply our needs is huge and it has been hard to find a perfect energy source that can meet those needs and not be depleted. One of the possible options is solar energy. Solar energy is claimed to be a source of clean and green electricity. There have been vast improvements recently that have led researchers to believe that solar energy is soon going to play an important role in electricity generation for the masses. The solar radiation - the sunlight - that reaches the surface of the earth makes available more than 100 times the total energy we need to meet all our present needs. Conversion of sunlight by means of silicon-based solar cells is a clean method experiencing a rapid growth in recent years ${ }^{[2]}$. The challenge today is to create the technology needed to establish solar energy as a practical and economical alternative to energy produced by fuels - and to use that solar-produced energy in a wide variety of applications ${ }^{[3]}$.

Figure 1 shows the global production growth of the silicon-based solar cell and US market share ${ }^{[4]}$ The growth rate of solar cell in Japan and Europe was/is higher than that in US. The US market share in the world has kept decreasing since 1995 although the absolute amount is increasing with years. Over $90 \%$ of current dominant materials used in PV cells is silicon ${ }^{[5]}$. Solar Grade (SoG) silicon feedstock can be developed using either a chemical approach or a pyro-metallurgical approach. In both cases, the starting point is metallurgical grade (MG) silicon and the target is to produce a high purity silicon feedstock for production of high performance devices ${ }^{[6]}$. The semiconductor industry uses the chemical approach to achieve purities in the ppba range. MG silicon has to be converted into a gaseous or liquid chemical (e.g. trichlorosilane, silane, etc.), which is then put through multiple distillations for purification and finally reduced via gaseous phase reactions. The resultant product is high purity polysilicon, which is left with B and $\mathrm{P}$, the most difficult elements to remove from silicon ${ }^{[6]}$, at levels less than $1 \mathrm{ppba}$ and all other impurities even lower.

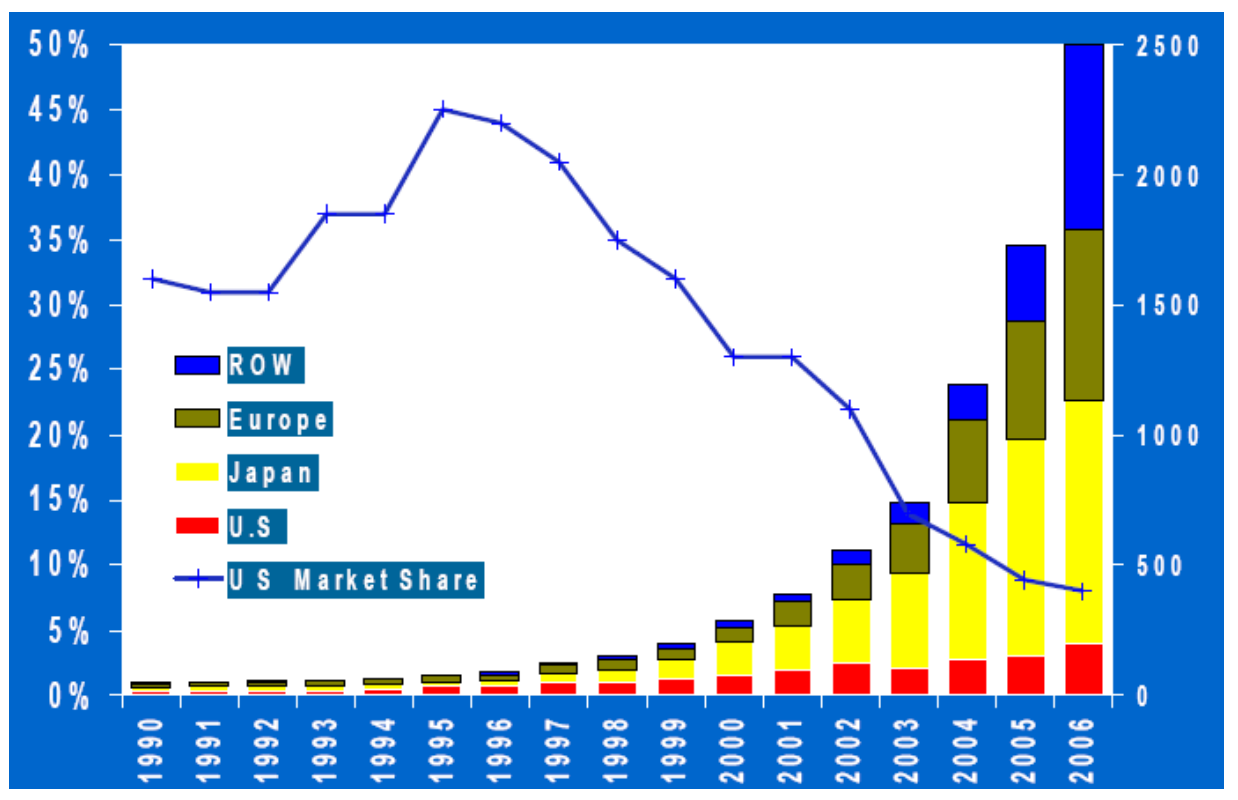

Fig.1 Silicon solar cell global production growth and U.S. market share (Data from PV news, Prometheus Institute, Vol.26, March 2007) ${ }^{[4]}$ 
Figure 2 shows the production process of $\mathrm{x}-\mathrm{Si} \mathrm{PV}$ system ${ }^{[7]}$, and Figure 3 is a schematic diagram of the traditional method of wafer manufacturing ${ }^{[8]}$, showing the production of the single crystalline $(\mathrm{Cz})$ silicon wafer and multicrystalline $(\mathrm{MC})$ silicon wafer. In the wire sawing process, an optionally diamond impregnated steel wire, about 180 micrometer in diameter running over control spindles, is placed under high tension and pushed onto the silicon ingot while an abrasive slurry composed of 25 micrometer or less silicon carbide ( $\mathrm{SiC})$ particles in a mineral oil or glycol-base is fed to the cutting zone between the wire and the workpiece. ${ }^{[9]}$.

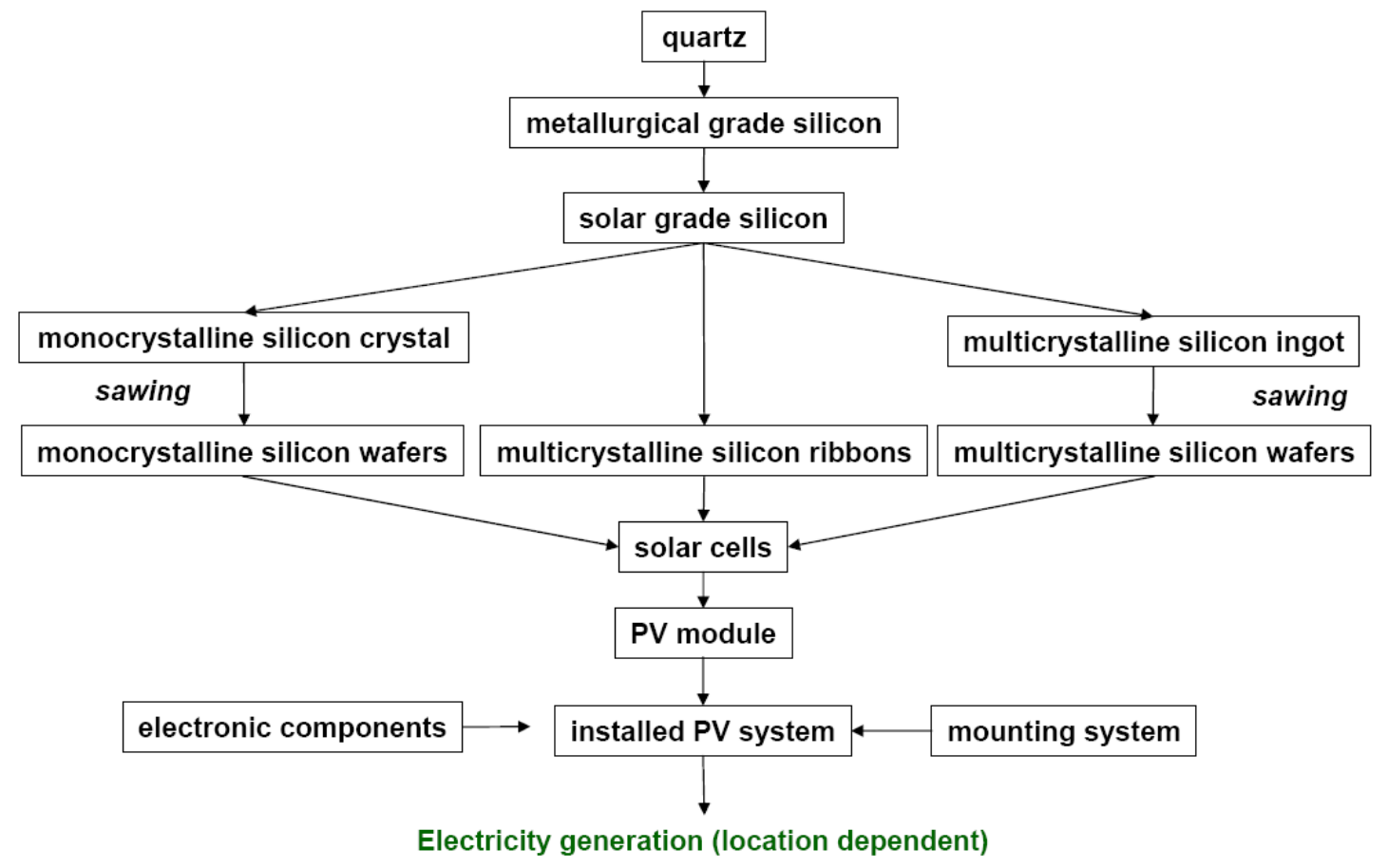

Fig.2 Production of $\mathrm{x}-\mathrm{Si}$ PV system ${ }^{[7]}$

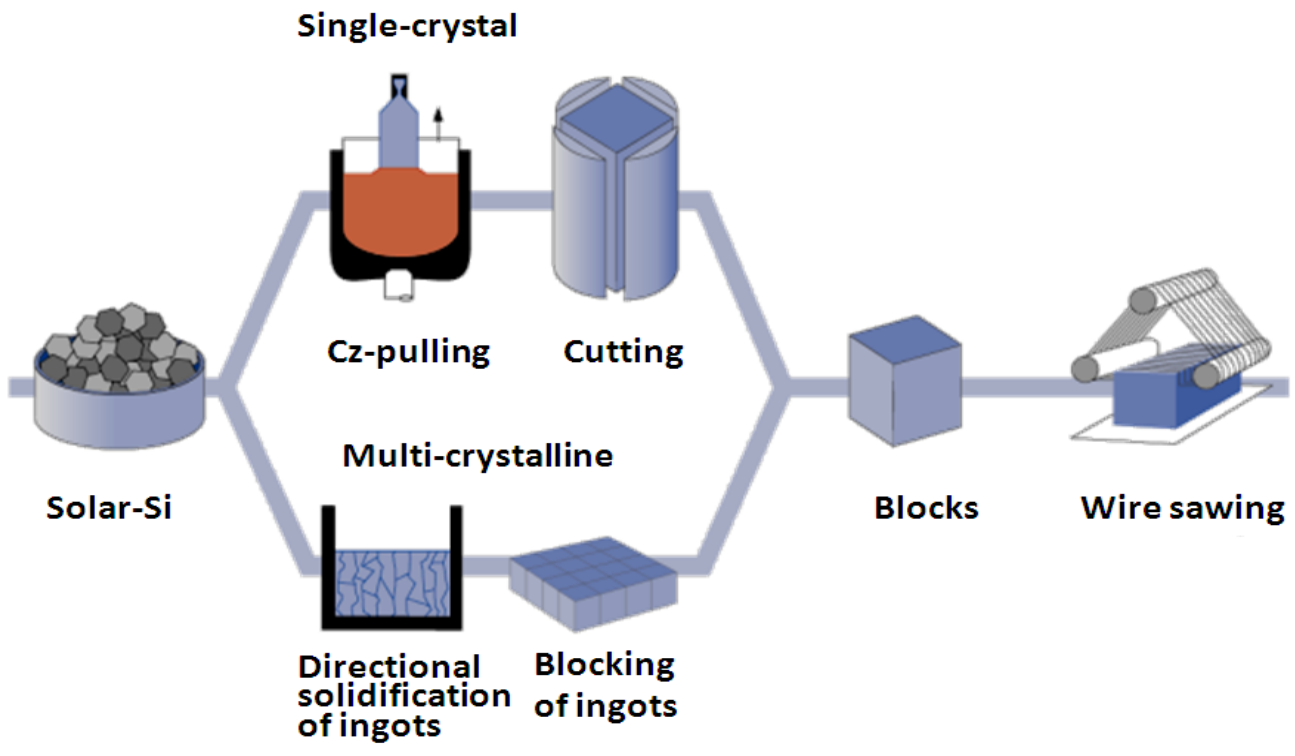

Fig.3 Typical silicon wafer production process ${ }^{[8]}$ 
The thin wafer comb as it comes off of the wire saw is as shown in Figure 4. After sawing, only $45 \%-50 \%$ of the silicon feedstock finally ends up in a wafer. The remaining $50 \%-55 \%$ is lost in the block cutting process (tops, tails and slabs) and the biggest portion (up to $40 \%$ ) is lost as sawing slurry in the wafer saw process and is currently not recoverable ${ }^{[10]}$. It was reported that the silicon shortage has been ceased since 2008 since many new producers enter the market, as shown in Figure 5. ${ }^{[11]}$ Only 15,000 tons of silicon were available for use in solar cells in 2005, this number grows to 123,000 tons by $2010^{[12]}$ and to no less than 144,000 tonnes by $2011 .^{[13]}$ However, as predicted by Homan (Figure $1^{[11]}$ ), the silicon shortage will appear again after the year 2013 because of the high growth rate of the PV output and the silicon demand for solar cells. Furthermore, even during the silicon non-shortage years - 2008-2013, the high production capacity of the silicon implies high silicon sawing wastes.

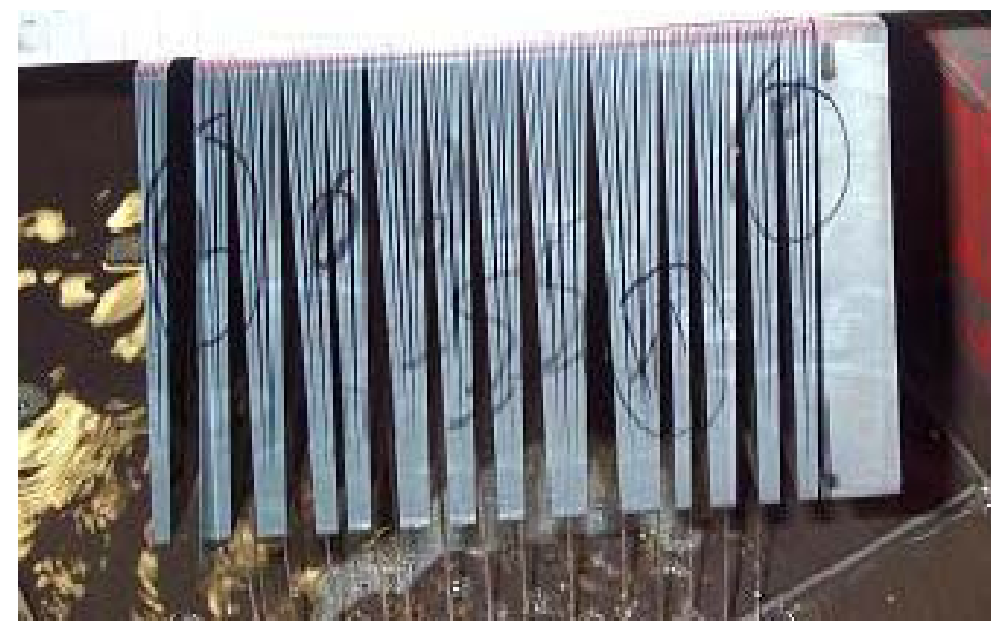

Fig.4 Thin Wafer Comb as it came off of the Wire Saw ${ }^{[14]}$

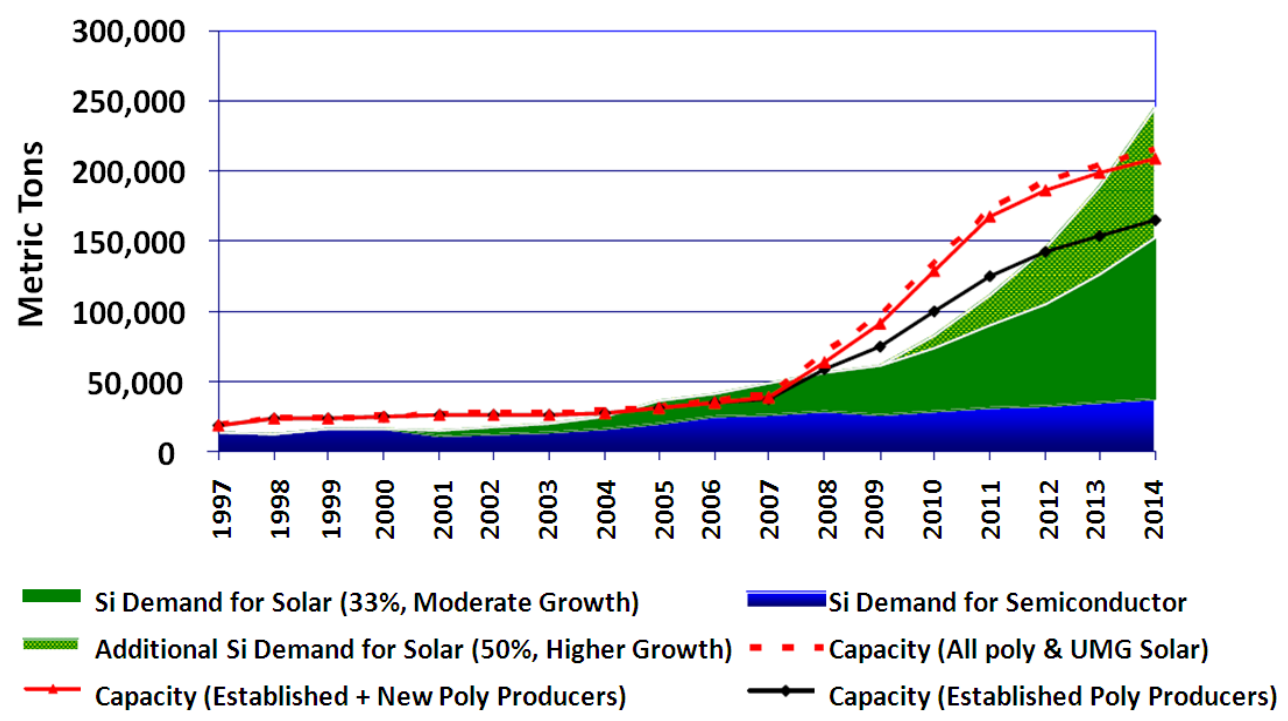

Fig.5 HSC's global MC-Si supply/demand forecast. ${ }^{[1]}$

Si wastes during the state-of-the-art MC-Si PV production (from ingot growth to solar cells and modules fabrication) include wastes from ingot top-cut scraps, wastes from the sawing slurry and other wastes. In total, $70 \%$ of the silicon feedstock that enters the PV production chain is lost as silicon-containing wastes. This quantity corresponds to almost 10 ton of lost silicon per MWp 
obtained module power, based on an assumed quantity of 15 ton silicon per produced MWp module power. ${ }^{[15]}$

\section{- $\quad$ Wastes from the Sawing Slurry}

Wafer production requires the cutting of large silicon ingot using the multi- wire slicing technology. ${ }^{[16]}$ The cutting slurry consists of $\mathrm{SiC}$ particles $\left(5-30 \mu \mathrm{m}\right.$ in size $\left.{ }^{[17]}\right)$ as the abrasives and glycol as the carrying fluid. The amount of silicon waste powder created by sawing a silicon ingot depends primarily on the diameter of the cutting steel wire. Since the wafer thickness is nowadays approaching the wire diameter $(150-200 \mu \mathrm{m}),{ }^{[18]}$ more wafers mean more silicon sawing slurry. For 1 ton silicon ingot, during wafer sawing, 35-60\% becomes silicon slurry powders $^{[19]}$ (diameter of $1 \mu \mathrm{m}$ and less ${ }^{[15]}$ ) with addition of 5 ton SiC/glycol slurry, and finally $\sim 550 \mathrm{~kg}$ wafers achieved. ${ }^{[16]}$ In slurry, there are iron particles that have been eroded from the wire during the cutting operation. ${ }^{[15]}$ So, the exhausted slurries contain up to $10 \%$ of silicon powders.

\section{- Wastes from SoG-Si ingot Top-Cut Scraps}

The top of the MC-Si ingot, $\sim 10 \%$ in mass of the whole ingot, is highly contaminated by impurities such as iron, aluminum, $\mathrm{SiC}$, and $\mathrm{Si}_{3} \mathrm{~N}_{4}$, thus must be cut off as scraps. Figure 6 shows a picture of typical top-cut SoG-Si scraps. $5-20 \mathrm{~mm}$ thick and $\sim 20 \%$ in mass of the whole ingot, ${ }^{[15]}$ must be removed from the side of the ingot to obtain a good square shape. The side-cut scraps have been recycled at most of the wafer plants. If inclusions and metallic impurities in the top-cut scraps can be removed, these top-cut scraps can become good feedstock for silicon PV cells. Zhang et al has successfully recycled these SoG-Si scraps through high temperature filtration. ${ }^{[20-24]}$

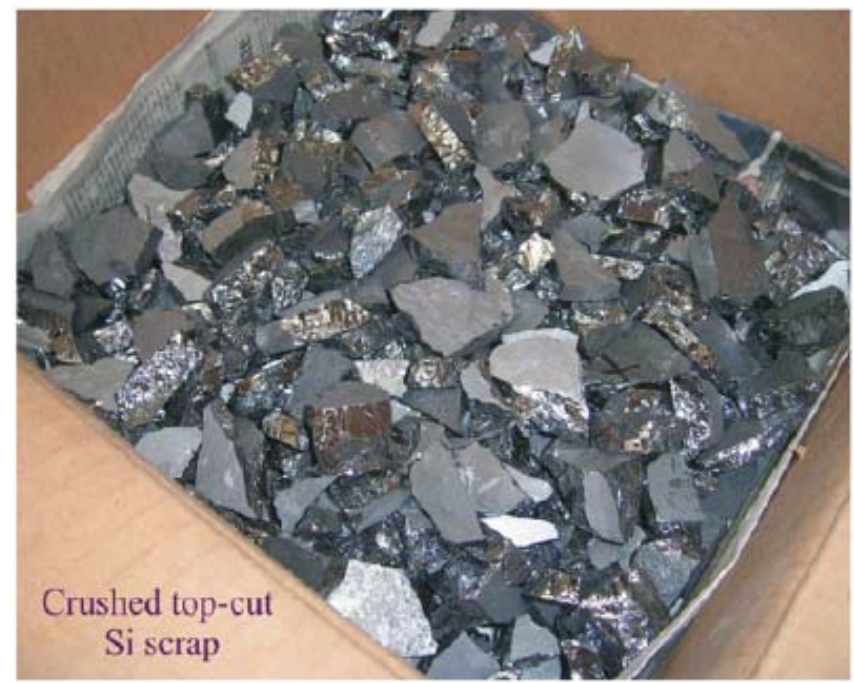

Fig.6 Typical top-cut SoG-Si scraps

- Other SoG-Si Wastes

Other SoG-Si wastes are, such as defective semi-finished products, broken wafers and cells and end-of-life modules. A quantity of $\sim 4 \%$ of the silicon feedstock entering the PV production chain is lost during cell production, mainly in form of mechanical breakage. ${ }^{[15]}$ Solar cell producers typically guarantee solar cell operating lifetimes of 25-30 years, and actual operating lifetimes are expected to be even longer. 
Figure 7 illustrates a Schematic of SoG-Si wastes generated during the process from $\mathrm{MC}-\mathrm{Si}$ ingot to wafer ${ }^{[2]}$. In the wafer cutting process, small particles of silicon are generally lost as kerf losses and mixed with silicon carbide - an abrasive used in the cutting of wafers with steel wire. Therefore, the PV industry has an immediate need to reduce the waste of valuable silicon, which represents $\sim 25 \%$ of the cost of a solar module. Recycling of the tops of ingots and recovery of silicon kerf loss has to be looked into urgently ${ }^{[8]}$. The kerf loss slurry waste also consists of metal impurities from cutting wire, lubricating oil (polyethylene glycol), and the additives for better particle suspension ${ }^{[9]}$.

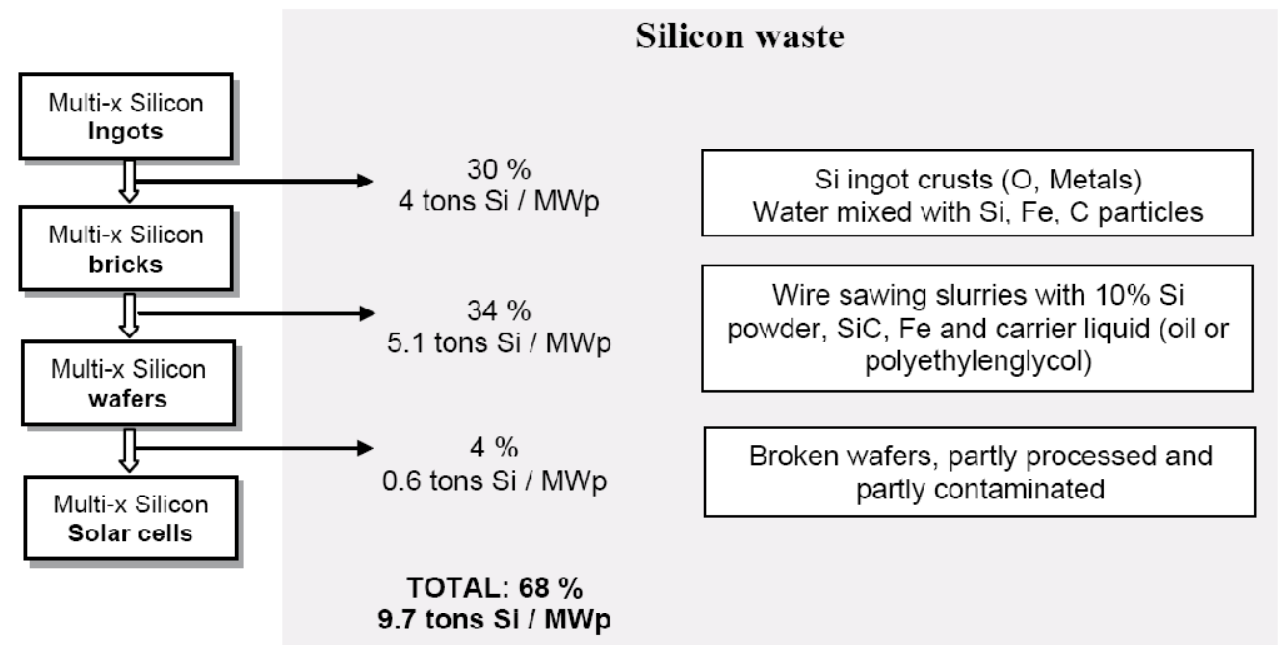

\begin{tabular}{|c|c|c|}
\hline SoG-Si scraps & Percentage of total silicon used in solar cell & Status \\
\hline Top-cut scraps & $10 \%, 1.3$ tons Si/MWp & NOT being recycled \\
\hline Side-cut scraps & $20 \%, 2.7$ tons Si/MWp & Partly being recycled \\
\hline Sawing slurry & $34 \%, 5.1$ tons Si/MWp & NOT being recycled \\
\hline Broken wafers & $4 \%, 0.6$ tons Si/MWp & Partly being recycled \\
\hline$\Sigma$ & $68 \%, 9.7$ tons Si/MWp & \\
\hline
\end{tabular}

Fig.7 Schematic of SoG-Si wastes generated during the process from MC-Si ingot to wafer

It is well known that during the production of the silicon, the energy consumption and the emission of $\mathrm{CO}_{2}$ (especially for carbon reduction process) are huge. There is no reason for us to produce more SoG-Si but keep the silicon wastes not being recycled.

\section{Objectives of the Current Project}

The Green Process Metallurgy and Modeling Laboratory (GPMM) at Missouri University of Science and Technology was commissioned by Department of Energy of the US (DOE) (Award No. DE-EE0000575) to conduct a study on development of solar grade silicon (SoG-si) feedstock by recycling SoG-si wastes.

The objective of the project is to develop processes to recycle SoG-Si wastes, including top cut scraps and sawing slurry wastes using low-cost, environmental-friendly, efficient and fast processes. Specifically, the researches include the following tasks, as illustrated in Figure 8:

(1) Pretreat the wafer sawing slurry of SoG-Si by a combination of mechanical and chemical treatments; 
(2) Recycle SoG-Si top-cut scraps through filtration;

(3) Remelt and Purify the SoG-Si scraps and the silicon powders separated from slurry using high frequency electromagnetic (EM) field;

(4) Design tentative industrial processes to recycle SoG-Si wastes.

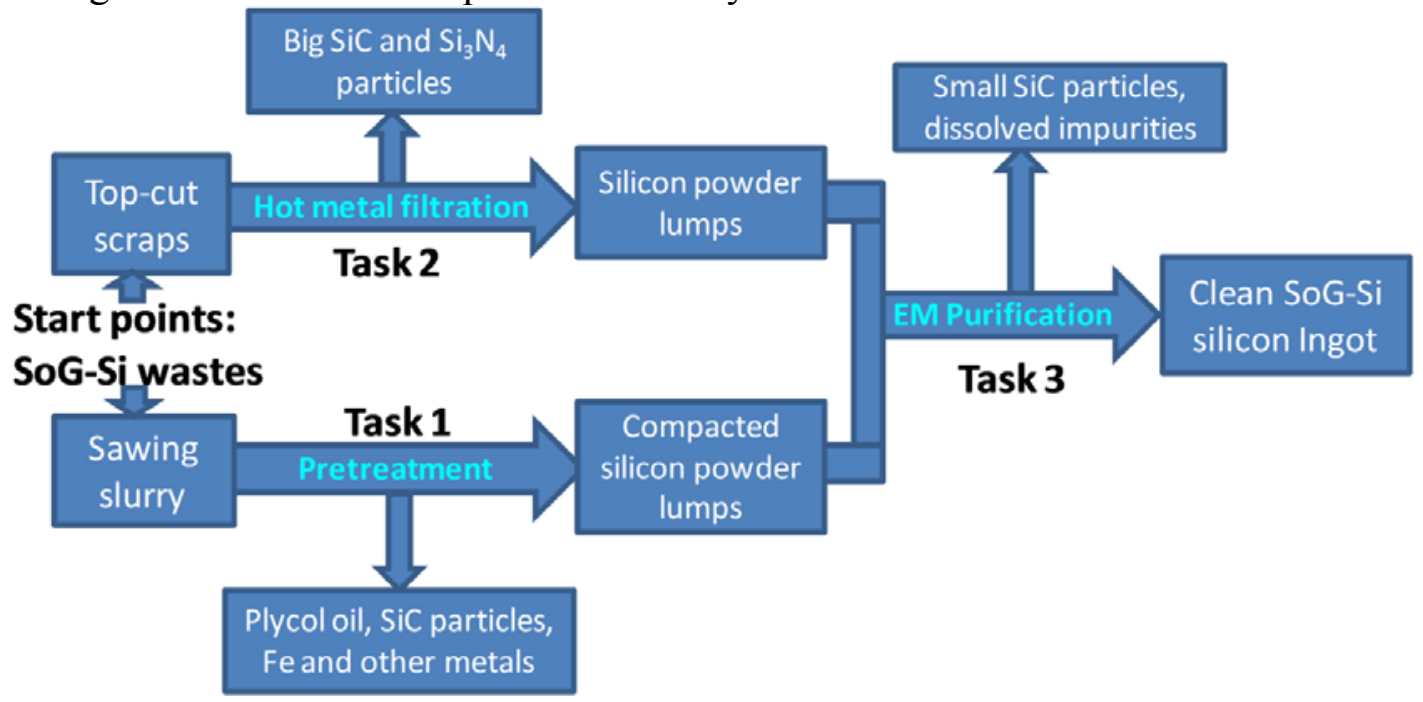

Fig.8 Technologies and tasks proposed in the current work

\section{Beneficial Analysis for Silicon Recycling}

Using the quantity of SoG-Si wastes 101750 tons in the year 2010 as an example, the value of these SoG-Si wastes can be analyzed as below:

\section{- Financial Value}

If the price of the silicon ingot is $\$ 50 / \mathrm{kg}^{[25]}$ then the monetary value of for these wastes is estimated at $\sim \$ 5.1$ billion per year. Most of the abrasives-SiC particles are not broken during the cutting and are reusable. ${ }^{[17]}$ If we consider the recycling of SiC abrasive particles and glycol oil, the value will be much higher. For 1 ton silicon ingot, during wafer sawing, 5 ton SiC/glycol slurry is added, and finally $\sim 550 \mathrm{~kg}$ wafers achieved. ${ }^{[15-16,26]}$ As a result, the exhausted slurries contain up to $10 \%$ of silicon powders. The value of the $\mathrm{SiC}$ particles and glycol in the slurry will also be an amazing number.

\section{- Energy Value}

The manufacture of a silicon ingot for photovoltaic applications is a very energy intensive process, since many of the individual steps of extraction, purification and melt growth require very high temperatures. While the cost for the recycling of SoG-Si wastes only $\sim 5 \%$ of the primary production of SoG-Si. It was reported that at least $100 \mathrm{MW}$.hours of electrical energy were required to produce 1 metric ton of all silicon ingots. ${ }^{[27-28]}$ Thus, the energy expended in making silicon sawing slurry wastes that are still not recycled is $\sim 10.2$ TeraWatt-hours per year.

- $\mathrm{CO}_{2}$ Emissions

From the estimation in 2006 , for the complete production of SoG-Si, 48 tonnes $\mathrm{CO}_{2}$ per tonne of MC-Si ingots and 62 metric ton $\mathrm{CO}_{2}$ per metric ton of $\mathrm{Cz}$ single crystalline $\mathrm{Si}$ is emitted ${ }^{\left[{ }^{[2]} \mathrm{In}\right.}$ 
2006, single crystal silicon accounted for 35\% of solar cell materials, and MC-Si accounted for $56 \% .{ }^{[29]}$ Then these SoG-Si sawing slurry wastes account for $\sim 5.4$ million tonnes of $\mathrm{CO}_{2}$ emissions per year.

\section{- Efficiency and Energy Payback Time}

Two of the main issues for the silicon photovoltaic industry are: the cost per watt of power generated and the energy payback (i.e. whether the energy generated by the solar cell exceeds the energy consumed by its manufacture). Recent studies indicate that crystalline silicon PV systems currently have an energy payback time of 1.5-3.5 years for locations with irradiation conditions of $1000-1700 \mathrm{kWh} / \mathrm{m}^{2} / \mathrm{yr}^{[30]}$ Indications are that future developments in the use of thinner wafers, new low energy feedstock processes and improved energy efficiencies in ingot growth will result in payback times approaching 1 year ${ }^{[30]}$ These figures are extremely encouraging for the future of crystalline silicon PV technology, especially since the PV module lifetime is commonly assumed to be 30 years. ${ }^{[30]}$ Efficient reduction or recycling of the waste silicon from sawing these thinner wafers would be a possible route for even further reduction of these pay-back times.

\section{Recovery of Siliocn from SoG Silicon Slurry Wastes}

\subsection{Characterization SoG-Si Slurry}

The silicon slurry wastes shipped to Missouri S\&T from a silicon wafer producer in the US was analyzed. Mainly four components were found in the liquid slurry: oil, silicon powder, SiC particles and iron powders. Figure 9 shows the image of the slurry. The oil floated on the top of the solid slurry. Most of the big particles sinked down to the bottom of the slurry. The powder at the bottom was almost dry and rigid. Figure 10 shows the powder at the bottom of the slurry after drying. Above the rigid solid there was a mixture of powders and oil. It was difficult to separate the oil and the powders in the oil.

In order to recover silicon from original slurry, the impurities must be removed step by step. The first stage is to remove and recycle oil from the slurry. Removing oil by heating the slurry was tried. Since the boiling point of polyethylene glycol is $250^{\circ} \mathrm{C}$, the heating temperature should at least be $450-500{ }^{\circ} \mathrm{C}$. During the heat process, if slurry is exposed in air, the silicon in the powder will react with oxygen and then it is difficult to recover silicon elements. Inert gas should be used to prevent the slurry from being oxidized. During heating process, even though under the inert atmosphere, the oil is still harmful to the lining refractory of the furnace.

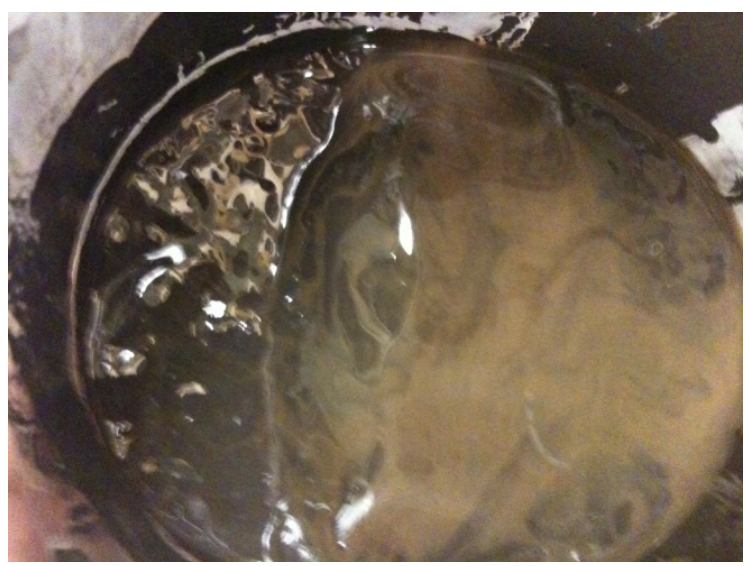

Fig.9 Image of the orginal slurry

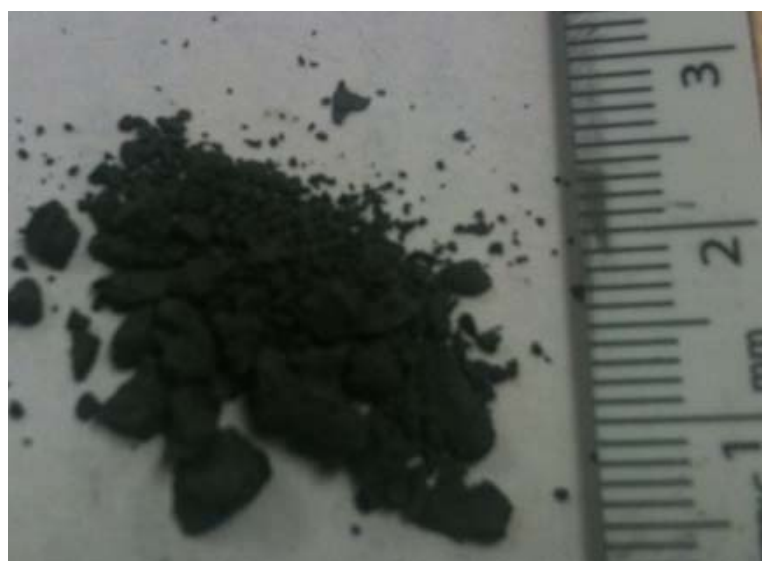

Fig.10 Image of the slurry powder 


\subsection{The Effects of Acid Treatment on Silicon Slurry}

Acid treatment is a typical method used to remove metal impurities from solid powders. During acid treatment, the metal, mainly iron powders, dissolves in a solution and thus can be separated via filtration or centrifugation.

\subsubsection{Original silicon slurry without acid treatment}

Figure 11 shows the particle size distribution of the slurry after mixing with water; washing by acetone and vacuum filtering using filter paper with pore size of $0.7 \mu \mathrm{m}$. Figure 12 shows the SEM and EDS results of the small and large particles of the slurry after washing with acetone and vacuum filtration. EDS results showed that for Particle-a in the Figure 12, the ratio of Si to $\mathrm{C}$ almost 1 and it also contained $\mathrm{Fe}$ and $\mathrm{O}$. It was supposed to be $\mathrm{SiC}$ in slurry, the difference between these two kinds of particles was the size. Although $<1 \mu \mathrm{m}$ inclusions had a big number fraction, their volume fraction was very small compared to the inclusions with size of $\sim 10 \mu \mathrm{m}$. The volume fraction of $<5 \mu \mathrm{m}$ inclusions was approximately $14 \%$.

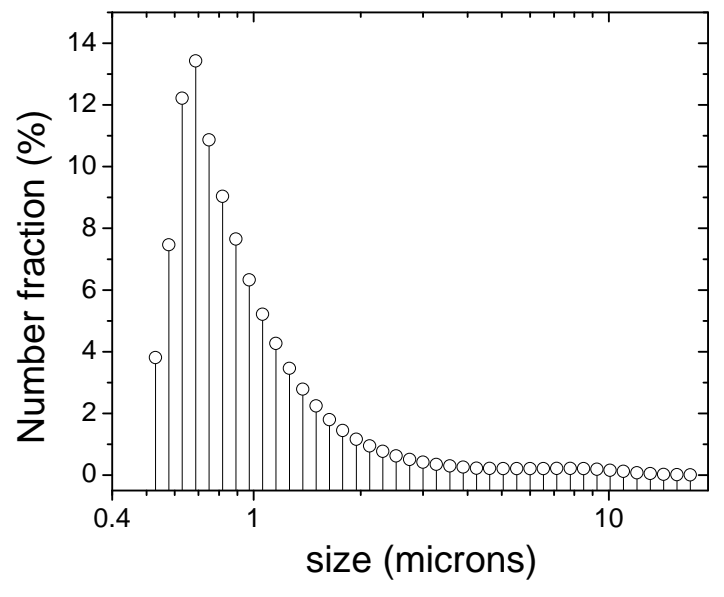

(a) Number fraction

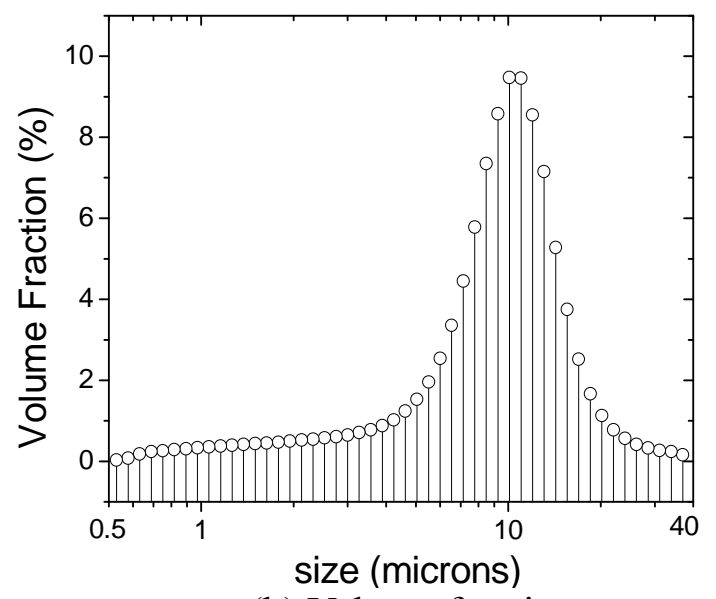

(b) Volume fraction

Fig.11 Particle size distribution of the original slurry after washing by acetone and vacuum

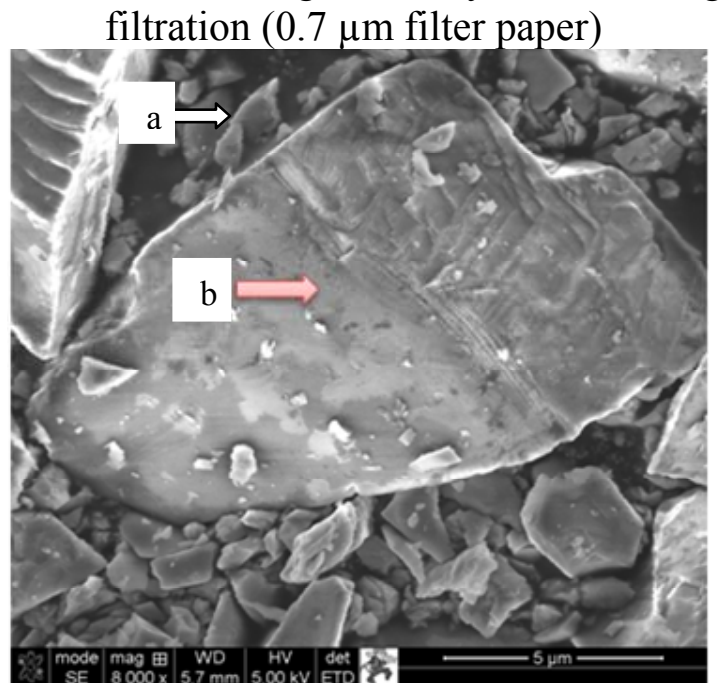

Fig.12 SEM and EDS results of the small particle of the slurry after washing with acetone and vacuum filtration. (a) Si: 52.54 at $\%$, C : 47.71 at $\%, 0.05$ at $\%$, and large (b) Si: 37.29 at $\%, C$ : 58.70 at $\%, 4.01$ at $\%$. 


\subsubsection{Original silicon slurry with acid treatment}

Acid treatment is used to remove iron from the slurry powders. In this study $15 \mathrm{~g}$ of the slurry powders was mixed with $150 \mathrm{ml} \mathrm{HNO}_{3}$. The concentration of the acid was $1 \mathrm{M}$ and the mixing duration was 40 minutes. Then the mixture was filtered using vacuum filtration method to separate the liquid from the powder. When the regular filter papers were used, the acid that was separated was dark. It indicated that some particles had passed the filter paper. The next filter paper used was Fisherbrand glass fiber circles. The filtration was fast and took less than 1 min to finish. Three methods were used to dry the powder: (1) Drying under room temperature after 72 hours; (2) Drying in a furnace at $150{ }^{\circ} \mathrm{C}$ for several hours and it was found that he powder obtained was dark and agglomerated; (3) Washing by acetone and it was performed just after vacuum filtration of the acid. The acetone was vacuum filtered and the powder was completely dried after less than $1 \mathrm{~min}$. No agglomeration occurred and the powders were very soft and fine by using method-3, as shown in Figure 13. The particle size distribution of the slurry that was acid treated and washed by acetone is also shown in Figure 13, indicating a size range of 0.5-40 $\mu \mathrm{m}$. The percentage of $10 \mu \mathrm{m}$ particle was a little bit higher than the slurry without acid treatment. Though the small inclusions had large number but its volume fraction was very small. From this figure, it concludes that the volume fraction of $<5 \mu \mathrm{m}$ inclusions is $\sim 8.0 \%$. Compared it to the results in Figure 11 that the volume fraction of $<5 \mu \mathrm{m}$ inclusions is $\sim 14 \%$ for the slurry without acid treatment. So the iron powder is around $6 \%$ of the total volume of the slurry powder.
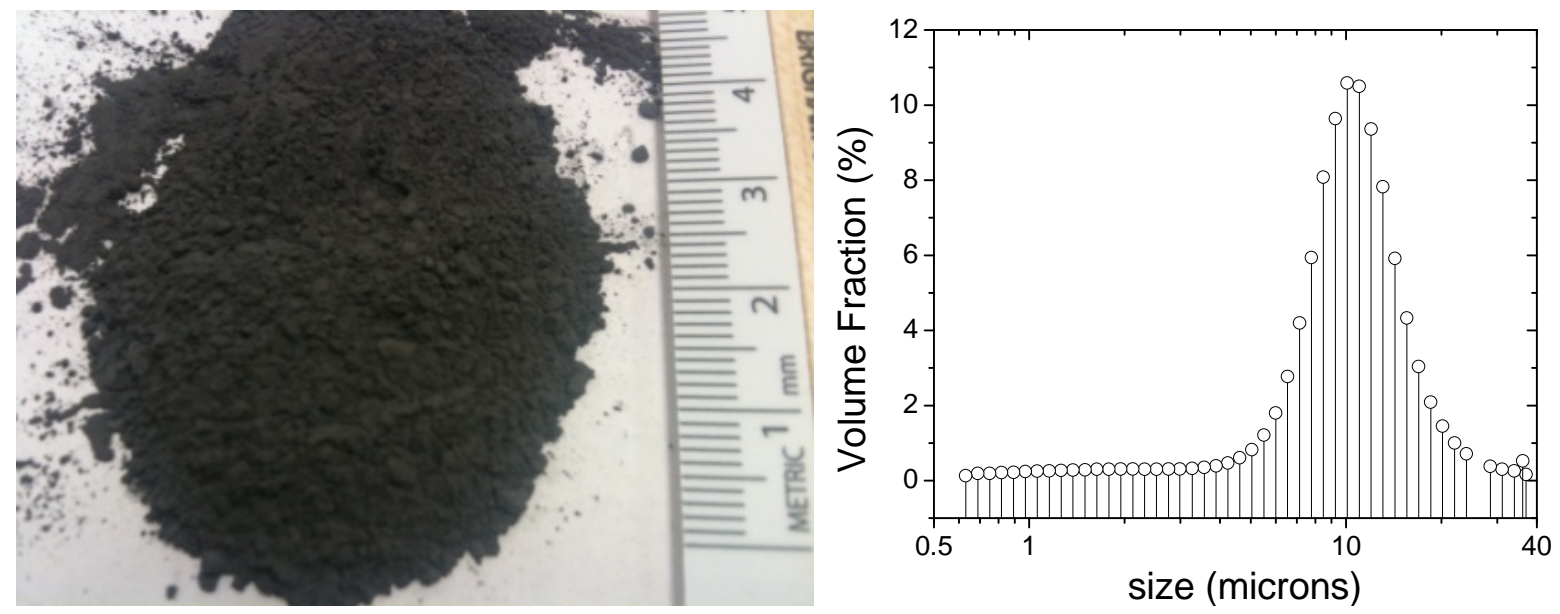

Fig.13 The image and the size distribution of the slurry powder after acid treatment and washing by acetone (filter paper pore size: $1.6 \mu \mathrm{m}$ )

The SEM image of the original silicon slurry that was acid-treated and washed by acetone is shown in Figure 17. EDS detection indicated that the large particles were SiC and the small particles were silicon powders. According to the fact that Si particles should be $10 \mathrm{wt} \%$ of the total particles, it was concluded that some of the Si particles with particle size less than $1.6 \mu \mathrm{m}$ have passed from the filter paper. Hence, it was supposed that using a filter paper with smaller pore size would result in the collection of more small particles.

\subsubsection{Summary of original silicon slurry analysis}

The dry powder and the original slurry from the sawing of the solar cell silicon were analyzed. Results indicated that they contained large SiC particles, small silicon particles, and with other 
impurity such as iron from the wire.

The slurry was acid treated by nitric acid to remove iron. The EDS analysis before and after acid treatment showed that iron was removed successfully. Using filter papers with finer pore size may prevent the fine silicon particles from entering into the waste acid.

The measurement of the size distribution showed that though the number of small inclusions is big, but their volume fraction is quite small. For the dry powder shipped from the industry, the volume fraction of $<5 \mu \mathrm{m}$ is $\sim 23 \%$; For the original slurry, this number is $14 \%$ for the slurry without acid treatment, and is $8 \%$ for the slurry with acid treatment, implying $6 \%$ of iron powder in the slurry powder.

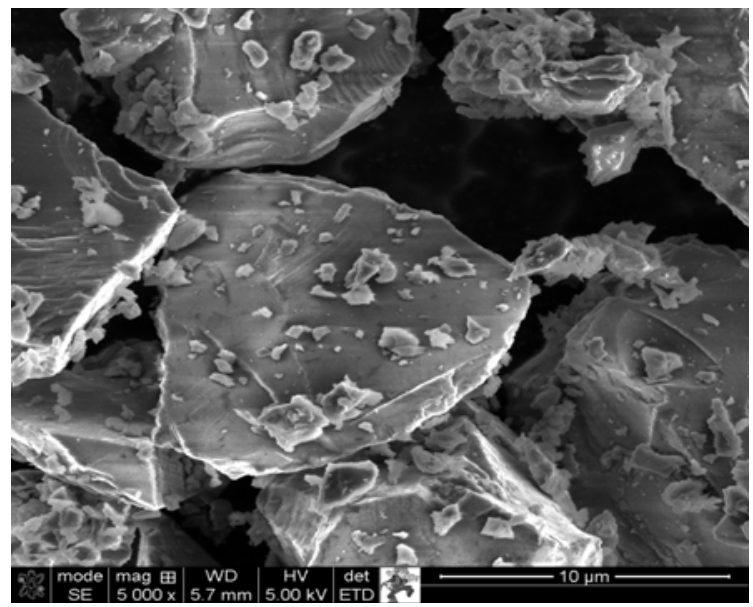

Fig.14 SEM image of the original slurry after acid treatment.

\subsubsection{Analysis of Silicon Slurry Powders}

From a silicon wafer producer, the solid slurry powders contained in plastic bottles were shipped to Missouri S\&T. These solid slurry powders were characterized at Missouri S\&T. The photo of these powders taken by a digital camera is shown in Figure 15, indicating bulky particles beside fine particles with different size.

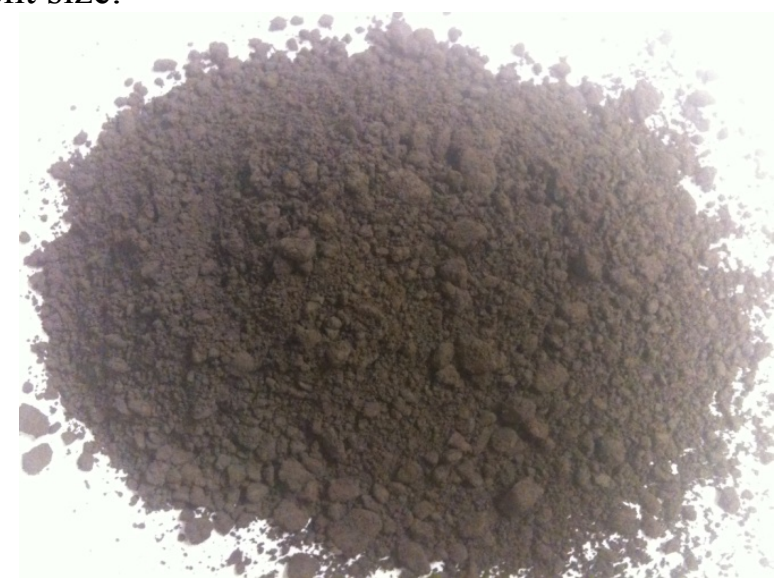

Fig.15 The image of the dry slurry powder from industry.

The size distribution of this solid slurry powder detected by Microtrac S3500 Particle Size Analyzer is shown Figure 16. The powder consists of a wide size range of particles: small particles $(<1 \mu \mathrm{m}), 10 \mu \mathrm{m}$ particles, and $50 \mu \mathrm{m}$ particles. The reported data for large particles might 
be incorrect since they easily sinked down to the bottom of the solution cup in the analyzer and were hardly detected.

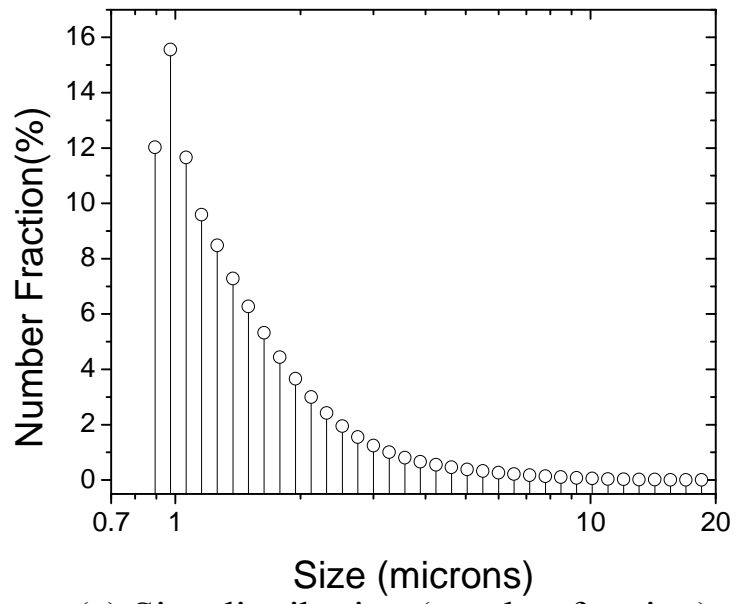

(a) Size distribution (number fraction)

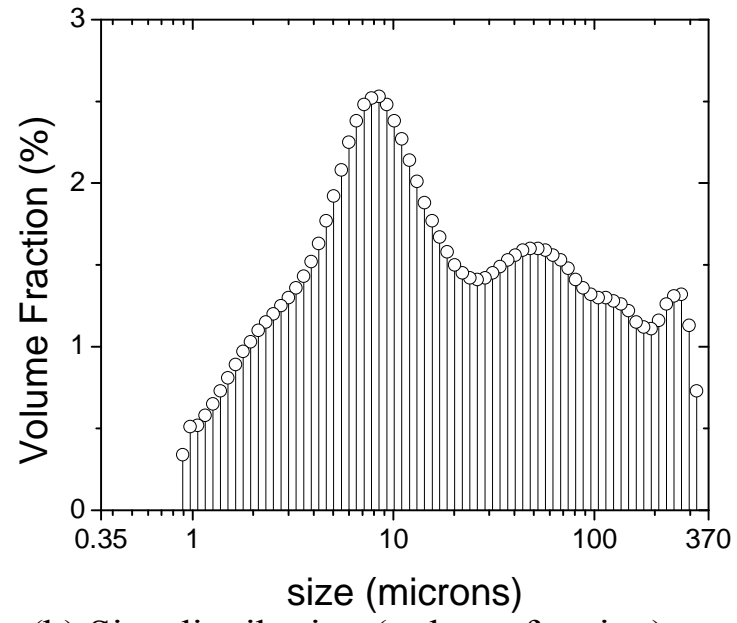

(b) Size distribution (volume fraction)

Fig.16 Particle size distribution of the silicon slurry powder

\section{SEM and EDS analysis}

The analysis of the slurry powders using SEM and EDS is shown in Figure 17. The powder contains particles with three different size ranges: a) $1-2 \mu \mathrm{m}$, b) $5-20 \mu \mathrm{m}$ and c) $20-40 \mu \mathrm{m}$. The particles with size of 5-20 $\mu \mathrm{m}$ seem to be resulted from some cutting procedure since they have flat sides and faces. The particles with size of 20-40 $\mu \mathrm{m}$ have strange shapes as can also be seen in Figure 17 (c) and the main phase of the area is $\mathrm{SiC}$ and the particle shown in this image contains $\mathrm{SiO}_{2}$ as the main phase. As shown in Figure 17 (a), the powder mainly consists of $\mathrm{SiC}$ with a significant amount of $\mathrm{SiO}_{2}$ and some small amount of $\mathrm{Fe}$ and $\mathrm{Al}$. In Figure 17b, the amount of $\mathrm{SiO}_{2}$ is considerably more than the amount of $\mathrm{SiC}$. Some small traces of $\mathrm{Al}, \mathrm{Na}, \mathrm{Fe}$ and $\mathrm{K}$ were also detected in this part of powder. The particle pointed in this image consists of $\mathrm{SiC}$ as the main phase, $\mathrm{SiO}_{2}$ and $\mathrm{Fe}$.

\begin{tabular}{|l|r|r|}
\hline Element & Wt \% & At \% \\
\hline C K & 40.62 & 57.7 \\
\hline O K & 16.62 & 17.72 \\
\hline FeL & 4.69 & 1.43 \\
\hline AlK & 0.68 & 0.43 \\
\hline SiK & 37.39 & 22.72 \\
\hline Total & 100 & 100 \\
\hline
\end{tabular}

(a)

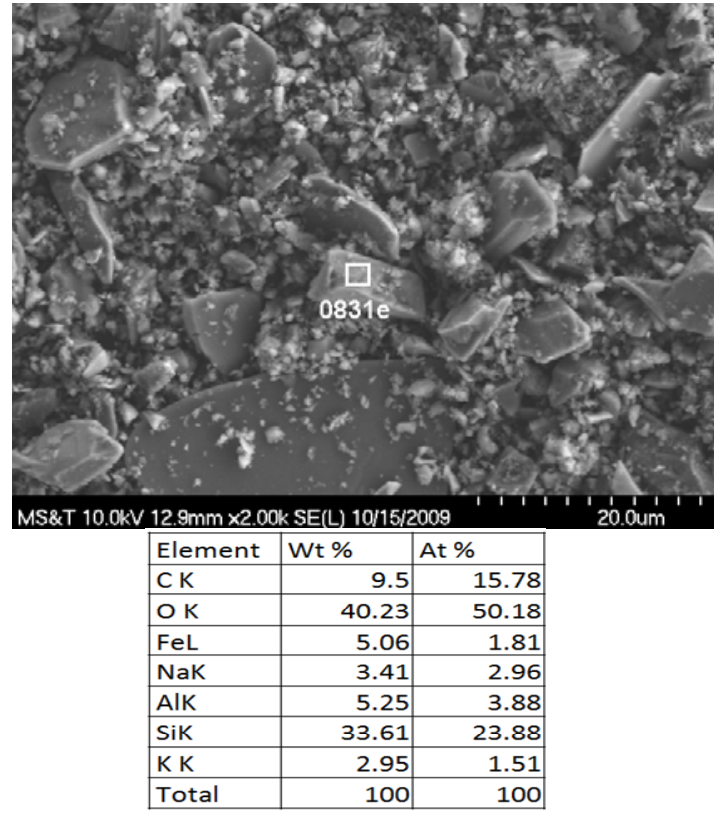

(b) 


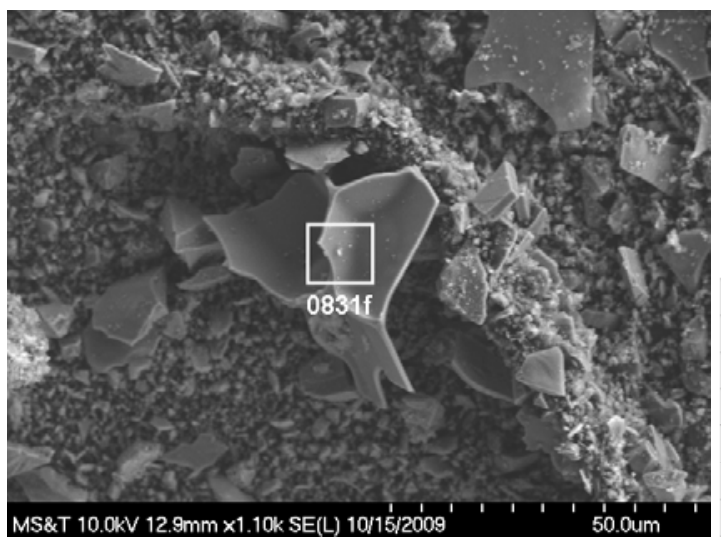

\begin{tabular}{|l|r|r|}
\hline Element & Wt \% & At \% \\
\hline O K & 40.43 & 54.46 \\
\hline NaK & 3.33 & 3.12 \\
\hline AlK & 7.24 & 5.78 \\
\hline SiK & 44.53 & 34.17 \\
\hline K K & 4.47 & 2.47 \\
\hline Total & 100 & 100 \\
\hline
\end{tabular}

(c)

Fig.17 The SEM image and EDS analysis of the powder showing three different size ranges: a) 1-2 $\mu \mathrm{m}$, b) 5-20 $\mu \mathrm{m}$ and c) $20-40 \mu \mathrm{m}$.

XRD analysis

In order to identify the phases in the silicon slurry, X-ray Powder Diffraction (XRPD) was conducted. Figures 18 and 19 show that the slurry was mainly composed of silicon and silicon carbide. CRS slurry contained $22 \%$ silicon and $78 \% \mathrm{SiC}$, and SPI slurry contained $28 \%$ silicon and $72 \% \mathrm{SiC}$.

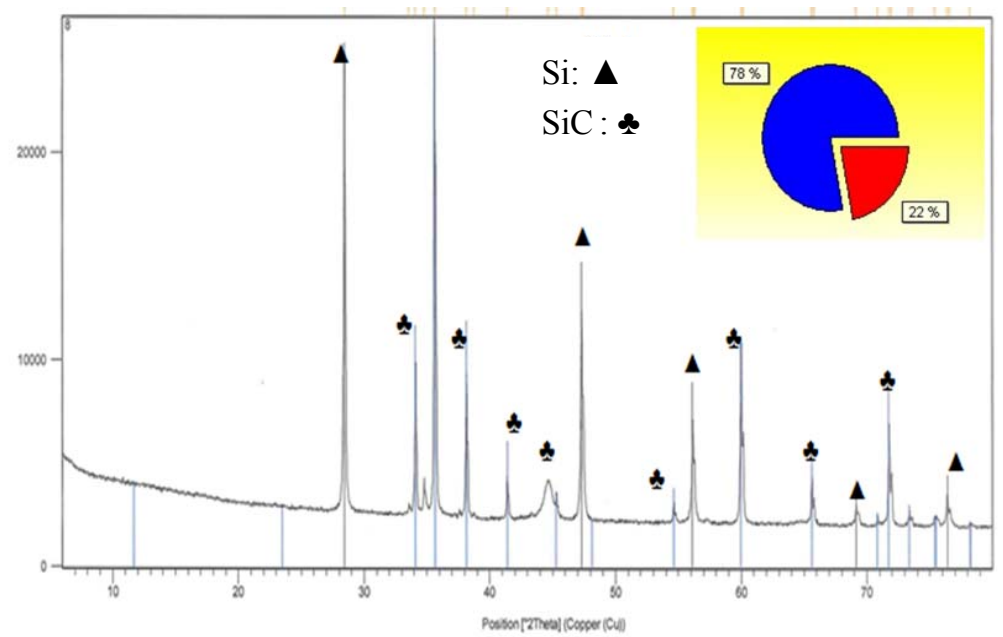

Si

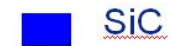

Fig.18 XRD analysis of CRS original silicon slurry

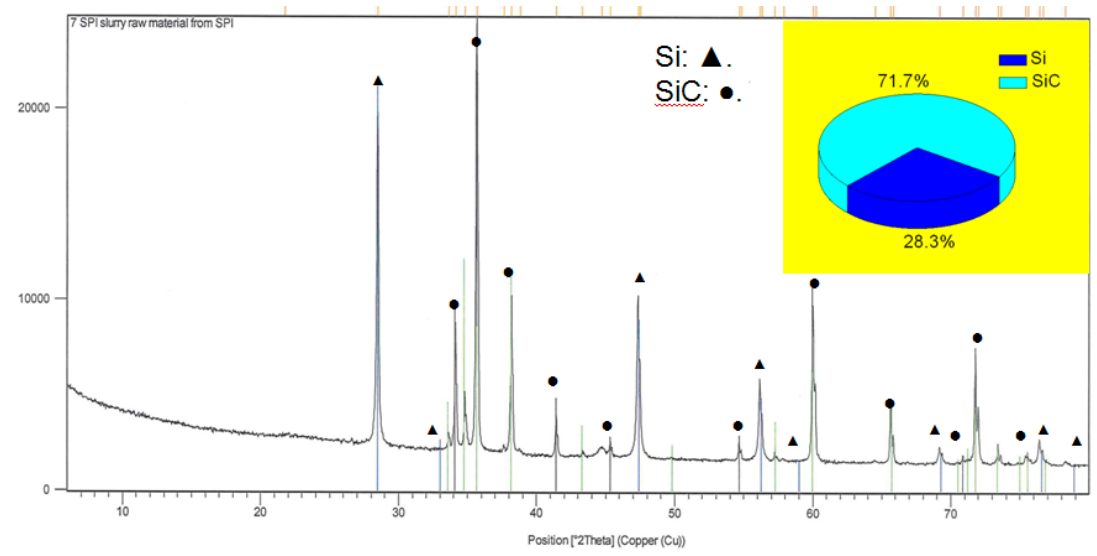

Fig.19 XRD analysis of SPI original silicon slurry 


\section{Analysis Using Carbon Analyzer}

Since the silicon slurry powders mainly contains $\mathrm{SiC}$ and $\mathrm{Si}$, if the carbon content is decided, the fraction of $\mathrm{SiC}$ can be calculated, and then the fraction of silicon can also be determined. Leco CS 600 was used for this purpose.

The as received CRS slurry powder was dried at $150{ }^{\circ} \mathrm{C}$ for 24 hours. CRS-1 slurry was the slurry after one stage centrifugal separation, and CRS-2 was the slurry after 2 times centrifugal separation. SPI is the silicon from another silicon wafer producer. The dried samples were analyzed using Leco CS 600 to determine the carbon, and repeated four times, and the results are shown in Table 1.

Table 1 Carbon content analysis of silicon slurry

\begin{tabular}{|c|c|c|c|c|c|c|}
\hline & & mass $(\mathrm{g})$ & $\mathrm{wt} \% \mathrm{C}$ in $1 \mathrm{~g}$ & $\mathrm{wt} \% \mathrm{C}$ total & $\mathrm{wt} \% \mathrm{~S}$ in $1 \mathrm{~g}$ & $\mathrm{wt} \% \mathrm{~S}$ total \\
\hline \multirow{4}{*}{ CRS-1 } & 1 & 0.1971 & 3.02 & 15.3729 & 0.0162 & 0.08219 \\
\cline { 2 - 7 } & 2 & 0.2313 & 3.57 & 15.4345 & 0.0165 & 0.07133 \\
\cline { 2 - 7 } & 3 & 0.2117 & 3.27 & 15.4464 & 0.0166 & 0.07841 \\
\cline { 2 - 7 } & 4 & 0.2116 & 3.27 & 15.4537 & 0.0162 & 0.07656 \\
\cline { 2 - 7 } & Average & 0.212925 & 3.2825 & 15.4269 & 0.01637 & 0.07712 \\
\cline { 2 - 7 } CRS-2 & 1 & 0.2701 & 3.48 & 12.8841 & -0.00292 & -0.01081 \\
\cline { 2 - 7 } & 2 & 0.2661 & 3.34 & 12.5517 & -0.00175 & -0.0066 \\
\cline { 2 - 7 } & 3 & 0.2772 & 3.73 & 13.3560 & -0.00287 & -0.01035 \\
\cline { 2 - 7 } & Average & 0.2598 & 3.28 & 12.6250 & -0.00213 & -0.0082 \\
\hline \multirow{5}{*}{ SPI } & 1 & 0.2683 & 3.4575 & 12.8792 & -0.00242 & -0.0090 \\
\cline { 2 - 7 } & 2 & 0.2123 & 2.74 & 12.9062 & 0.0171 & 0.08055 \\
\cline { 2 - 7 } & 3 & 0.2393 & 3.47 & 13.5335 & 0.0174 & 0.06786 \\
\cline { 2 - 7 } & Average & 0.236 & 3.1433 & 13.4559 & 0.0182 & 0.07606 \\
\hline
\end{tabular}

For CRS-1, the $\mathrm{wt} \% \mathrm{C}$ in $\mathrm{SiC}=12.01 / 40.096=29.053 \%$, therefore, $w \mathrm{t} \% \mathrm{SiC}$ in CRS- 1 slurry $=$ $15.4269 / 29.053=51.5 \%$, and then it can be concluded that the CRS-1 slurry contains $48.5 \%$ silicon.

For CRS-2, wt $\% \mathrm{C}$ in $\mathrm{SiC}=12.01 / 40.096=29.053 \%$, therefore, $\mathrm{wt} \% \mathrm{SiC}$ in $\mathrm{CRS}-1$ slurry $=$ $12.879 / 29.053=44.32 \%$. Hence, CRS-2 sample contains $55.68 \%$ silicon, which is higher than CRS-1 slurry.

For SPI slurry, $\mathrm{wt} \% \mathrm{C}$ in $\mathrm{SiC}=12.01 / 40.096=29.053 \%$, therefore $\mathrm{wt} \% \mathrm{SiC}$ in SPI slurry $=$ $13.2985 / 29.053=45.77 \%$. Hence, SPI slurry contains $54.23 \%$ silicon.

\subsubsection{Summary}

From SEM, EDS, and XRD analysis results, it can be concluded that there are three different kinds of particles in the slurry powders:

- Very tiny particles with size of about 1-2 $\mu \mathrm{m}$ (even smaller) which are the silicon powders that were cut from the silicon ingot. The volume fraction of $<5 \mu \mathrm{m}$ inclusions is $\sim 23 \%$ in the slurry;

- Particles with size of about 5-20 $\mu \mathrm{m}$ which are the SiC particles from the abrasive media, and these particles are in lumpy shape;

- Relatively large particles with plate-like shapes (20-40 $\mu \mathrm{m}$ and even over this) that consist of 
$\mathrm{SiO}_{2}$ are more likely the oxidized silica during the drying process of the powders.

- A certain amount of $\mathrm{Al}, \mathrm{Fe}, \mathrm{Na}$ and $\mathrm{K}$ were also detected from EDS results.

Methods have been proposed on the recovery of big SiC particles and glycol from the slurry. However, the size of silicon particles in the slurry was much smaller, and it is difficult to separate those fine silicon particles from the $\mathrm{SiC}$ particles in the equivalent size. The possible methods to recycle silicon from SoG-Si slurry wastes and to purify the SoG-Si and its wastes will be discussed include methods to remove non-metallic particles from the melt (such as sedimentation, bubble flotation ${ }^{[31-32]}$, centrifugal separation ${ }^{[33]}$, filtration ${ }^{[20-24]}$, electromagnetic separation, and directional solidification) and methods to remove metallic and other dissolved impurities (such as acid leaching, gas blowing $\left(\mathrm{Cl}_{2}, \mathrm{O}_{2}{ }^{[34]}, \mathrm{SiCl}_{4}\right.$, etc), plasma refining ${ }^{[35]}$, evaporation ${ }^{[36]}$, electron-beam furnace ${ }^{[35]}$, fractional melting process $^{[37]}$, and solidification control.

\subsection{Recovery of Silicon from Waste Silicon Slurry by High Temperature Remelting}

The aim of the high temperature remelting process is to remelt the silicon in the slurry and the molten silicon will accumulated together as big lumps and then can be separated from the solid $\mathrm{SiC}$ particles, and the liquid silicon may go up to the top of the crucible. The slurry will be placed in an alumina crucible and be subjected to heat treatment at approximately $1500^{\circ} \mathrm{C}$ for several hours using a high temperature furnace. Figure 20 shows the schematic of the agglomeration of molten silicon. Once the silicon lumps were formed, the material was cooled down. The silicon lumps and $\mathrm{SiC}$ particles could now be easily separated by simple water cleaning because Si clusters were non-adherent to the $\mathrm{SiC}$ particles.

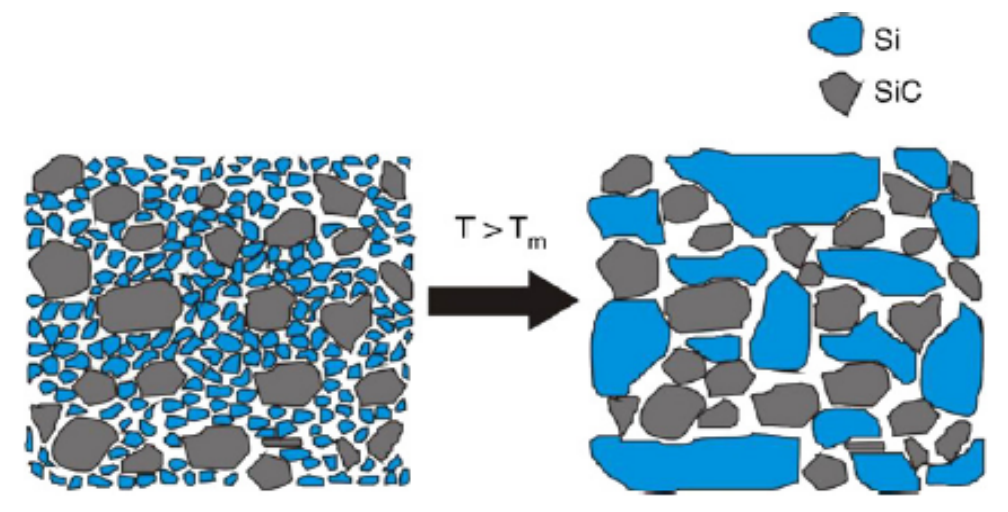

Fig.20 Silicon conglomeration process during high temperature treatment ${ }^{[38]}$.

\subsubsection{Using a Mo-heated High Temperature Furnace}

Figure 21 shows the Mo-heated high temperature furnace. It is a bottom loading furnace, and argon gas was purged into the furnace during the heating process. However, since the sealing is very loose, thus air was absorbed into the furnace even though the argon was used. Figure 22 shows the temperature curve during heating process. At each heat, 10-gram slurry each crucible was used and two crucibles were filled with slurry and heated in the furnace.

Figure 23 is the schematic figure of the remelted materials in the crucible, showing two different layers. The dark material was on the top and the gray material was at the bottom of the crucible. There was little silicon droplets in the crucible. Later XRD composition analysis indicates that silicon was reoxidized to silica that was the dark materials at the top.

Figure 24 shows the XRD analysis of the materials in the two layers. For the top dark materials, 
$\mathrm{SiC}, \mathrm{SiO}_{2}$, and $\mathrm{FeSi}$ were the main phases and $\mathrm{SiO}_{2}$ is the product of the reactionbetween silicon and oxygen. The XRD results at least indicate that the silicon was firstly oozed to the top and then was oxidized there later.

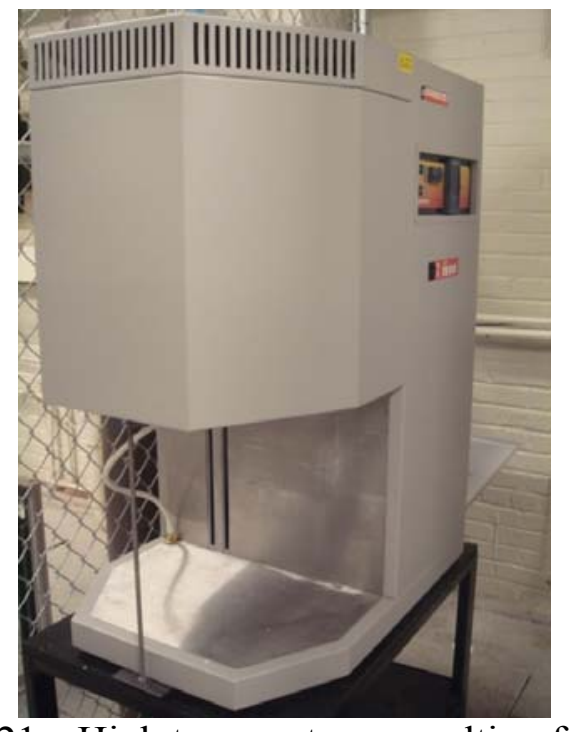

Fig.21 High temperature remelting furnace

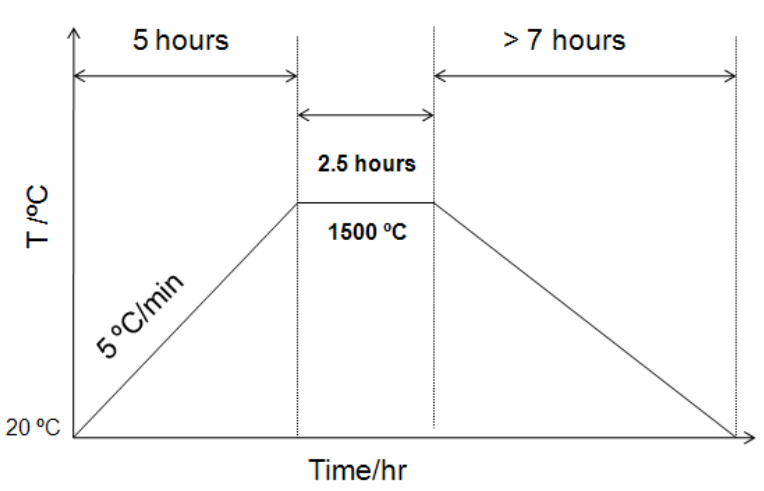

Fig.22 Temperature curve

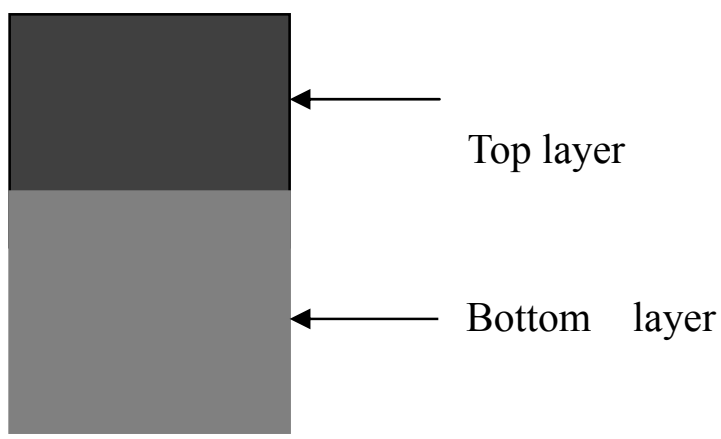

Fig.23 Schematic of the remelted material in the crucible

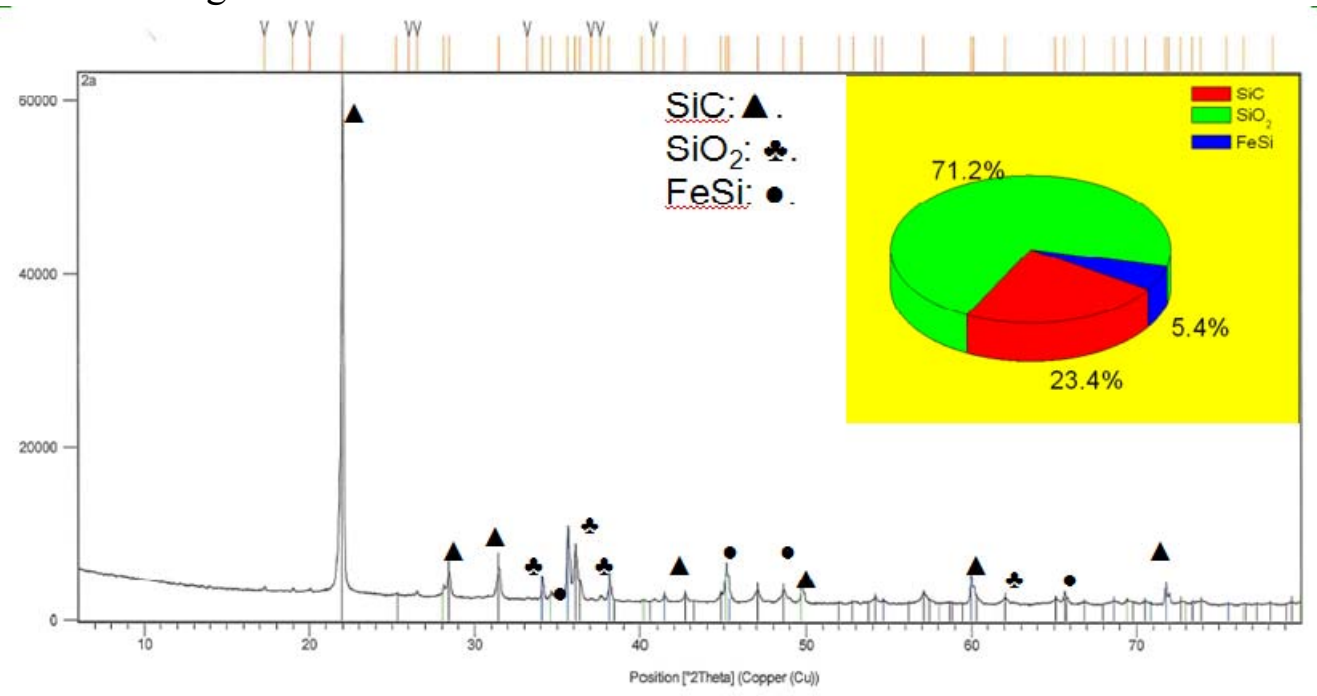

(a) the top layer 


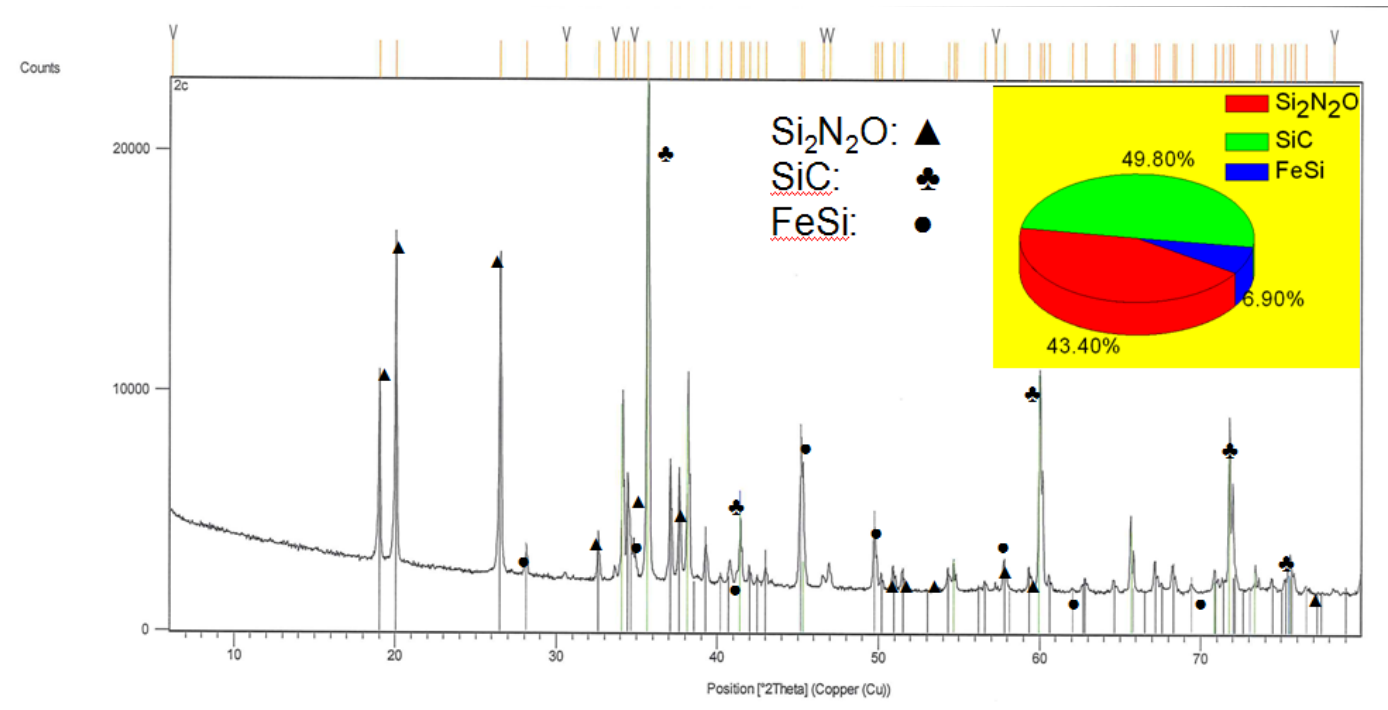

(b) the bottom layer

Fig.24 XRD analysis of remelted CRS slurry

\subsubsection{Using a Vacuum Inductor Furnace}

In this experiment, an $8 \mathrm{kHz}$ frequency and a $5-12 \mathrm{~kW}$ power were used during the current vacuum induction heating process. To facilitate the melting process, pure silicon particles were added in layers to the dried slurry samples in a graphite crucible. Figure 25 shows the schematic of the sample subjected to being heated. The power was changed within the above range in order to control the temperature. The holding time was 90 minutes at $\sim 1500^{\circ} \mathrm{C}$.

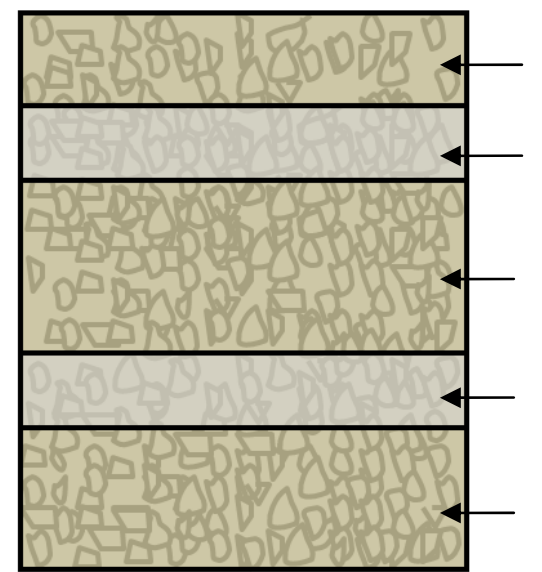

\section{E. Dried shurry \\ D. Silicon scrap \\ C. Dried shurry \\ B. Silicon scrap \\ A. Dried shurry}

Fig.25 Schematic of the slurry powder and pure silicon scraps in the graphite crucible

After remelting and cooling, three distinct layers were identified, as shown in Figure 26: top layer (E), middle layer (C) and bottom layer (A). The two silicon scrap layers before the induction heating (B) and (D) were classified as the fourth layer after the heating process.

Beads of silicon were oozed out of the slurry particles at the bottom of the graphite crucible (see Figures 26a and b) whiles the top layer turned from black to near cream (near white) color. The middle slurry layer and the silicon layer remained unmelted (see Figures 26c and d). As long as the temperature was higher enough and the holding time was longer enough, the unmelted silicon scraps were supposed to melt completely. 


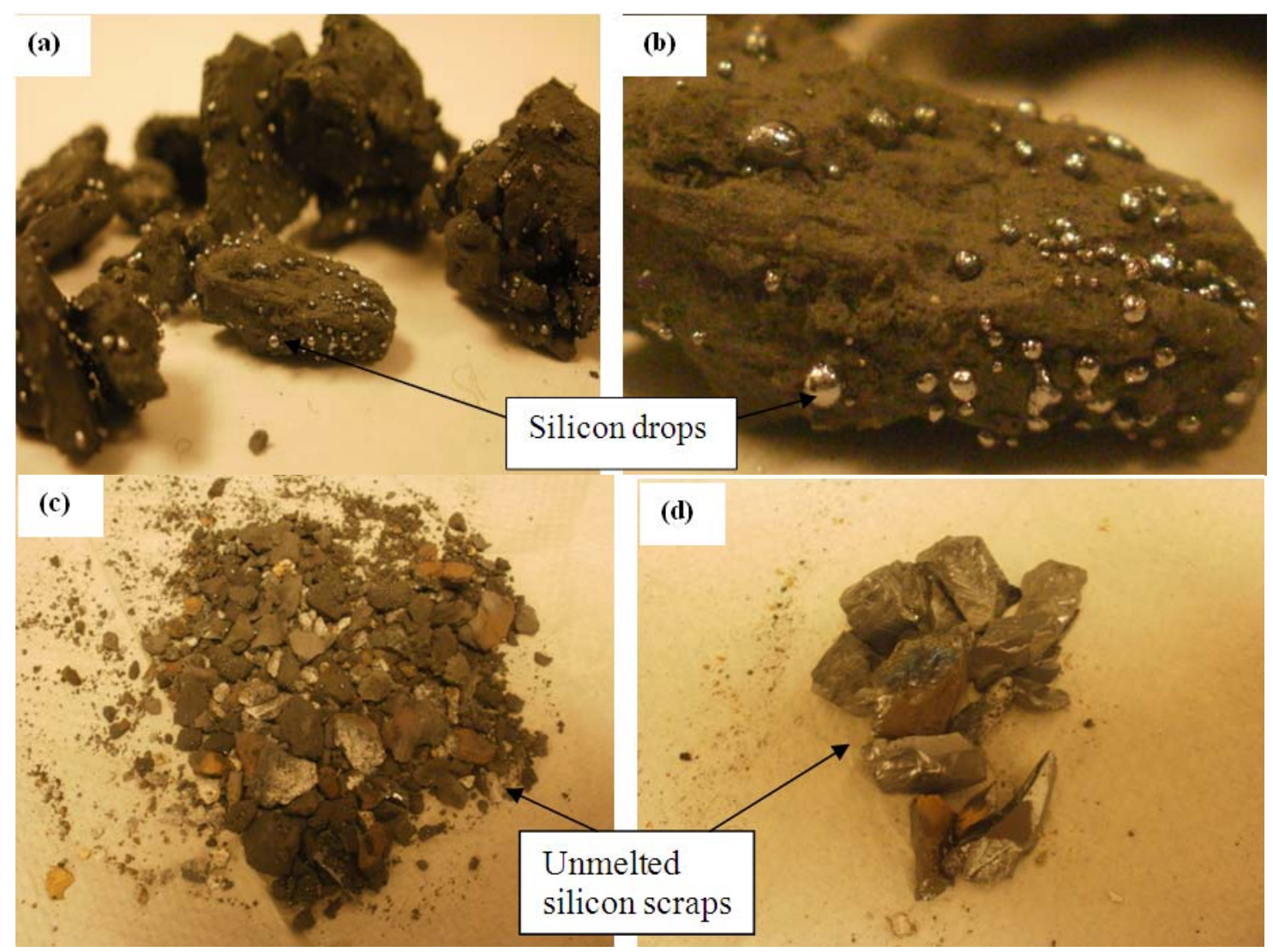

Fig.26 Results from induction melting of dried $\mathrm{SiC} / \mathrm{Si}$ slurry at $\sim 1500{ }^{\circ} \mathrm{C}$ for $90 \mathrm{~min}$. showing (a) bottom layer, (b) bottom layer, (c) middle layer and (d) silicon craps.

\subsubsection{Using High Frequency Electromagnetic Heating}

Figure 27 shows the high frequency electromagnetic heating unit, which is composed of a high frequency power supply $(50-200 \mathrm{kHz}$, and $100 \mathrm{~kW})$, a special induction coil, and an alumina-graphite crucible system. The desired alternating EM field can be generated in the induction coil. In the current study, a Pyrex tube was used. On the top part of the Pyrex tube, there were gas inlet, gas outlet, and thermocouple. During the experiment process, both the frequency of EM field and output power could be adjusted. Forty gram dried silicon slurry was put in an alumina crucible. Table 2 gives the experimental parameters.

After experiment, optical microscope observation and SEM-EDS detection were used to evaluate the separate silicon drops. It was found that silicon lumps and droplets formed inside the melted slurry, and the size of this silicon material varied from several hundred micrometers to several millimeters. The silicon lumps could be easily separated from the $\mathrm{SiC}$ particle powders. Figure 28 shows the collected silicon pieces after EM remelting. The formation of clusters is schematically shown in Figure 20.

The collected silicon droplets were mounted and polished and observed under microscope. Figure 29 shows its optical microscope photo. The drops had a boundary layer of $\mathrm{SiC}$ particles with size of $\sim 10 \mu \mathrm{m}$ or smaller, which was almost the same size as the $\mathrm{SiC}$ particles in the original silicon slurry. There were few $\mathrm{SiC}$ particles in the center of the drop because the silicon droplets were oozed out from the $\mathrm{Si} / \mathrm{SiC}$ slurry powder. For the drop in thie figure, the diameter of the drop is $3 \mathrm{~mm}$, and the thickness of SiC boundary layer is $375 \mu \mathrm{m}$. One more time 
remelting of theses silicon droplets under the high frequency EM unit will push and separate the remained $\mathrm{SiC}$ particles in the boundary layer. The experiments of the EM separation will be discussed later in Chapter 5.
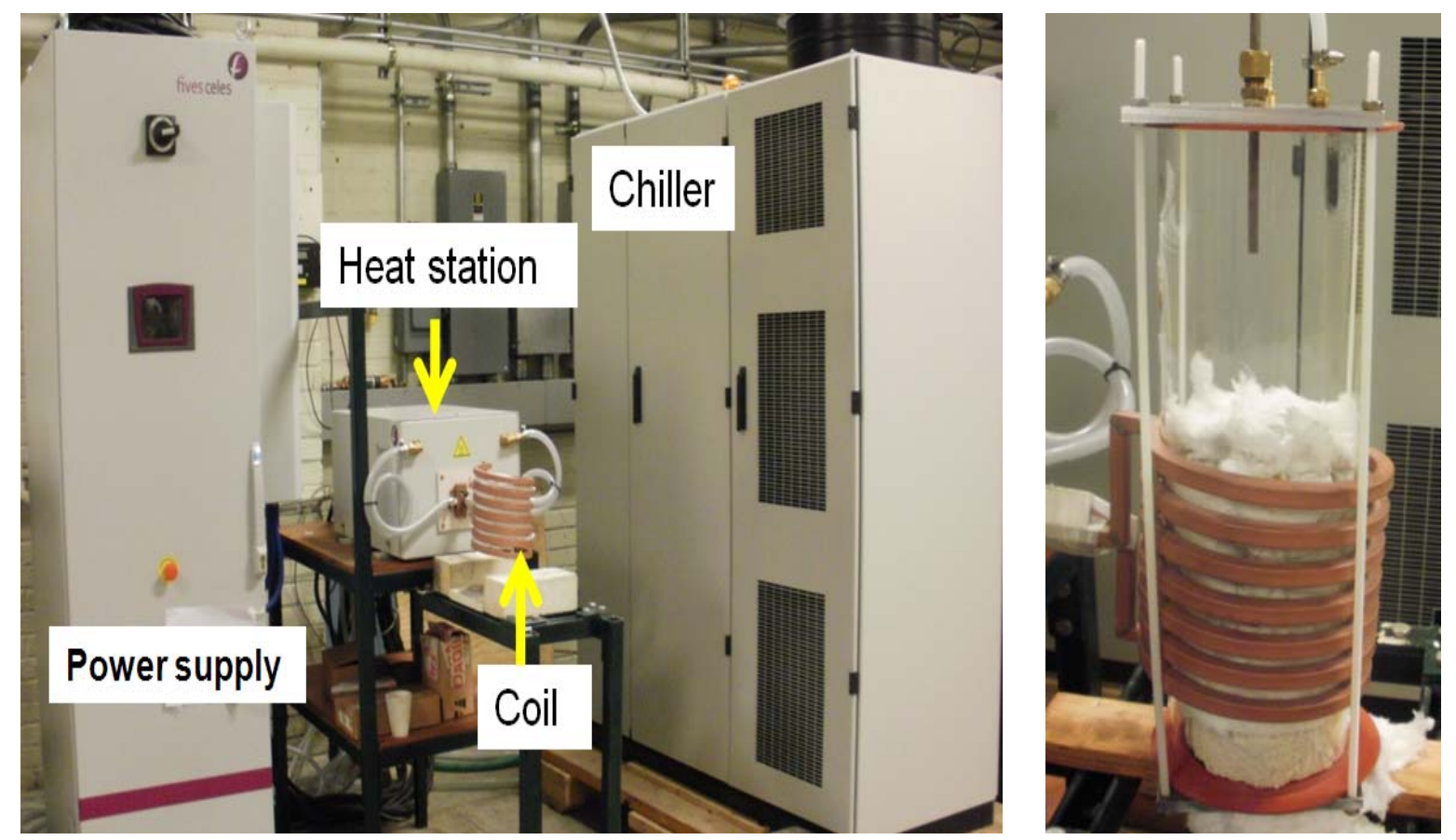

Fig.27 Electromagnetic unit for the remelting of the silicon slurry

Table 2 Experimental parameters of silicon slurry remleting using EM unit

\begin{tabular}{|c|c|c|c|c|}
\hline Heating time, $\min$ & Current, $\mathrm{A}$ & Voltage, $\mathrm{V}$ & Frequency, $\mathrm{kHz}$ & Power, $\mathrm{kW}$ \\
\hline 20 & 14.7 & 288 & 60 & 4.0 \\
\hline
\end{tabular}

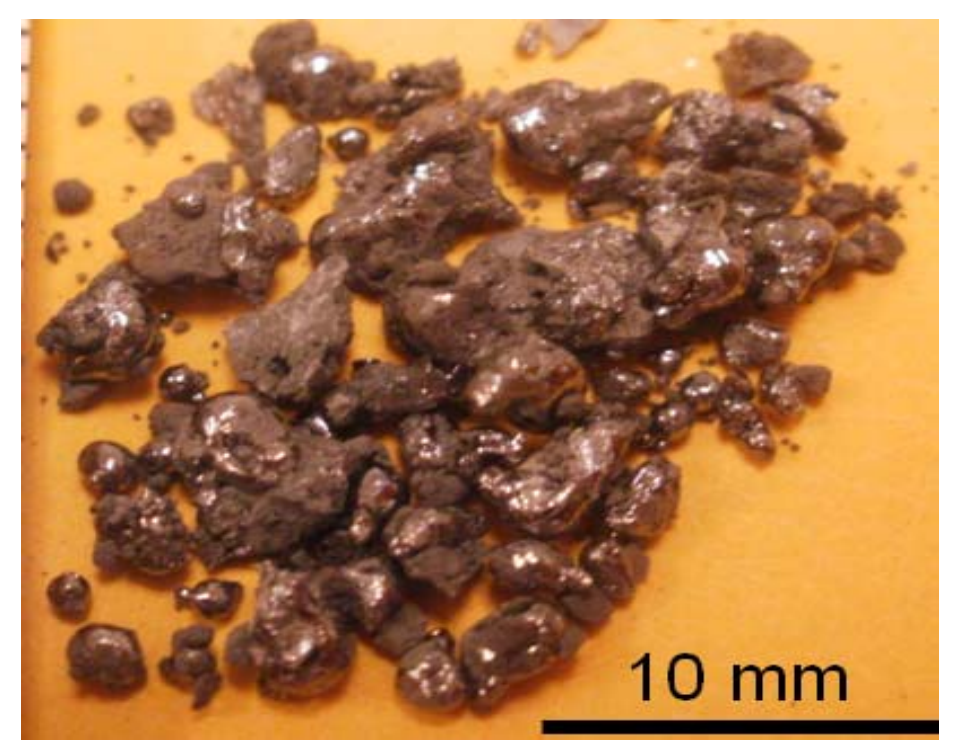

Fig.28 The collected clean silicon pieces after high temperature process. 


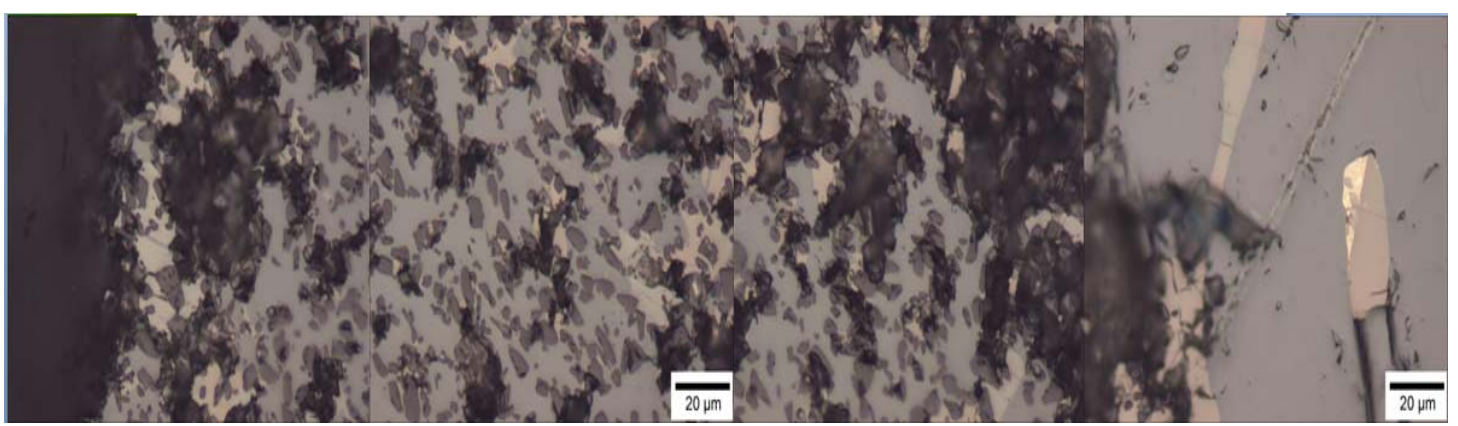

Fig.29 The optical microscope photos of the collected silicon droplets

\subsection{Recovery of Silicon from Waste Silicon Slurry by Centrifugation Separation}

\subsubsection{Background of Centrifuge Separation}

Centrifugation force is a sedimentation process of suspended and some dissolved particles occur due to centrifugal force. Centrifugation has two different cases: the first is separate out solid matter as a pellet from a dissolved solute as supernatant; another case is to separate soluble macromolecules of different mass of density. In the current experiment, a fixed angle rotor was used. This kind of rotor has some advantages such as that sedimenting particles have only a short distance to travel before pelleting. It shortens the run time compared to the swinging bucket rotor, and it is the most widely used rotor type. Figure $\mathbf{3 0}$ shows the schematic of the fixed angle rotor.
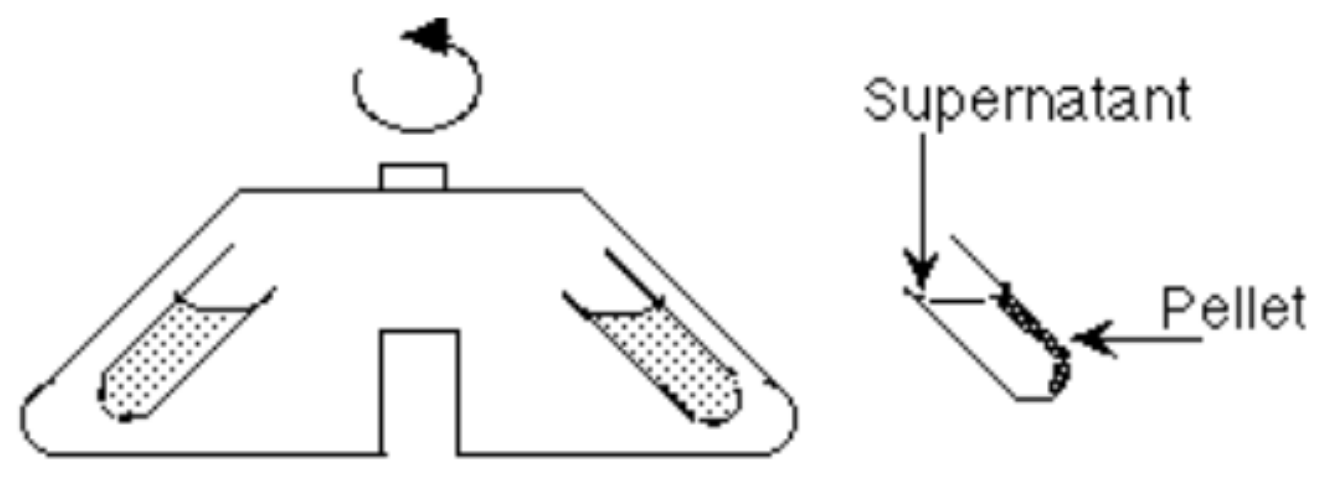

Fig.30 Schematic for the fixed angle rotor.

Figure 31 shows the schematic of the expected centrifugation process. Silicon slurry in this experiment contained $\sim 50 \mathrm{wt} . \% \mathrm{Si}$ and $\sim 50 \mathrm{wt} . \% \mathrm{SiC}$. A heavy liquid with a $2.86 \mathrm{~g} / \mathrm{cm}^{3}$ density was used, which was in between the density of the silicon $\left(\rho_{\mathrm{Si}}=2.37 \mathrm{~g} / \mathrm{cm}^{3}\right)$ and the silicon carbide $\left(\rho_{\mathrm{SiC}}=3.22 \mathrm{~g} / \mathrm{cm}^{3}\right)$. After mixing, ultrasonic stirring, centrifuge separation, the mixture was supposed to have three different layers: the top layer of silicon with a little of silicon carbide, the bottom layer of SiC particles and a heavy liquid layer between the two.

The schematic of centrifugal force is shown in Figure 32. The centrifugal force acting on the particle $F$ is the function of the particle mass, the rotation speed and the location of the particle, which can expressed by:

$$
F=M \omega^{2} r
$$

where $\omega$ is angular velocity of rotor (radians/sec), $M$ is the mass of the material, $r$ is radius (i.e. distance of particle from axis of rotation). 


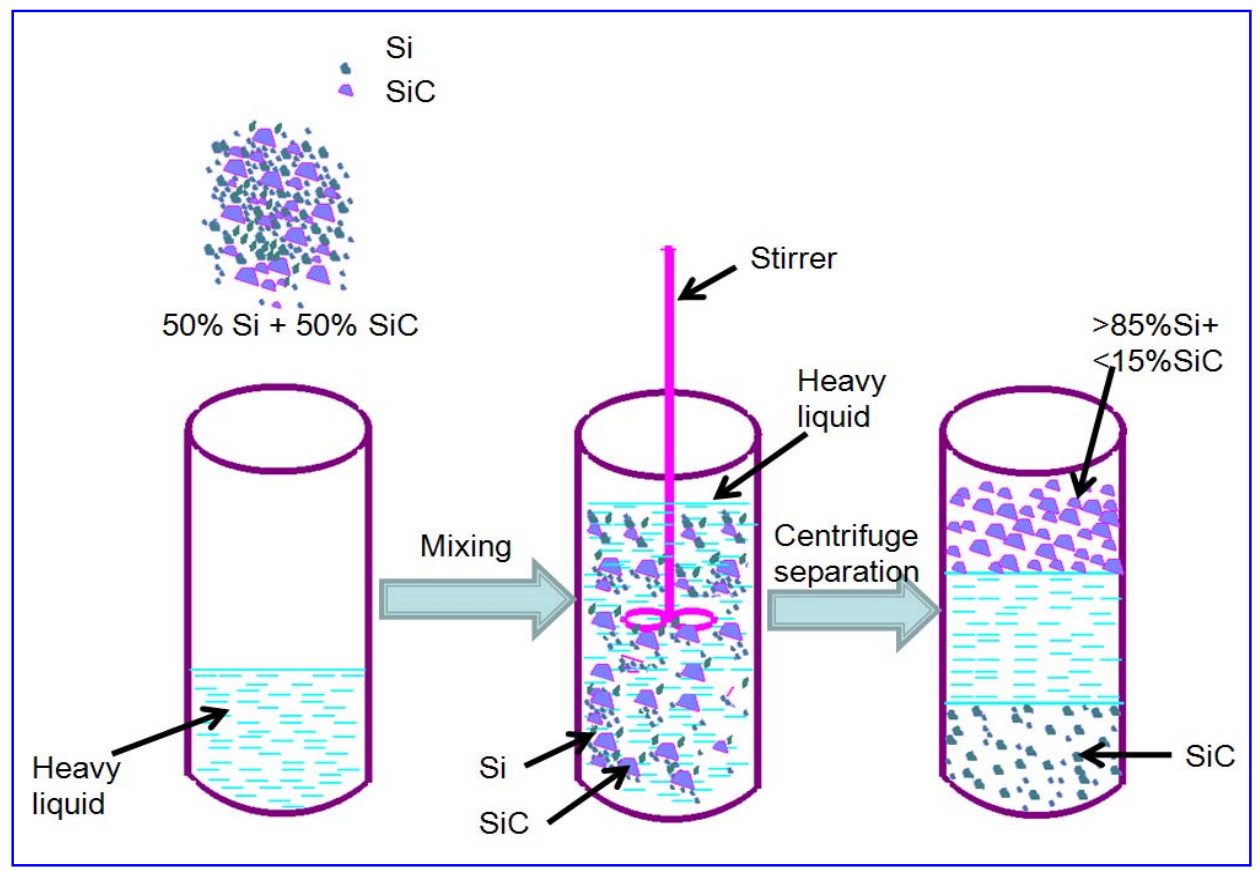

Fig.31 Schematic of the centrifuge separation process.

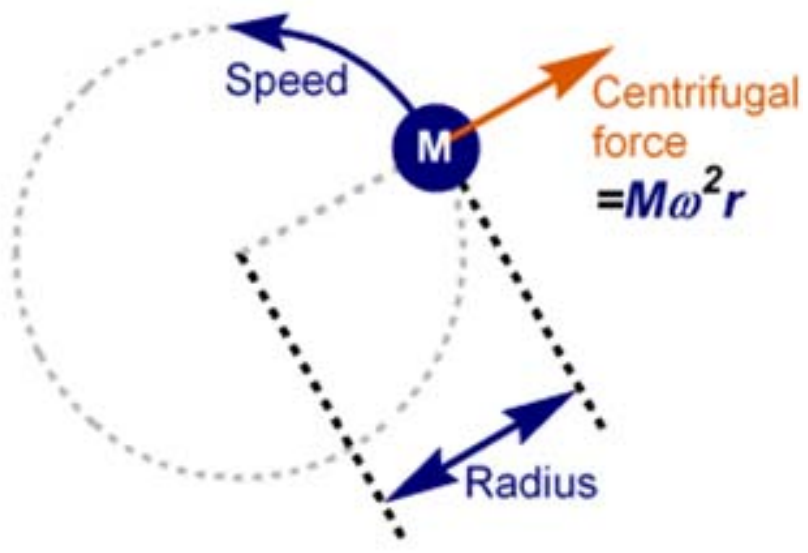

Fig.32 The schematic figure of centrifugal force.

\subsubsection{Experimental Set-up}

Figure 33 shows photos of the Sorvall RC 6 Puls centrifuge equipment. In this experiment, rotation speed was set at $4000 \mathrm{rpm}$ and centrifugation time was $60 \mathrm{~min}$. Figure 34 is the schematic flow chart for centrifugation experiment procedure.

A slurry sample of $20 \mathrm{~g}$ was placed in a centrifuge tube, and then $15 \mathrm{~g}$ acetone was added and mixed. The glycol solution in the slurry together with the acetone was removed by centrifuging and decanting. This washing step was repeated twice. For different volume fraction of the slurry powders, the yield and purity of the production were different ${ }^{[39]}$. When the solid volume fraction increased, the purity decreased and the yield increased, as shown in Figure 35. So, 5\% and 6\% slurry powder in volume fraction were used in current experiments. Table $\mathbf{3}$ gives the experimental plan for different densities of the heavy liquid. 


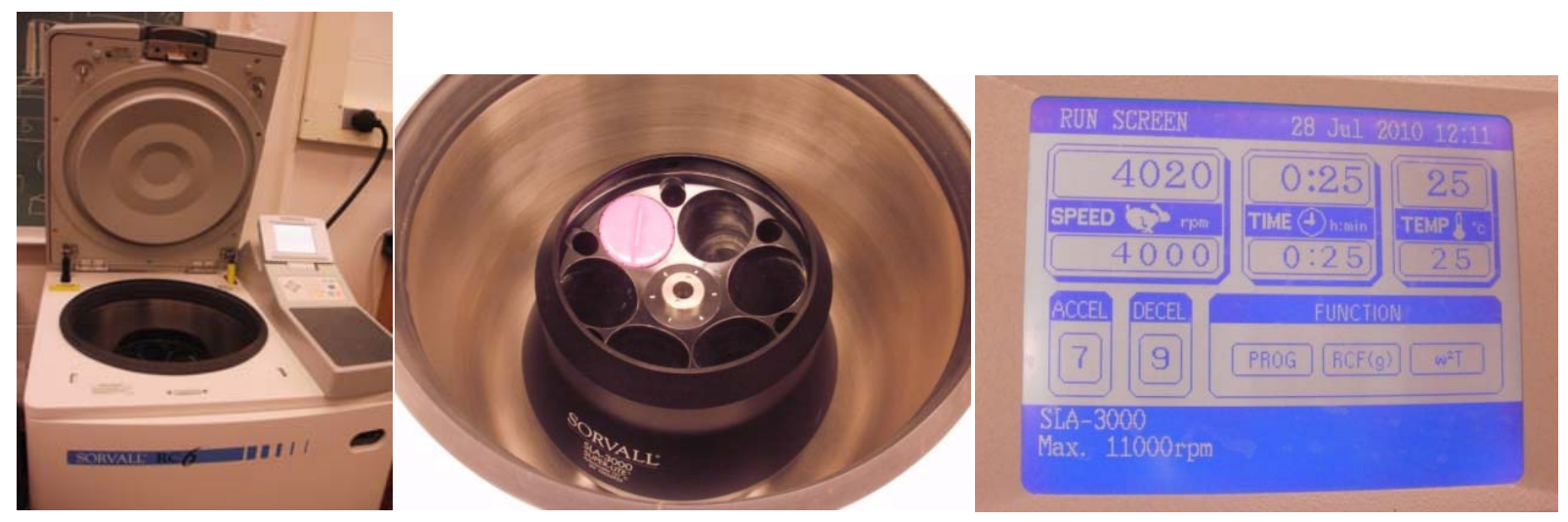

Fig.33 The Sorvall RC 6 Plus centrifuge equipment.

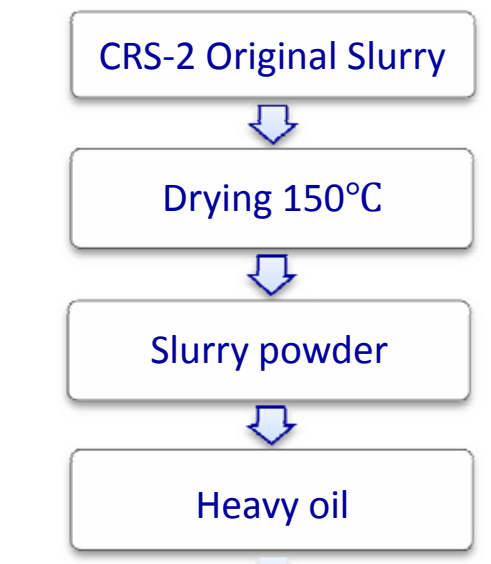

\section{Bath stirring for 6 min}

\section{Centrifugation}

Fig.34 The schematic flow chart for centrifugation separation process.

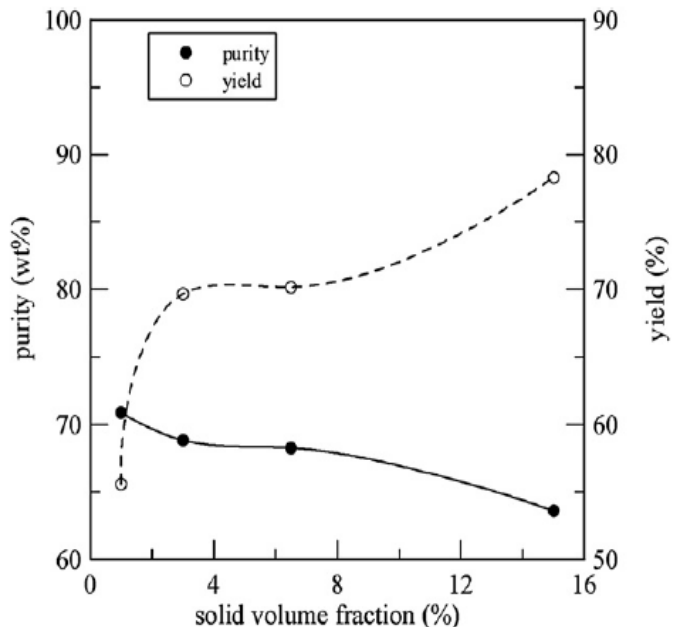

Fig.35 Purity and yield of recovered silicon as a function of solid volume fraction (Rotation 60 with a $3300 \mathrm{rpm}$ rotation speed) ${ }^{[39]}$. 
Table 3 Heavy liquids with different density and solid volume fraction

\begin{tabular}{|c|c|c|c|c|c|}
\hline $\begin{array}{c}\text { Slurry powder concentration } \\
\text { (volume fraction) }\end{array}$ & Liquid 1 & Liquid 2 & Liquid 3 & Liquid 4 & Liquid 5 \\
\hline $5 \%$ & $2.25 \mathrm{~g} / \mathrm{cm}^{3}$ & $2.86 \mathrm{~g} / \mathrm{cm}^{3}$ & $2.41 \mathrm{~g} / \mathrm{cm}^{3}$ & $2.63 \mathrm{~g} / \mathrm{cm}^{3}$ & $2.63 \mathrm{~g} / \mathrm{cm}^{3}$ \\
\hline $6 \%$ & $2.25 \mathrm{~g} / \mathrm{cm}^{3}$ & $2.86 \mathrm{~g} / \mathrm{cm}^{3}$ & $2.41 \mathrm{~g} / \mathrm{cm}^{3}$ & $2.63 \mathrm{~g} / \mathrm{cm}^{3}$ & $2.63 \mathrm{~g} / \mathrm{cm}^{3}$ \\
\hline
\end{tabular}

\subsubsection{Results and Discussions}

For experiment group 1, there were three different liquids with density of $\rho_{1}=2.86 \mathrm{~g} / \mathrm{cm}^{3}, \rho_{2}=$ $2.63 \mathrm{~g} / \mathrm{cm}^{3}$ and $\rho_{3}=2.41 \mathrm{~g} / \mathrm{cm}^{3}$ respectively. Figures 36a-c show the separation results using the three heavy liquids above, indicating that the silicon slurry stayed on the top of the liquid and no solid materials sinked down to the bottom of liquid, and thus the silicon powders were not separated from the $\mathrm{SiC}$ particles. Thus, the density of the heavy liquid density should be decreased.

For experiment group 2, another three heavy liquid with density of $\rho_{4}=2.08 \mathrm{~g} / \mathrm{cm}^{3}, \rho_{5}=2.25$ $\mathrm{g} / \mathrm{cm}^{3}$ and $\rho_{6}=2.35 \mathrm{~g} / \mathrm{cm}^{3}$ respectively were used. Figures 36d-f indicates that the density of $\rho_{4}$ $=2.08 \mathrm{~g} / \mathrm{cm}^{3}$ and $\rho_{5}=2.25 \mathrm{~g} / \mathrm{cm}^{3}$ was so small that the slurry all sinked to the bottom of the liquid. When the heavy liquid density was $\rho_{6}=2.35 \mathrm{~g} / \mathrm{cm}^{3}$, there were three layers in the heavy liquid after centrifuge separation, and it was very close to the separation situation in Figure 31. The top layer should be silicon-based and the bottom layer should be SiC-based. A further experiment was performed with a heavy liquid with a density of $\rho_{7}=2.37 \mathrm{~g} / \mathrm{cm}^{3}$, as shown in Figure 36g, indicating a clearer three-layer structure after centrifugal separation. Thus, the suitable density of the heavy liquid for the separation of the silicon powders from the $\mathrm{SiC}$ particles in the slurry should be approximately $2.37 \mathrm{~g} / \mathrm{cm}^{3}$.
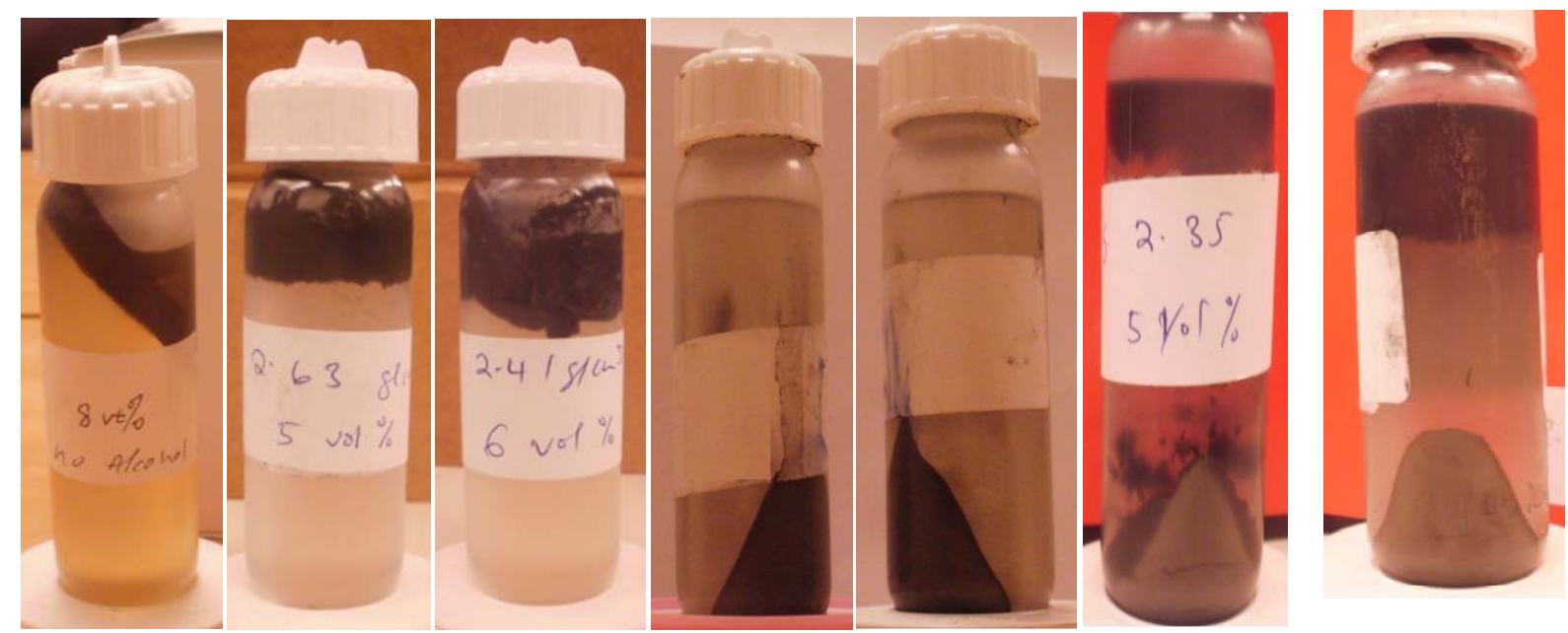

Fig.36 Centrifugation separation results with different heavy liquid (from left to right: (a) $\rho_{1}=$ $2.86 \mathrm{~g} / \mathrm{cm}^{3}$ (b) $\rho_{2}=2.63 \mathrm{~g} / \mathrm{cm}^{3}$ (c) $\rho_{3}=2.41 \mathrm{~g} / \mathrm{cm}^{3}$ (d) $\rho_{4}=2.08 \mathrm{~g} / \mathrm{cm}^{3}$ (e) $\rho_{5}=2.25 \mathrm{~g} / \mathrm{cm}^{3}$ (f) $\rho_{6}=$ $2.35 \mathrm{~g} / \mathrm{cm}^{3},(\mathrm{~g}) \rho_{7}=2.37 \mathrm{~g} / \mathrm{cm}^{3}$ ) 


\section{Removal of Non-metallic Inclusions from the Silicon Using EM Separation}

\subsection{Non-metallic Inclusions in SoG Silicon}

As mentioned in Chapter 1, during SoG silicon production process, directional solidification is employed and results in the top of the silicon ingots being highly contaminated by impurities such as iron, aluminum, $\mathrm{SiC}$, and $\mathrm{Si}_{3} \mathrm{~N}_{4}$. Therefore, $\sim 110 \mathrm{~mm}$ thick top layer is usually cut off. The conversion efficiency of solar cells typically ranges between $12-15 \%$, and it is limited by minority carrier recombination at dislocations and those intra-granular defects such as impurities, small clusters of atoms, or precipitates ${ }^{[40]}$. Among these impurities, $\mathrm{Si}_{3} \mathrm{~N}_{4}$ is mainly from the coating materials at the inside surface of the silica crucible and from the air absorption during solidification process, and the $\mathrm{SiC}$ particles mainly stem from the carbon reduction process of the primary production of silicon ${ }^{[41]}$. If $\mathrm{Si}_{3} \mathrm{~N}_{4}$ and $\mathrm{SiC}$ can be removed from the top-cut scrap, the silicon scrap can be mixed with pure polysilicon and thus, can be used as a feedstock in fabrication of multicrystalline ingots for PV cell production. It is important to identify the inclusions distribution along the height direction of the silicon ingot. In the current project, the morphology and composition of silicon scraps from different companies were analyzed using ASPEX, SEM\&EDS, and optical microscope observation.

\subsubsection{Inclusions in Top Surface of Unpolished Top-cut Scraps}

Figure 37a shows the schematic position of the top-cut SoG-Si and different layers from the very top surface to $5 \mathrm{~mm}$ beneath the top surface inside the sample. In our experiments, $1-5 \mathrm{~mm}$ surfaces beneath the top surface were analyzed. The big inclusions of $\mathrm{SiC}$ and $\mathrm{Si}_{3} \mathrm{~N}_{4}$ at the top of the scrap were even visible directly by eye, as shown in Figure 37b.

(a)

Top surface
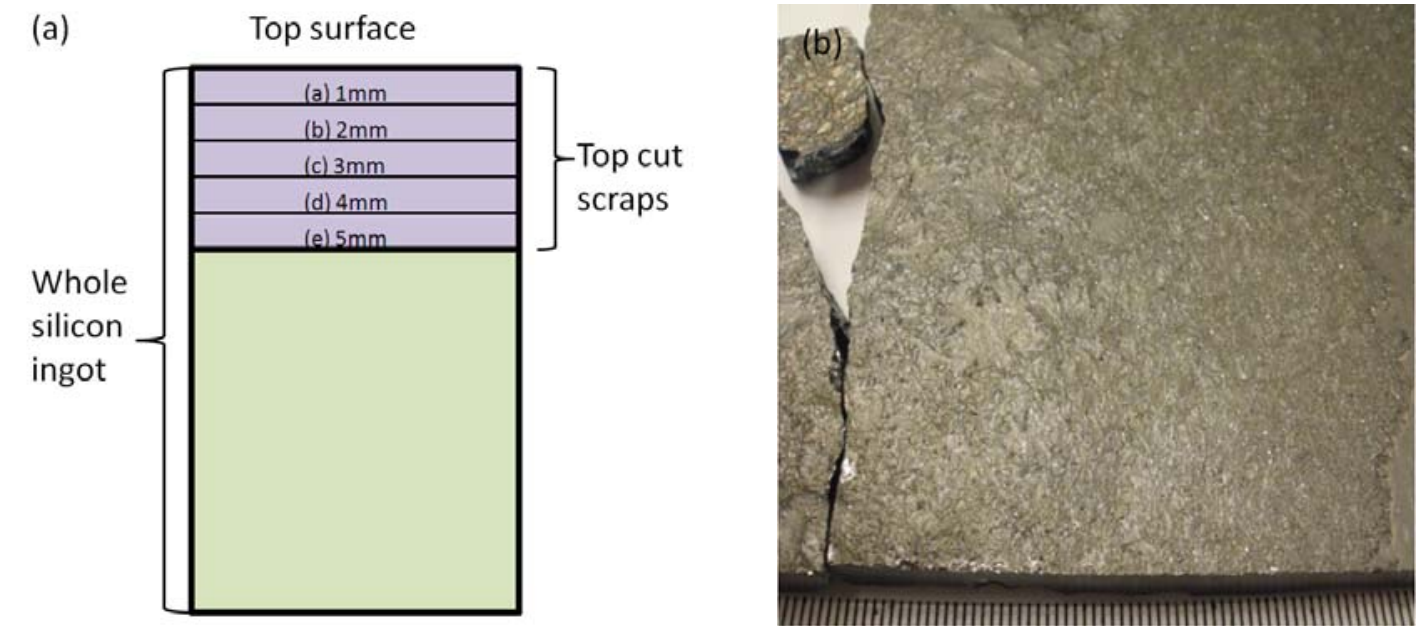

Fig.37 Schematic of top-cut silicon scraps (a) and eye view of top-cut SoG silicon (b)

The main inclusions observed on the topmost surface of the unpolished top-cut samples were $\mathrm{Si}_{3} \mathrm{~N}_{4}$ and $\mathrm{SiC}$ particles. Figure 38 shows the morphology of these inclusions. SEM and EDS results showed that $\mathrm{Si}_{3} \mathrm{~N}_{4}$ inclusions appeared needlelike and had dimensions of several millimeters while the $\mathrm{SiC}$ particles were lumpy with much smaller size. $\mathrm{Si}_{3} \mathrm{~N}_{4}$ inclusions inside the silicon scraps were usually shorter $500 \mu \mathrm{m}$, with average diameter of $\sim 20 \mu \mathrm{m}$, and $\mathrm{SiC}$ inclusions were smaller than $500 \mu \mathrm{m}$. Inclusion clusters with complex shapes were also observed, and these clusters contained both $\mathrm{SiC}$ and $\mathrm{Si}_{3} \mathrm{~N}_{4}$ particles. These particles were pushed upward to the surface by the solidification front during the directional solidification process. Figure 39 shows the 3D morphology of $\mathrm{Si}_{3} \mathrm{~N}_{4}$ and $\mathrm{SiC}$ inclusions at the side surface of the broken silicon 
scrap. Figure 40 shows the bottom surface of the unpolished top-cut solar silicon scraps. SEM \& EDS detection indicated that no inclusions found at the bottom suffice and some scratches on the sample due to the sawing process.

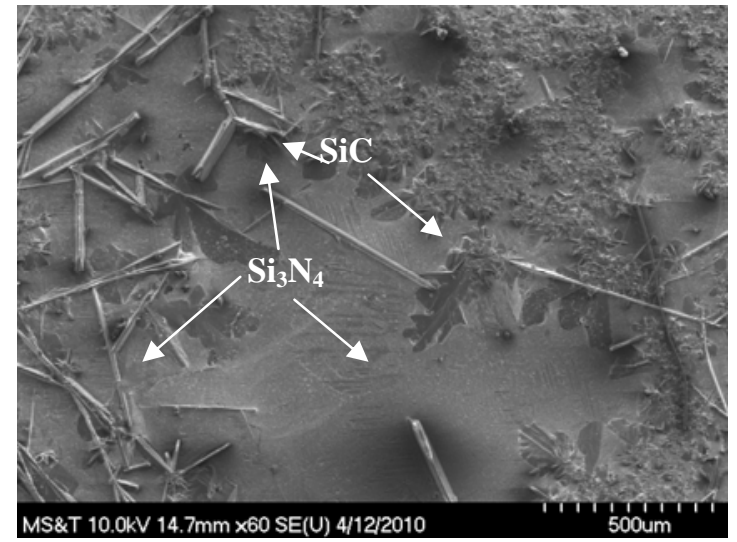

(a) Morphology of $\mathrm{Si}_{3} \mathrm{~N}_{4}$ and $\mathrm{SiC}$ Inclusions on the surface of top cut
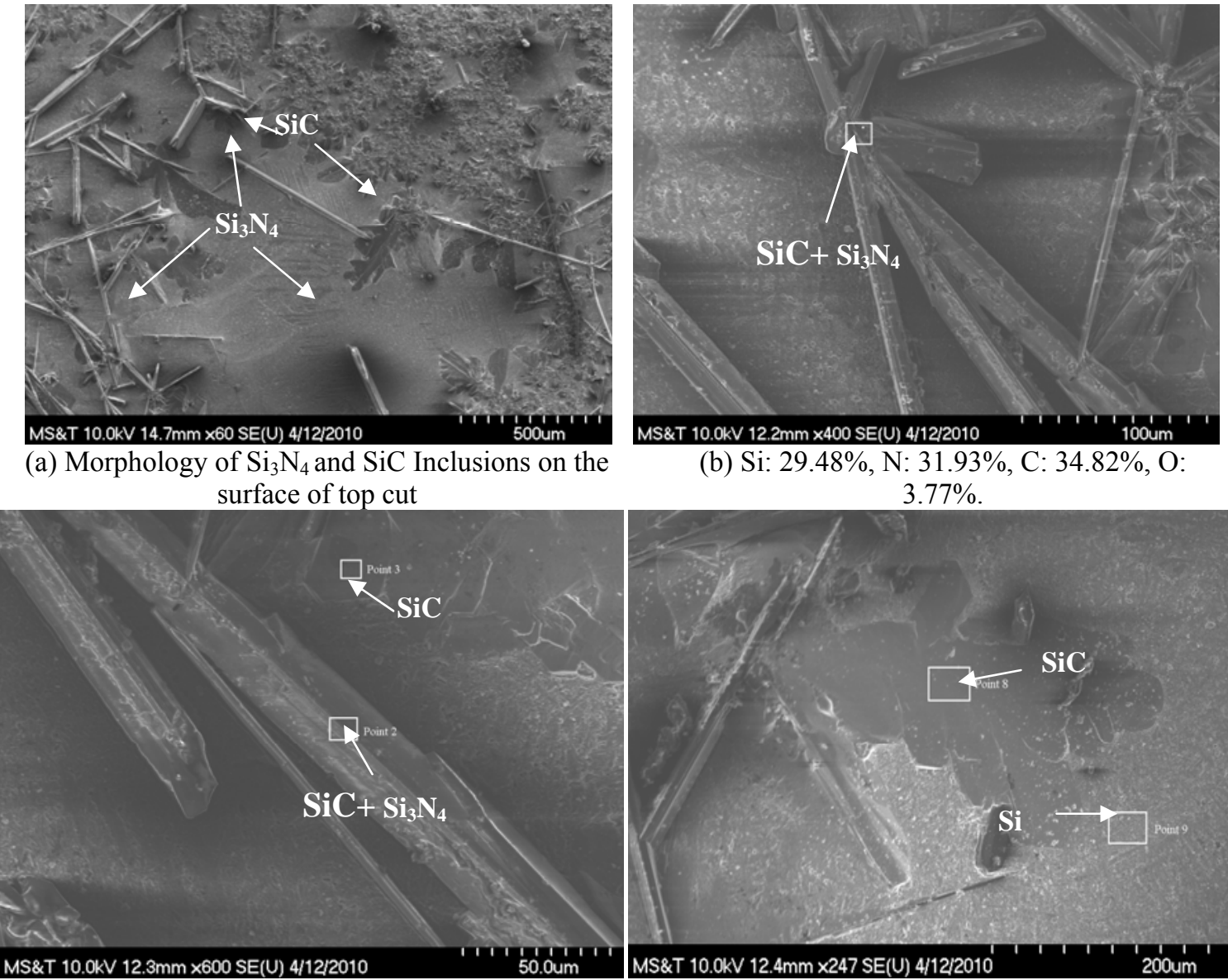

(c) Upper area: Si: $52.83 \%, \mathrm{~N}: 1.73 \%$, C: $45.44 \%$. Lower area: $\mathrm{Si}: 42.03 \%$, N: $40.44 \%$, C: $17.53 \%$.

(b) Si: $29.48 \%$, N: $31.93 \%$, C: $34.82 \%$, O: $3.77 \%$.

Fig.38 Inclusions on top surface of unpolished top-cut solar silicon scraps
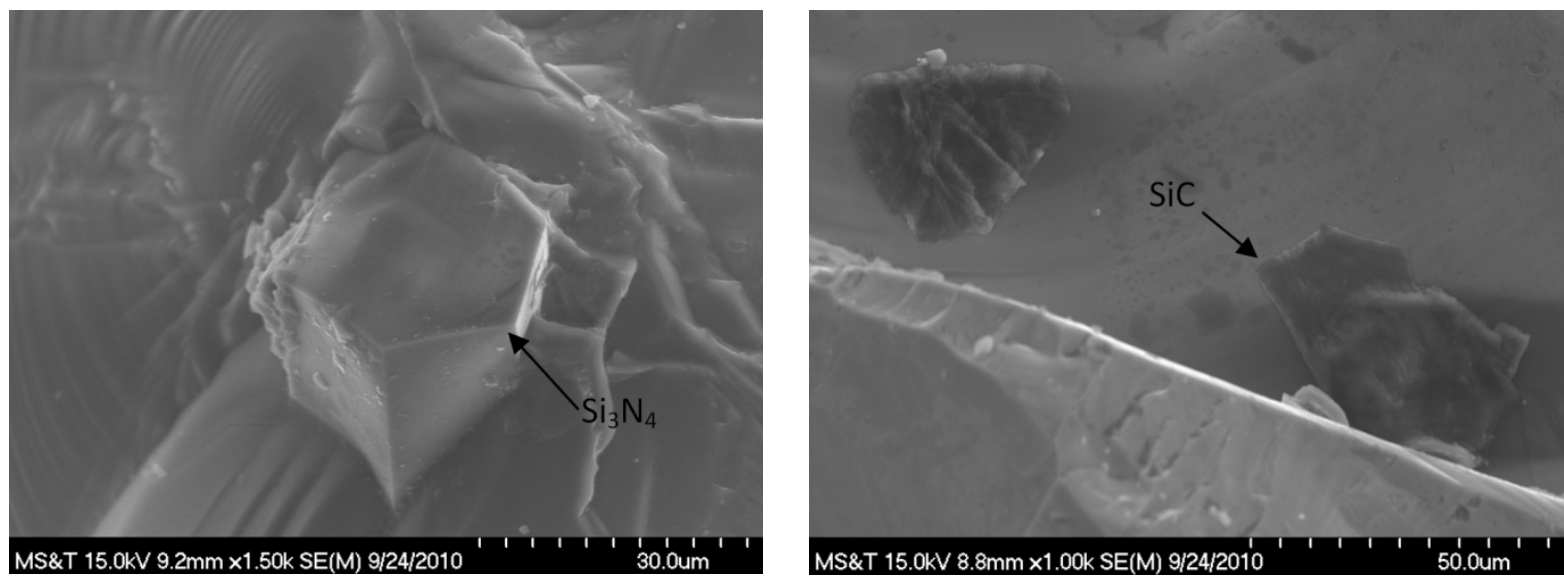

Fig.39 Inclusions on side surface of unpolished top-cut solar silicon scraps 

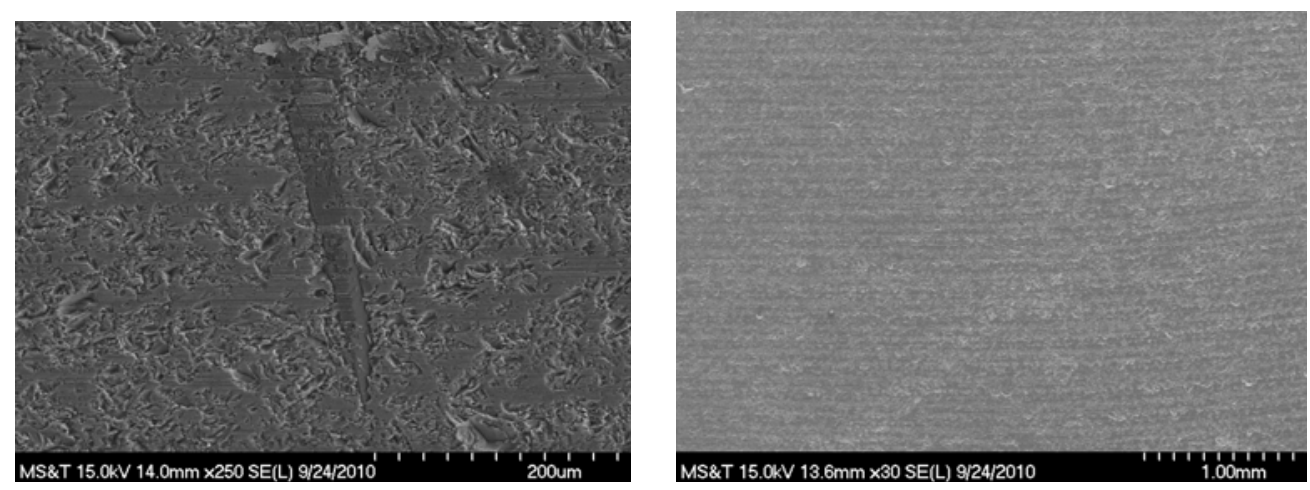

Fig.40 Inclusions on bottom surface of unpolished top-cut solar silicon scraps

\subsubsection{Inclusions inside Top-cut Scraps from Company X (Sample X)}

The silicon scrap was polished layer by layer of every $1 \mathrm{~mm}$ from the top surface, and inclusions on each layer were detected by the optical microscope observation and ASPEX analysis.

Inclusions $1 \mathrm{~mm}$ beneath the top surface

Figure 41 shows the morphology of $\mathrm{Si}_{3} \mathrm{~N}_{4}$ and $\mathrm{SiC}$ particles by optical microscope observation. These big particles varied from several micrometers to $\sim 300 \mu \mathrm{m}$. Some inclusions appeared as a cluster. The typical morphology and composition of inclusions $1 \mathrm{~mm}$ beneath the top surface of top-cut silicon scraps by ASPEX analysis are given in Figure 42. Needle-like $\mathrm{Si}_{3} \mathrm{~N}_{4}$ particles and lumpy SiC inclusions were found.

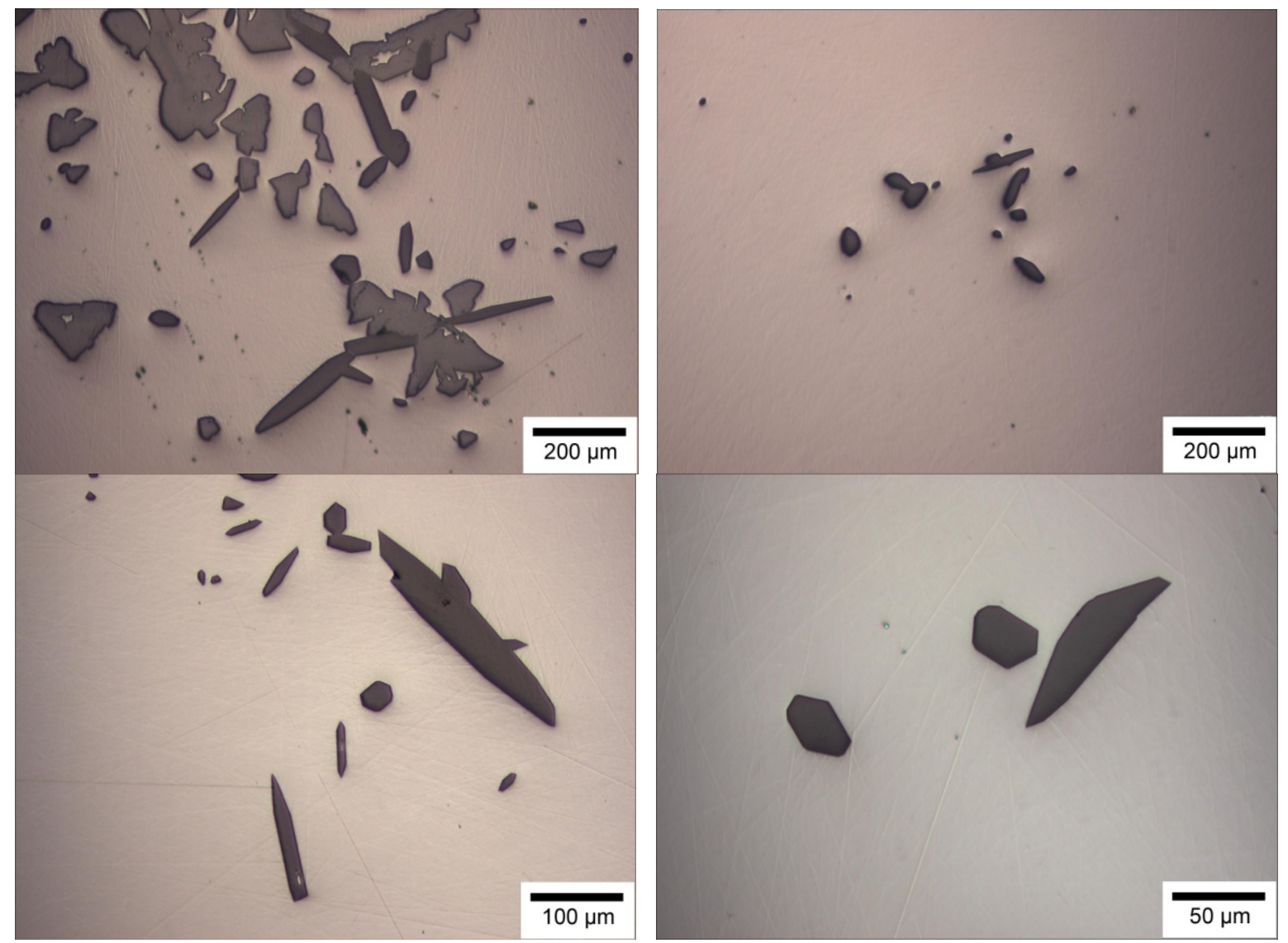

Fig.41 Inclusions 1mm beneath the top surface (optical microscope observation) 


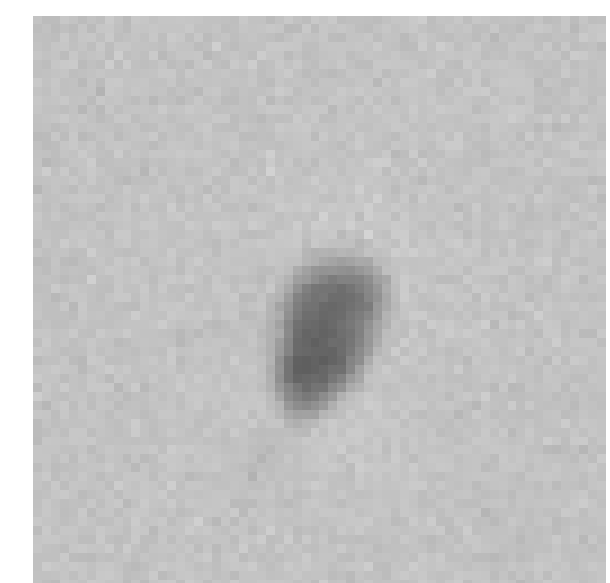

(a) Si: $82.3 \mathrm{wt} \%$, C: $14.50 \mathrm{wt} \%$, O: $2.60 \mathrm{at} \%$, Ca: $0.10 \mathrm{wt} \%, \mathrm{Al}: 0.40 \mathrm{wt} \%$.

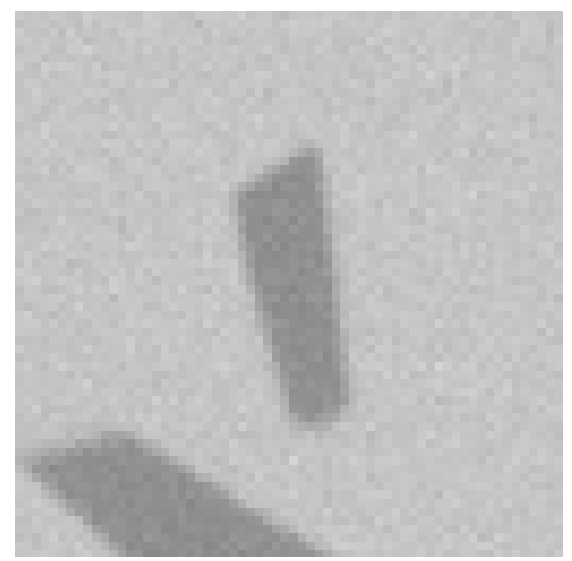

(c) Si: $75.20 \mathrm{wt} \%, \mathrm{~N}: 24.20 \mathrm{wt} \%$, Fe: $0.20 \mathrm{at} \%$, Al: $0.30 \mathrm{wt} \%$.

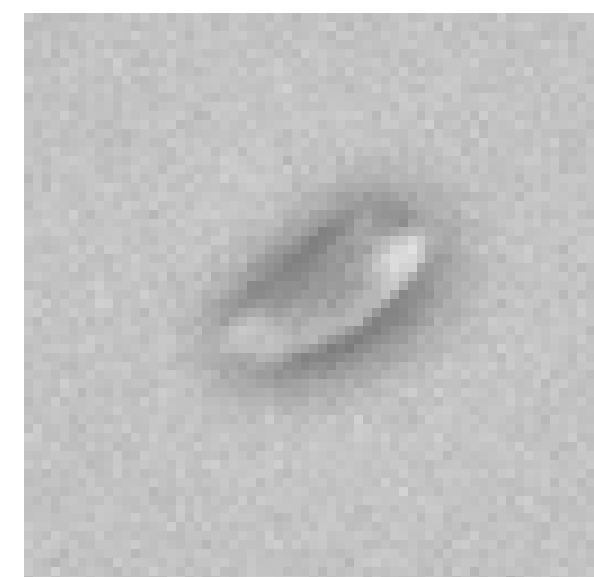

(b) Si: $82.3 \mathrm{wt} \%, \mathrm{C}: 8.30 \mathrm{wt} \%$, O: 3.90 at $\%$, Ti: 0.20 wt $\%$, Ca: $0.30 \mathrm{wt} \%$, Al: 0.60 at $\%$, Fe: $0.20 \mathrm{wt} \%$.

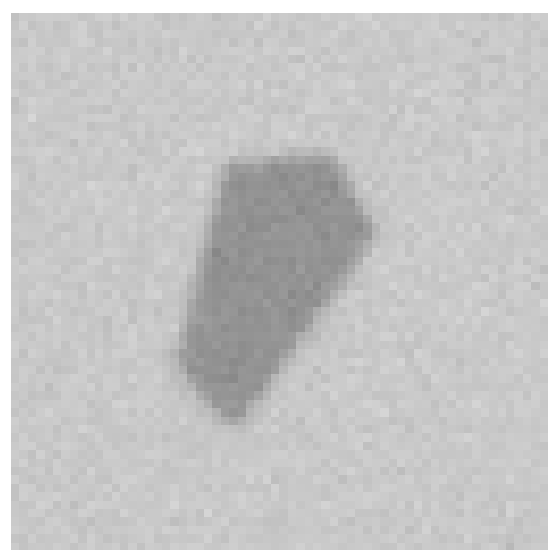

(d) Si: $79.30 \mathrm{wt} \%, \mathrm{~N}: 20.20 \mathrm{wt} \%$, Fe: 0.10 at $\%, \mathrm{Al}: 0.40 \mathrm{wt} \%$.

Fig.42 Morphology and composition of inclusions (ASPEX detection)

Table 4 lists the detected inclusions by ASPEX on a $9.8 \mathrm{~mm}^{2}$ area. Analysis results revealed that most inclusions were $\mathrm{Si}_{3} \mathrm{~N}_{4}$ and $\mathrm{SiC}$. The area percentage of $\mathrm{Si}_{3} \mathrm{~N}_{4}$ inclusions over all the detected inclusions was $72.27 \%$, and the total area percentage of $\mathrm{Si}_{3} \mathrm{~N}_{4}$ and $\mathrm{SiC}$ reached $\sim 90 \%$. The area of all the detected inclusions over the scanned area was $0.197 \%$ for the surface $1 \mathrm{~mm}$ beneath the surface. Over the $9.8 \mathrm{~mm}^{2}$ scanned area, there were 387 inclusions $1 \mathrm{~mm}$ beneath the surface. ASPEX analysis only detected the 2D cross-section of the particle rather than the full diameter and length of the particles, especially the long needle-like $\mathrm{Si}_{3} \mathrm{~N}_{4}$ inclusions.

Table 4 Different inclusions in the areas of $9.8 \mathrm{~mm}^{2} 1 \mathrm{~mm}$ beneath the top surface

\begin{tabular}{ccccccc}
\hline Inclusion & Numbers & $\begin{array}{c}\text { Total area } \\
\left(1 \times 10^{-6} \mathrm{~mm}^{2}\right)\end{array}$ & $\begin{array}{c}\text { Average area } \\
\left(1 \times 10^{-6} \mathrm{~mm}^{2}\right)\end{array}$ & $\begin{array}{c}\text { Max area } \\
\left(1 \times 10^{-6} \mathrm{~mm}^{2}\right)\end{array}$ & $\begin{array}{c}\text { Min area } \\
\left(1 \times 10^{-6} \mathrm{~mm}^{2}\right)\end{array}$ & $\%$ \\
\hline $\mathrm{Si}_{3} \mathrm{~N}_{4}$ & 105 & 13958 & 132.9 & 1928.6 & 0.098 & 72.27 \\
$\mathrm{SiC}$ & 27 & 3147.9 & 116.6 & 1738.9 & 0.44 & 16.30 \\
$\mathrm{Al}$ & 156 & 1288.6 & 8.3 & 428.0 & 0.27 & 6.67 \\
$\mathrm{Fe}$ & 3 & 150.3 & 75.2 & 143.1 & 7.25 & 0.78 \\
$\mathrm{Ca}$ & 1 & 10.8 & 10.8 & 10.8 & 10.80 & 0.056 \\
Others & 95 & 817.2 & 8.6 & 412 & 0.16 & 4.23 \\
\hline
\end{tabular}


The two-dimensional size distribution of inclusions is shown in Figure 43. The inclusions size ranged from less than $1 \mu \mathrm{m}$ to $\sim 50 \mu \mathrm{m}$, and most of the inclusions were smaller than $5 \mu \mathrm{m}$. Some metallic phases in the silicon scrap were detected, such as $\mathrm{Al}, \mathrm{Fe}$, and $\mathrm{Ca}$ phased. The size of most of Al phase was smaller than $3 \mu \mathrm{m}$.

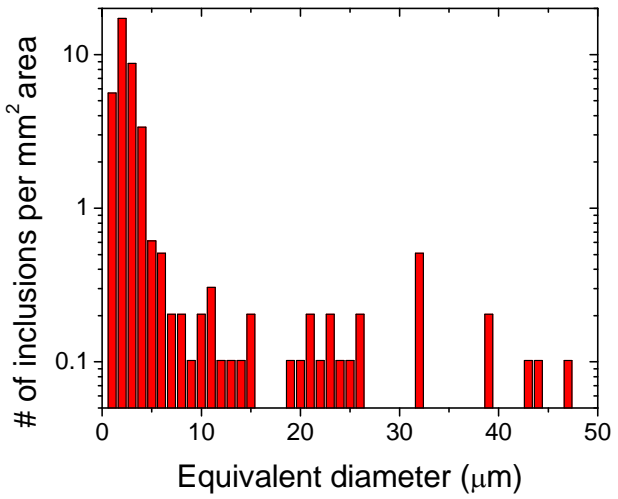

Fig.43 Two-dimensional size distribution of inclusions (ASPEX analysis)

\section{Inclusions $2 \mathrm{~mm}$ beneath the top surface}

Figure 44 shows the optical microscope observation of inclusions $2 \mathrm{~mm}$ beneath the top surface of the top cut silicon scrap. It was found that most of the inclusions gathered at the corner of the sample. The particle size varied from several micrometers to almost $1 \mathrm{~mm}$, it was very similar to the inclusions $1 \mathrm{~mm}$ beneath the top surface. Table 5 lists different inclusions analyzed by ASPEX. A $9.8 \mathrm{~mm}^{2}$ area was scanned. Aspex analysis revealed that most inclusions were $\mathrm{Si}_{3} \mathrm{~N}_{4}$ and $\mathrm{SiC}$, and mainly $\mathrm{SiC}$ inclusions. There was a huge difference between $2 \mathrm{~mm}$ and $1 \mathrm{~mm}$ beneath the top surface of the silicon scrap. For $1 \mathrm{~mm}$ beneath the top surface, the area percent of $\mathrm{Si}_{3} \mathrm{~N}_{4}$ was $72.27 \%$; while for $2 \mathrm{~mm}$ beneath the top surface, this value decreased to 17.43 and there was an obvious increase in the area percentage of SiC particles. Furthermore, the area percent of total particles decreased from $0.197 \%$ to $0.114 \%$. There were 387 inclusions detected $1 \mathrm{~mm}$ beneath the top and the average diameter of inclusions in $3.52 \mu \mathrm{m}$, which there was only 44 inclusions $2 \mathrm{~mm}$ beneath the top surface, and with an average diameter of $14.23 \mu \mathrm{m}$. The two-dimensional size distribution of inclusions $2 \mathrm{~mm}$ beneath the surface is shown in Figure 45 . The inclusions size ranged from $<1 \mu \mathrm{m}$ to $60 \mu \mathrm{m}$, and most of the inclusions were smaller than $25 \mu \mathrm{m}$.

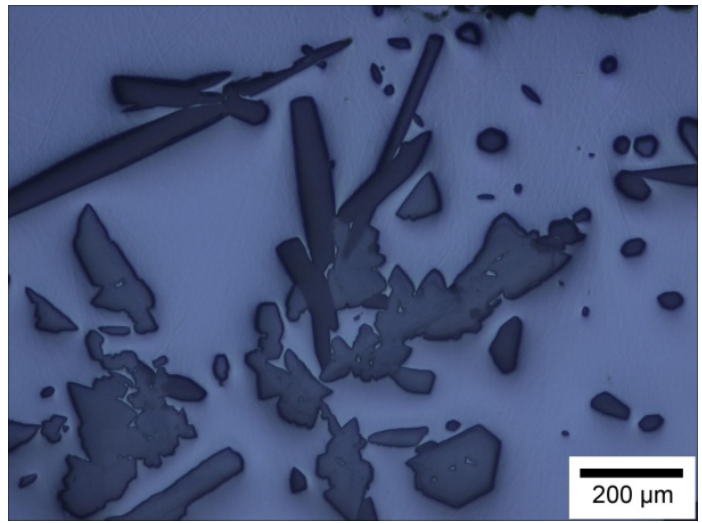

(a)

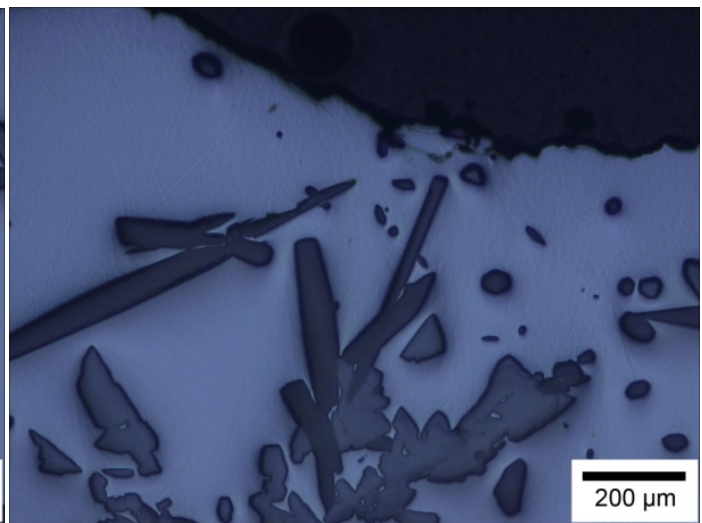

(b) 


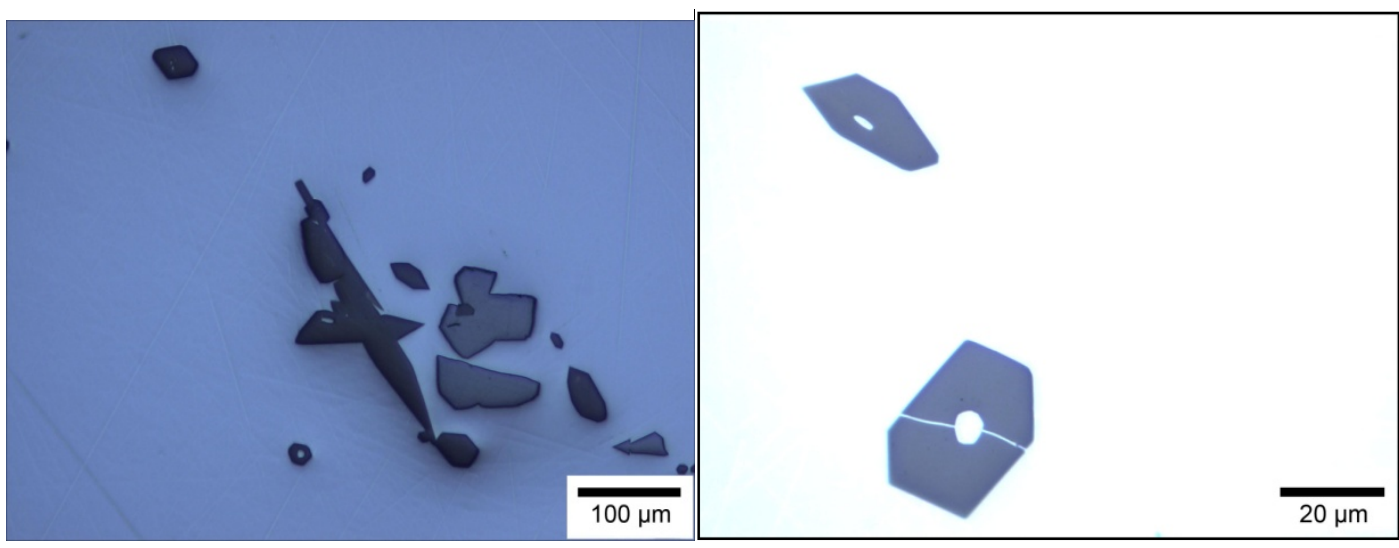

(c)

(d)

Fig.44 Inclusions morphology $2 \mathrm{~mm}$ beneath the top surface

Table 5 Different inclusions in the area of $9.8 \mathrm{~mm}^{2} 2 \mathrm{~mm}$ beneath the top surface.

\begin{tabular}{ccccccc}
\hline Inclusion & Numbers & $\begin{array}{c}\text { Total area } \\
\left(1 \times 10^{-6} \mathrm{~mm}^{2}\right)\end{array}$ & $\begin{array}{c}\text { Average area } \\
\left(1 \times 10^{-6} \mathrm{~mm}^{2}\right)\end{array}$ & $\begin{array}{c}\text { Max area } \\
\left(1 \times 10^{-6} \mathrm{~mm}^{2}\right)\end{array}$ & $\begin{array}{c}\text { Min area } \\
\left(1 \times 10^{-6} \mathrm{~mm}^{2}\right)\end{array}$ & $\%$ \\
\hline $\mathrm{Si}_{3} \mathrm{~N}_{4}$ & 7 & 1939.28 & 277.04 & 468.16 & 102.67 & 17.43 \\
$\mathrm{SiC}$ & 33 & 8919.05 & 278.72 & 2826.2 & 31.96 & 80.15 \\
$\mathrm{Al}$ & 1 & 31.82 & 31.82 & 31.82 & 31.82 & 0.29 \\
$\mathrm{Ca}$ & 1 & 52.92 & 52.92 & 52.92 & 52.92 & 0.47 \\
Others & 3 & 185.24 & 61.75 & 166.39 & 5.25 & 1.66 \\
total & 44 & 11128.31 & 252.92 & 2826.2 & 5.25 & 100 \\
\hline
\end{tabular}

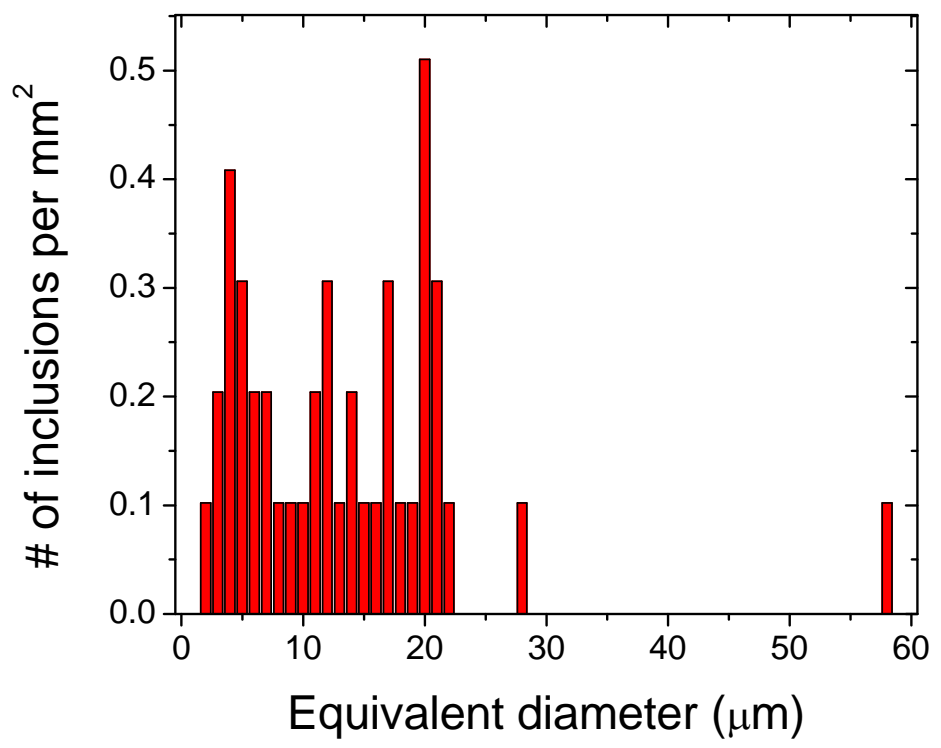

Fig.45 2D size distribution of inclusions $2 \mathrm{~mm}$ beneath the top surface

\section{Inclusions 3-5mm beneath the top surface}

Figure 46 shows the morphology of inclusions $3 \mathrm{~mm}, 4 \mathrm{~mm}$ and $5 \mathrm{~mm}$ beneath the top surface. The deeper beneath the surface, the less inclusions were observed, and the smaller size of the inclusions. Only a few inclusions on the $9.8 \mathrm{~mm}^{2}$ area were observed $4 \mathrm{~mm}$ and $5 \mathrm{~mm}$ beneath the surface. No $\mathrm{Si}_{3} \mathrm{~N}_{4}$ inclusions were observed after $3 \mathrm{~mm}$ beneath the top surface. Beyond 3 $\mathrm{mm}$ depth, only $\mathrm{SiC}$ particles were observed. No particles were detected beyond $6 \mathrm{~mm}$ depth. 


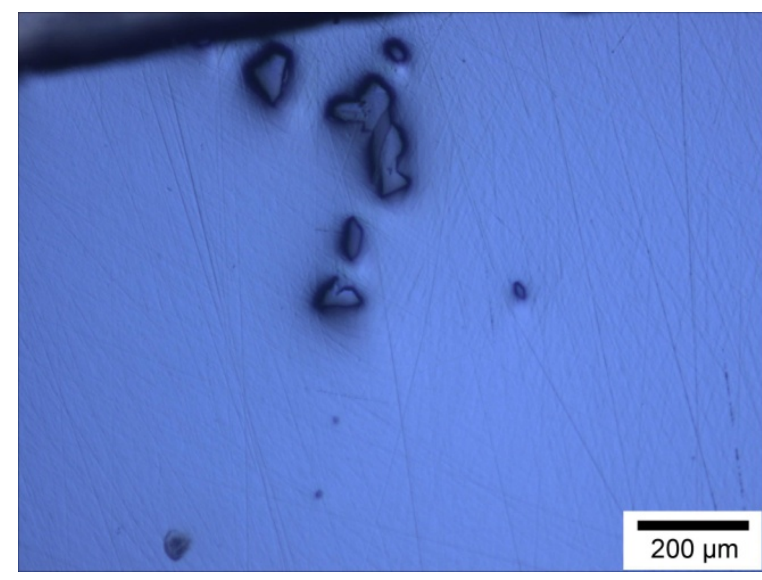

(a) $3 \mathrm{~mm}$

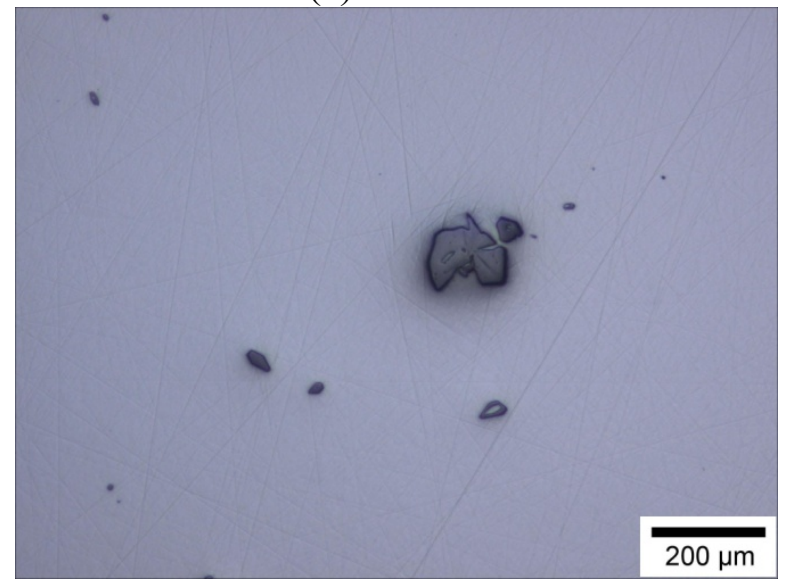

(c) $4 \mathrm{~mm}$

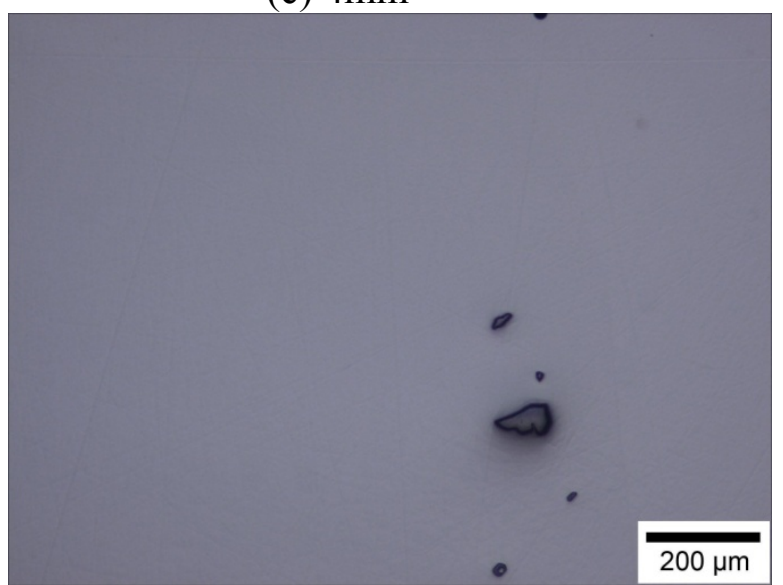

(e) $5 \mathrm{~mm}$

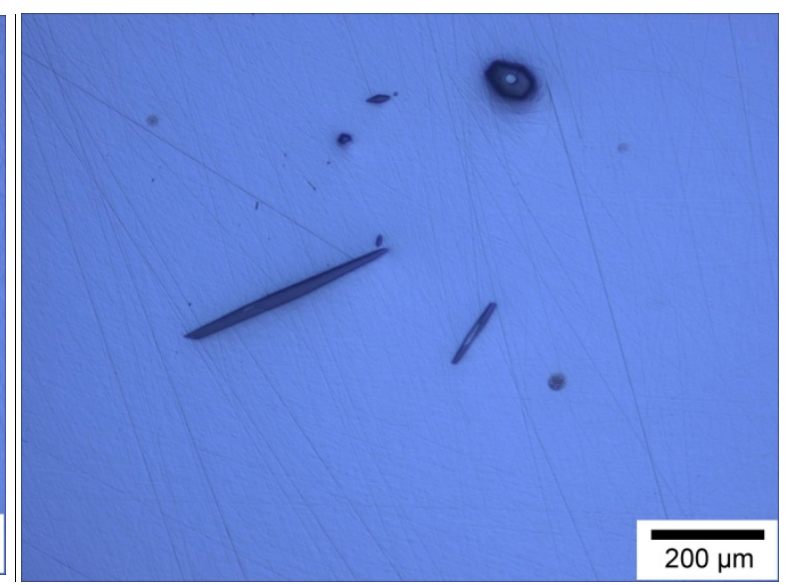

(b) $3 \mathrm{~mm}$

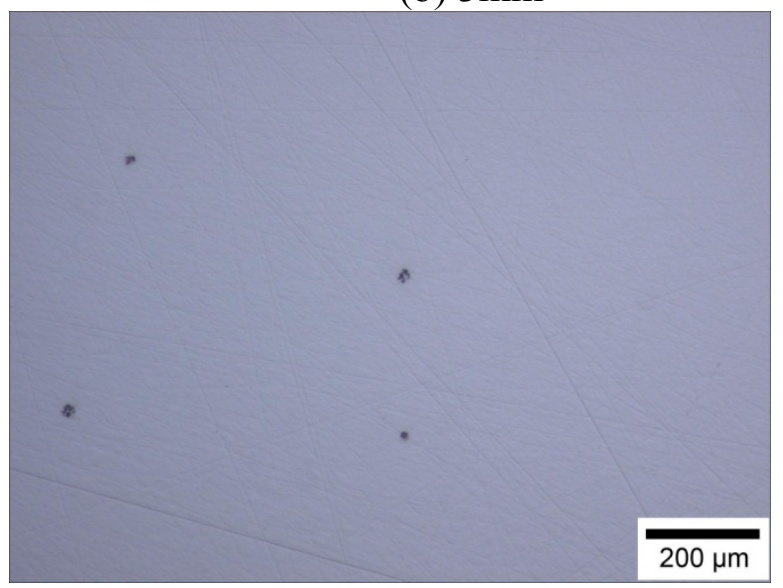

(d) $4 \mathrm{~mm}$

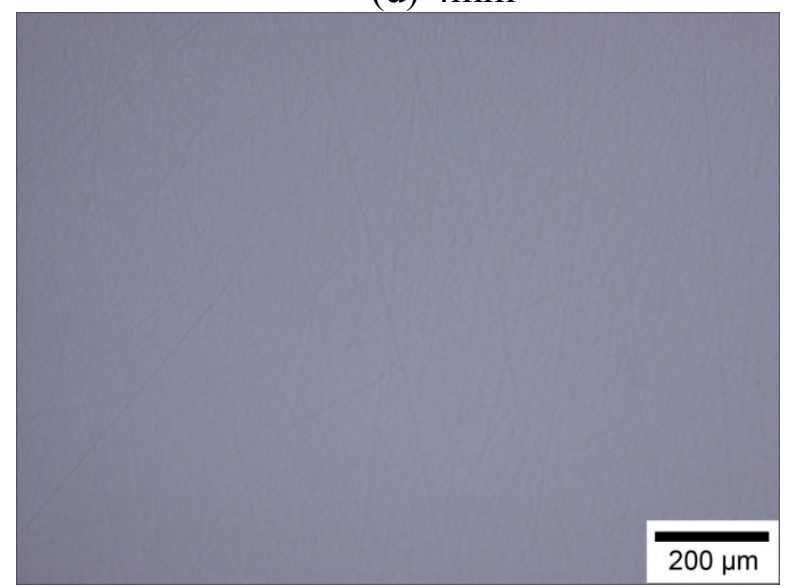

(f) $5 \mathrm{~mm}$

Fig.46 Inclusions inside a top-cut SoG-Si scrap 3-5mm beneath its surface

\subsubsection{Inclusions inside Top-cut Scraps from Company Y (Sample Y)}

Figure 47 summarized the size distributions of inclusions on the cut face of $1 \mathrm{~mm}, 2 \mathrm{~mm}, 3 \mathrm{~mm}$ and $4 \mathrm{~mm}$ beneath the surface of the silicon top-cut scrap from another company (Sample Y). Most of the inclusions observed in this sample were $\mathrm{SiC}$ and $\mathrm{Si}_{3} \mathrm{~N}_{4}$ lumps and sometimes their agglomerates. The number of $\mathrm{Si}_{3} \mathrm{~N}_{4}$ inclusions detected $(\sim 60.5 \%)$ was far more than the $\mathrm{SiC}$ inclusions $(\sim 39.5 \%)$ in this sample, with average diameter of $\sim 2-15 \mu \mathrm{m}$. Deeper into the scrap 
from the top surface, less number of inclusions were observed. However, the average size of the inclusions detected farther into the sample from the surface was $\sim 10-20 \mu \mathrm{m}$ and they were mainly lumps of $\mathrm{SiC}$ particles compared to the samples shown Figures 41-46 (Sample X) in which smaller particles were detected deeper into the scrap than larger ones.

For sample $\mathrm{Y}$, impurities such as $\mathrm{Al}, \mathrm{Ca}, \mathrm{Fe}, \mathrm{Ti}, \mathrm{Zr}$ and $\mathrm{O}$ were detected by ASPEX in some of the inclusions, as shown in Table 6. These impurities were mainly detected within the layer 1 $\mathrm{mm}$ beneath the top surface. Below this layer, other impurities apart from $\mathrm{Ca}$ were hardly detected. Furthermore, the concentrations of the impurities decreased with depth into the scrap.
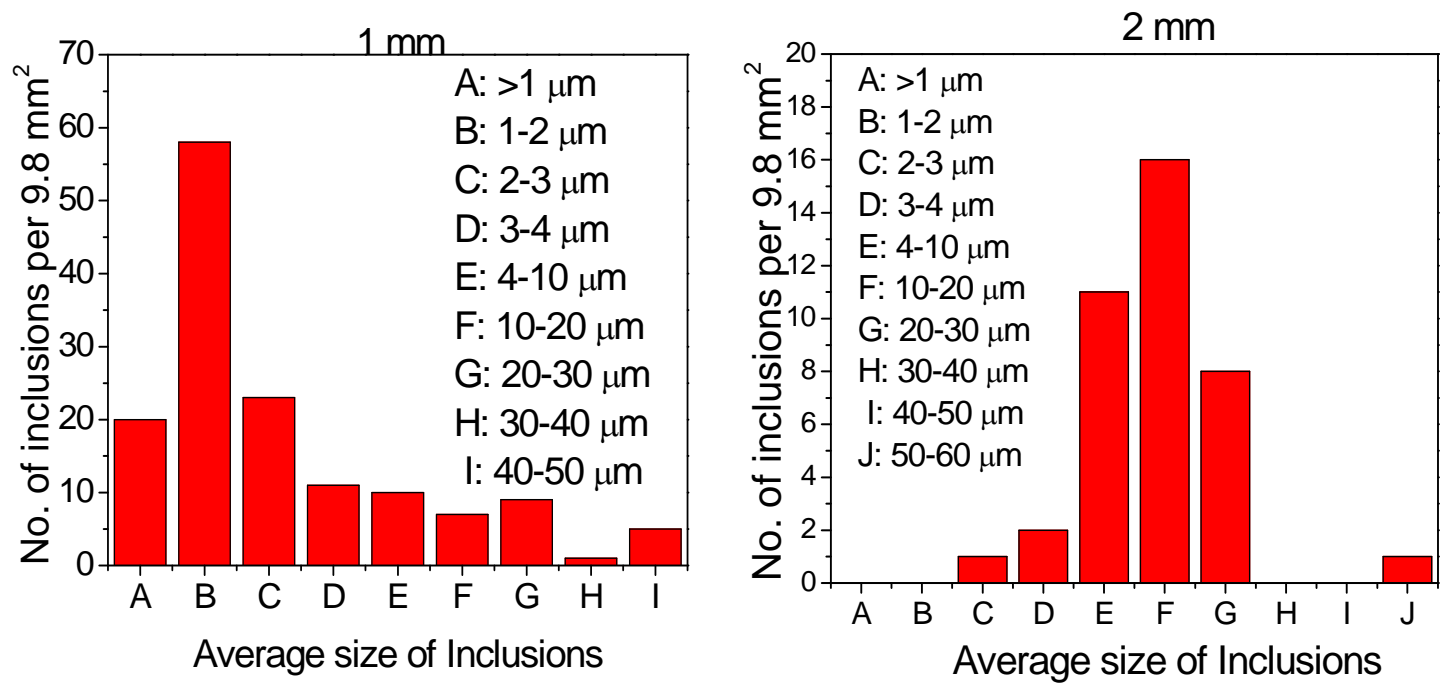

Average size of Inclusions
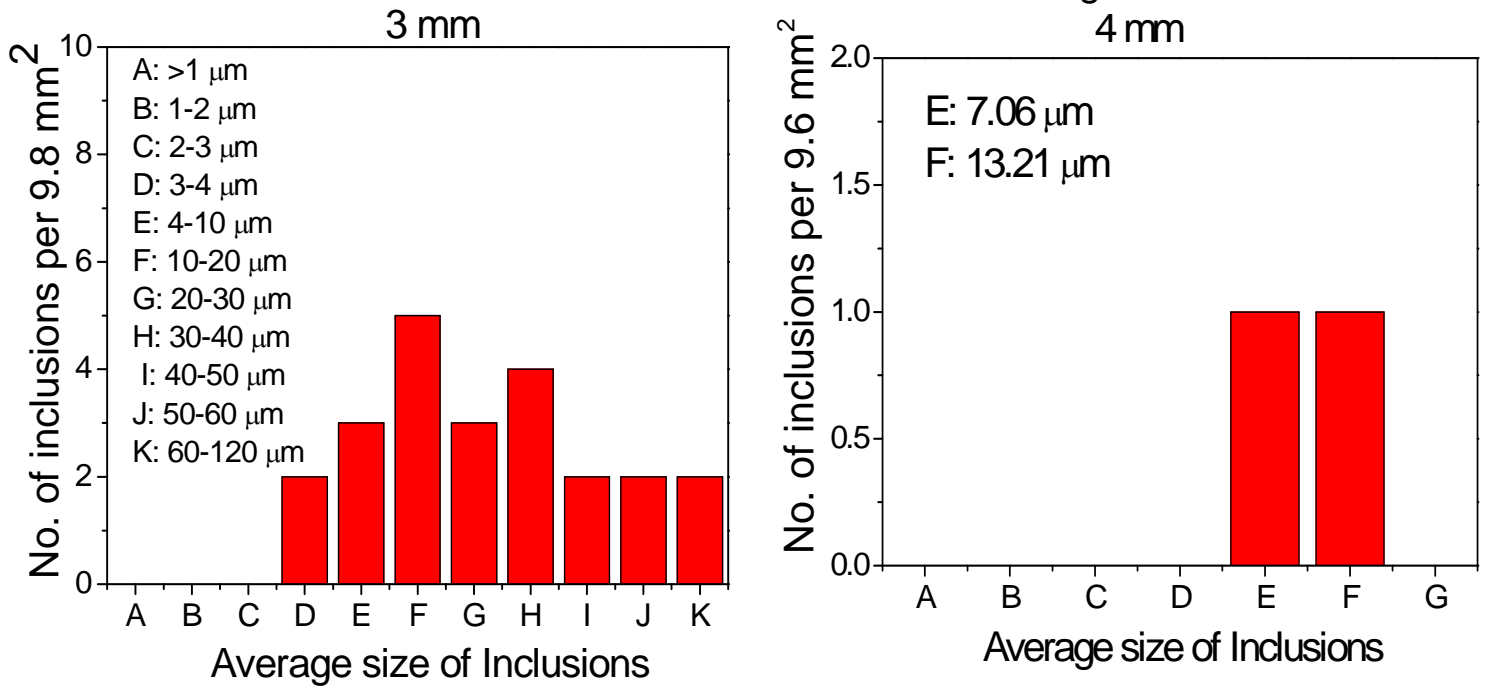

Fig.47 Size distribution of inclusions $1 \mathrm{~mm}, 2 \mathrm{~mm}, 3 \mathrm{~mm}$ and $4 \mathrm{~mm}$ beneath the top surface 
Table 6 ASPEX composition (wt \%) of some $\mathrm{SiC}$ and $\mathrm{Si}_{3} \mathrm{~N}_{4}$ particles detected at various levels beneath the top surface of Samples Y.

\begin{tabular}{|c|c|c|c|c|c|c|c|}
\hline Inclusion & $\mathrm{Si}$ & $\mathrm{Al}$ & $\mathrm{C}$ & $\mathrm{Fe}$ & $\mathrm{N}$ & $\mathrm{Ti}$ or $\mathrm{Ca}$ & $\mathrm{Zr}$ \\
\hline \multicolumn{8}{|l|}{$1 \mathrm{~mm}$} \\
\hline $\mathrm{Si}_{3} \mathrm{~N}_{4}$ & 55.53 & 6.11 & & 1.32 & 28.04 & & 9.00 \\
\hline $\mathrm{Si}_{3} \mathrm{~N}_{4}$ & 56.8 & 9.06 & & 1.53 & 24.42 & & 8.19 \\
\hline $\mathrm{Si}_{3} \mathrm{~N}_{4}$ * & 60.12 & 4.01 & & & 29.54 & 2.31 & 4.02 \\
\hline $\mathrm{Si}_{3} \mathrm{~N}_{4}$ & 58.64 & 0.99 & & 0.58 & 34.55 & & 5.34 \\
\hline $\mathrm{Si}_{3} \mathrm{~N}_{4}$ & 58.79 & 1.65 & & 0.88 & 33.74 & & 4.94 \\
\hline $\mathrm{SiC}$ & 62.53 & 5.10 & 29.05 & 1.30 & & & 2.02 \\
\hline $\mathrm{SiC}$ & 60.80 & 5.06 & 26.45 & 1.50 & & & 6.19 \\
\hline $\mathrm{SiC}^{* *}$ & 58.00 & 5.22 & 29.83 & & & 1.16 & 5.80 \\
\hline \multicolumn{8}{|l|}{$2 \mathrm{~mm}$} \\
\hline $\mathrm{Si}_{3} \mathrm{~N}_{4}$ & 75.8 & & 24.2 & & & & \\
\hline $\mathrm{SiC}$ & 76.47 & & 23.53 & & & & \\
\hline $\mathrm{SiC}^{* *}$ & 68.90 & & 18.90 & & & 1.30 & \\
\hline \multicolumn{8}{|l|}{$3 \mathrm{~mm}$} \\
\hline $\mathrm{Si}_{3} \mathrm{~N}_{4}$ & 76.30 & & & & 23.7 & & \\
\hline $\mathrm{SiC}^{* *}$ & 75.21 & & 20.7 & & & 4.09 & \\
\hline \multicolumn{8}{|l|}{$4 \mathrm{~mm}$} \\
\hline $\mathrm{SiC}$ & 83.00 & & 10.60 & & & & \\
\hline $\mathrm{SiC}$ & 72.70 & & 18.40 & & & & \\
\hline \multicolumn{8}{|l|}{$5 \mathrm{~mm}$} \\
\hline $\mathrm{SiC}$ & 82.00 & & 16.20 & & & 1.80 & \\
\hline
\end{tabular}

\subsubsection{Formation of Inclusions in SoG-Si}

Figure 48 shows a plot of the solubility of carbon, and nitrogen against the number of $\mathrm{SiC}$ and $\mathrm{Si}_{3} \mathrm{~N}_{4}$ inclusions that can form in the molten silicon. ${ }^{[42]}$ These inclusions forms in the silicon since carbon and nitrogen are present in the molten silicon within the concentration range shown in Figure 48. There are two possible sources of nitrogen in the melt: the crucible coating (i.e.

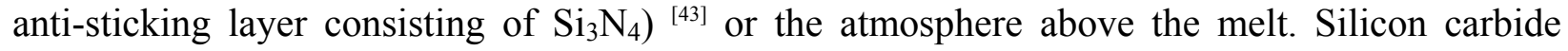
inclusions are generated through a reaction between carbon from the graphite heating elements and the silicon melt during the directional solidification process ${ }^{[44-47]}$ or from the SiC lining refractory.

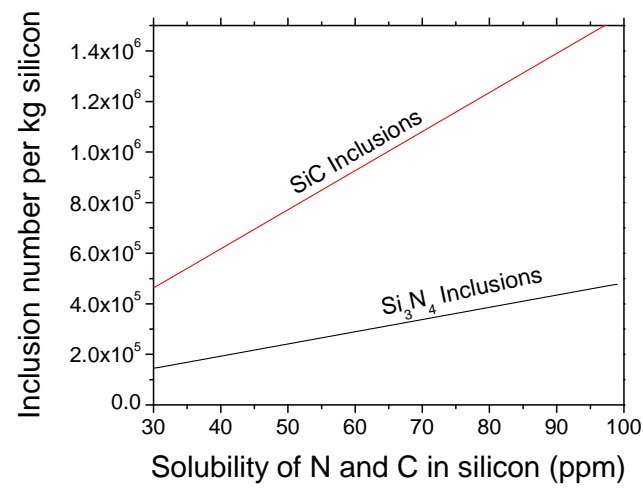

Fig.48 Inclusions number as a function of solubility of $\mathrm{N}$ and $\mathrm{C}$ in silicon (Si3N4: $500 \mu \mathrm{m}$ long and $20 \mu \mathrm{m}$ in diameter, with density of $3300 \mathrm{~kg} / \mathrm{m}^{3} ; \mathrm{Si}_{3} \mathrm{~N}_{4}: 50 \mu \mathrm{m}$ in equivalent diameter, with density of $\left.3300 \mathrm{~kg} / \mathrm{m}^{3}\right)^{[42]}$ 


\subsubsection{Summary}

This chapter investigated the inclusions in SoG MC silicon scraps. The main inclusions in SoG-Si top-cut scraps from two manufacturers-Sample X and Sample Y, were investigated using acid extraction, automated feature analysis techniques SEM and Optical Microscopy. Inclusions were needle-like $\mathrm{Si}_{3} \mathrm{~N}_{4}$ and lumpy $\mathrm{SiC}$ inclusions and their clusters with sizes ranging from 500 $\mu \mathrm{m}$ for $\mathrm{SiC}$ and several millimeters for $\mathrm{Si}_{3} \mathrm{~N}_{4}$ on top of top-cut scrap to between $2-500 \mu \mathrm{m}$ for both particles inside the top-cut scrap. $\mathrm{Si}_{3} \mathrm{~N}_{4}$ particles were present from the top surface to a depth of $3 \mathrm{~mm}$ beneath top surface. The particles detected beyond a depth of $3 \mathrm{~mm}$ were mainly $\mathrm{SiC}$ particles. Almost no particles were detected for Sample X beyond $8 \mathrm{~mm}$, and beyond $6 \mathrm{~mm}$ for Sample Y. In Sample X SiC particles were more than $\mathrm{Si}_{3} \mathrm{~N}_{4}$ whereas in Sample $\mathrm{Y} \mathrm{Si}_{3} \mathrm{~N}_{4}$ particles were $\sim 62 \%$. Some of these particles had impurities such as $\mathrm{Al}, \mathrm{Ca}, \mathrm{Fe}, \mathrm{O}, \mathrm{Ti}$ and $\mathrm{Zr}$ in them. For the directional solidified silicon ingot, an approximate distance of $\sim 10 \mathrm{~mm}$ gives an encouraging cutoff thickness to increase productivity.

\subsection{Recycling of SoG Silicon Top-Cut Scraps using Electromagnetic Purification}

Non-metallic particles in the silicon have a strong detrimental effect on the conversion efficiency of the solar cell. Removing non-metallic particles, such as $\mathrm{SiC}$ and $\mathrm{Si}_{3} \mathrm{~N}_{4}$, from the silicon is important in order to recycle the top-cut scraps to a useful feedstock for the silicon solar cells. It can enhance the market for recycling silicon scraps ${ }^{[24]}$.

Though the density of $\mathrm{SiC}$ and $\mathrm{Si}_{3} \mathrm{~N}_{4}$ particles are larger than silicon melt, the sedimentation removal will not industrially work because 1 ) the natural sedimentation takes long time ${ }^{[48-49]}$; 2 ) the solidification front during the cooling process pushes the particles to the top for a direction solidification process; and 3) the natural convection during melting and cooling process generates a recirculating flow pattern which brings the particles to the top.

Filtration using ceramic foam filters to remove $\mathrm{SiC}$ and $\mathrm{Si}_{3} \mathrm{~N}_{4}$ inclusions has been investigated by the PI Zhang and his group ${ }^{[24,50]}$ and the filtration can remove over $97 \%$ of the $>10 \mu \mathrm{m}$ inclusions. However, there are three issues for the filtration process that have to be solved before it can be used in an industrial scale: 1) how to realize a continuous filtration rather than a batch process since with more and more inclusions are captured by the filter, the holes of the filter will be blocked; 2) how to control the pollution from the filter materials to the silicon. The investigation by the current author Zhang ${ }^{[50]}$ has showed that the impurities elements in the silicon, such as $\mathrm{Fe}, \mathrm{Al}, \mathrm{P}, \mathrm{B}$, were greatly increased after filtration, although the filtration removed most of big inclusions; and 3) filtration is not efficient to remove $<10 \mu \mathrm{m}$ inclusions which are still very detrimental for solar cell silicon.

A new approach to purify silicon - electromagnetic (EM) separation was proposed in the current project.

\subsubsection{Principle of EM Separation}

The principle of EM separation of particles from liquids was firstly proposed by Kolin in 1953 ${ }^{[51]}$, and by Leenov and Kolin in $1954{ }^{[52]}$. The mechanism of particle separation by EM field is similar to that of gravitational separation. Both the gravitational separation and the EM separation utilize a difference in the physical properties of the metal and the inclusion particle. These differences can deduce a force driving particle motion in the melt under an applied external force field. In the case of the gravitational separation, it is the density difference between the melt and the particles to drive the motion of the particle. In the case of 
electromagnetic separation, it is the difference in the electrical conductivity between the inclusions and the melt. Figure 49 is schematic of the EM force under an EM field separation. When a uniform EM force is applied to a molten metal, the metal is compressed by the EM force (Lorentz force) and a pressure gradient is generated in the metal. The non-conductive particles $\left(\sigma_{\mathrm{P}}=0\right)$ or less conductive particles $\left(\sigma_{\mathrm{p}} / \sigma_{\mathrm{f}}<<1\right)$ are forced to move in the opposite direction of EM force $f_{0}$, the total force imposed upon the particle $F_{\mathrm{p}}$ is expressed by ${ }^{[33-54]}$ :

$$
F_{p}=-\frac{3}{4} \frac{\pi d_{p}^{3}}{6} f_{0}
$$

$f_{0}$ is the imposed electromagnetic force, which can be expressed by

$$
f_{0}=J \times B
$$

where $\sigma_{\mathrm{p}}$ is the electrical conductivity of the particle, $\sigma_{\mathrm{f}}$ is the electrical conductivity of the melt, $d_{\mathrm{p}}$ is the diameter of the particles, $J$ is imposed electric current density $\left(\mathrm{A} / \mathrm{m}^{2}\right)$, and $B$ is the imposed magnetic flux density $(\mathrm{T})$.

For particles in the molten silicon, the electrical conductivity of the silicon melt (at melting temperature $1414^{\circ} \mathrm{C}$ ), $\mathrm{SiC}$ particle and $\mathrm{Si}_{3} \mathrm{~N}_{4}$ particle are $1.29 \times 10^{6} \mathrm{~S} / \mathrm{m}^{[55]}, 10^{-4}-1.0 \mathrm{~S} / \mathrm{m}$, and $10^{-11}$ $\mathrm{S} / \mathrm{m}^{[56]}$ respectively, indicating that the electrical conductivity of the silicon melt is at least 10 orders larger than that of the non-metallic inclusions. Thus, $\mathrm{SiC}$ and $\mathrm{Si}_{3} \mathrm{~N}_{4}$ particles will experience a strong repulsive force in the silicon melt.

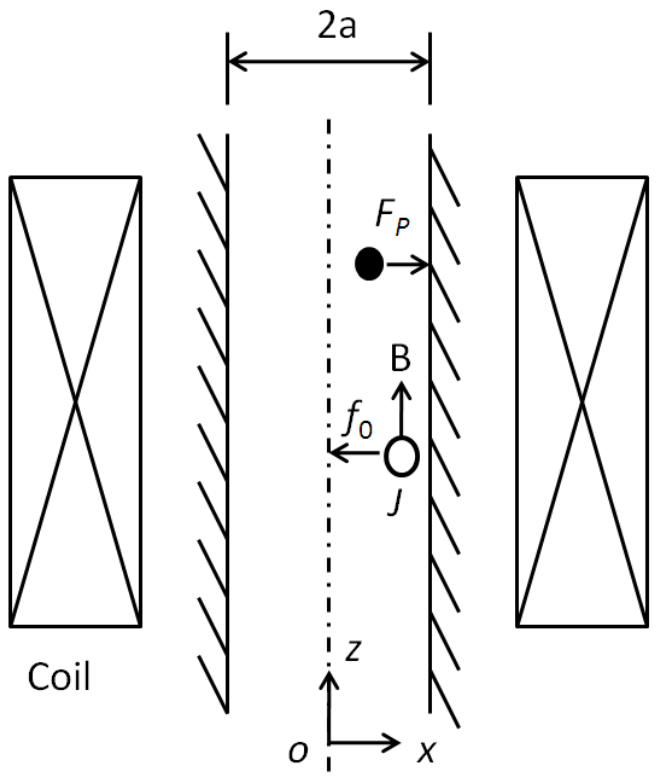

Fig.49 Principle for the separation of inclusions from the liquid metal under EM field

\subsubsection{Experimental Set-up}

In the current experiment, the top-cut silicon scraps with $\mathrm{SiC}$ and $\mathrm{Si}_{3} \mathrm{~N}_{4}$ inclusion particles were melted in a crucible that was under an EM field, as shown in Figure 72. The EM apparatus was composed of a high frequency power supply $(50-200 \mathrm{kHz}$, and $100 \mathrm{~kW})$, a special induction coil, and a special crucible system. The desired alternating EM field was generated in the induction coil. After EM separation, the cleanliness of the purified silicon samples was analyzed using optical microscope, automatic inclusion analyzer (ASPEX) and SEM-EDS. Top-cut SoG scraps 
was broken into pieces and remelted in a cylindrical crucible under high frequency EM field. Table 7 lists the experimental parameters for the EM separation experiments.

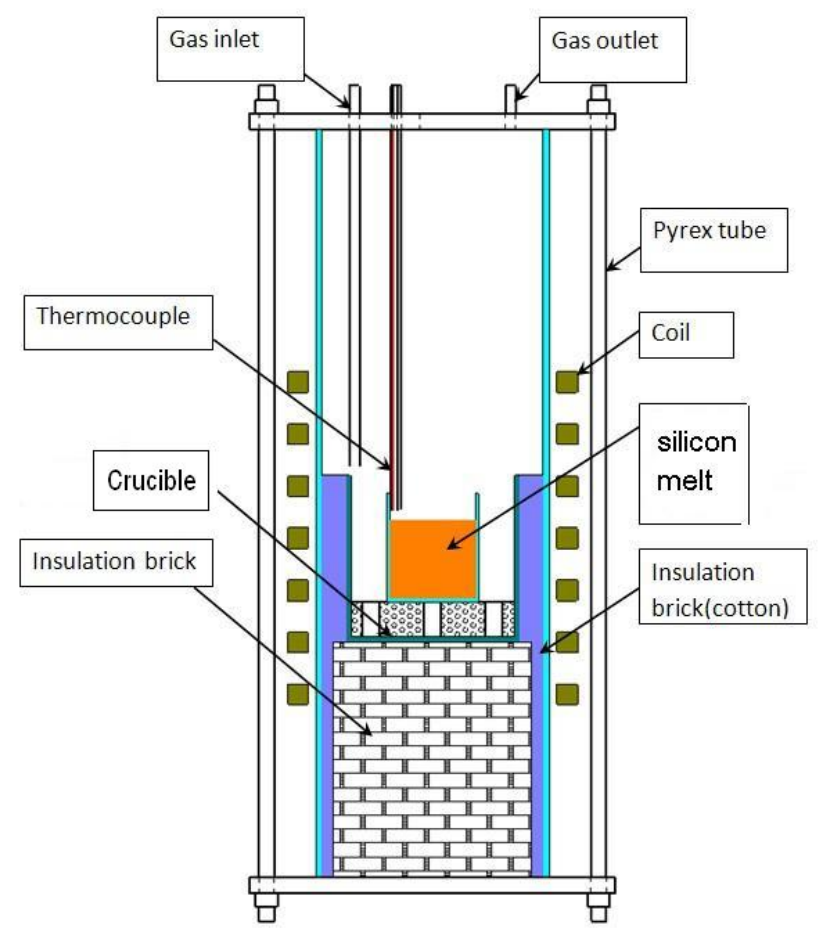

Fig.50 Sketch figure of experimental apparatus for the EM separation

Table 7 Experimental parameters for EM separation experiments

\begin{tabular}{|c|c|c|c|c|c|}
\hline Experiment \# & Stage & Current, A & Voltage, V & Frequency, $\mathrm{kHz}$ & Power, $\mathrm{kW}$ \\
\hline \multirow{2}{*}{ E1 } & Preheat time & 13.4 & 324 & 60 & 4.0 \\
\cline { 2 - 6 } & Separation time & 15.0 & 422 & 60 & 5.6 \\
\hline \multirow{2}{*}{ E2 } & Preheat time & 12.2 & 343 & 72 & 4.0 \\
\cline { 2 - 6 } & Separation time & 13.1 & 383 & 72 & 4.8 \\
\hline
\end{tabular}

\subsubsection{Separation of Inclusions from Silicon Using EM field}

Figure 51a shows the solidified silicon ingot after EM remelting and purification for experiment-E1. Figure 51b shows a quarter cross section close to the bottom of the ingot. An inclusion layer close to the boundary can be observed in the cross section area, and the maximum thickness of the inclusion layer is approximately $8 \mathrm{~mm}$, approximately $1 / 8$ of the crucible radius. Figure 52 illustrates the optical microscope image of the cross-sectional of the silicon after EM separation for experiment E1. Many separate and clustered SiC inclusions were pushed to the wall region. Some of the particles were captured by the wall, and some of them were close to the wall. The thickness of the inclusion layer for these two photos was approximately $200 \mu \mathrm{m}$. Most of the separate inclusions were smaller than $50 \mu \mathrm{m}$. Few inclusions were observed in the center of the cross section of the silicon ingot after EM purification, which implies that most of the inclusions were pushed to the boundary layer. 


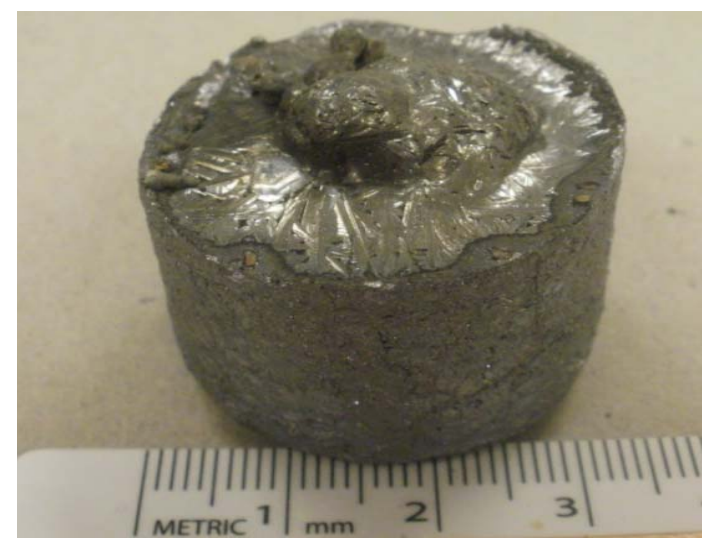

(a) Silicon ingot after EM purification

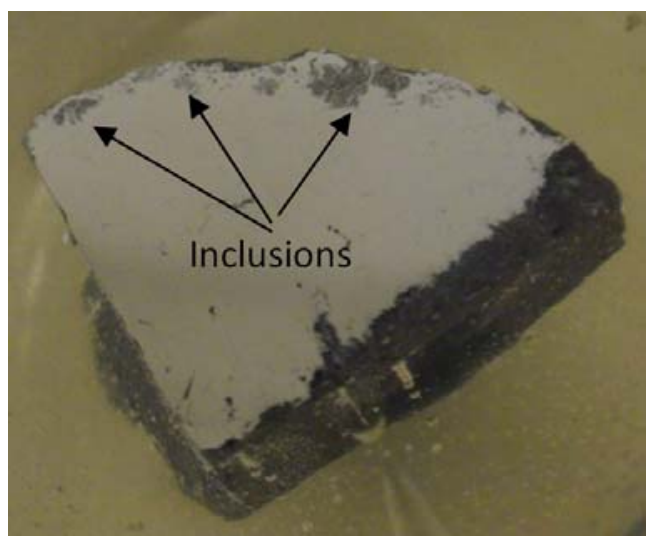

(b) A quarter cross section of the ingot

Fig.51 The silicon ingot after EM purification (experiment E1)

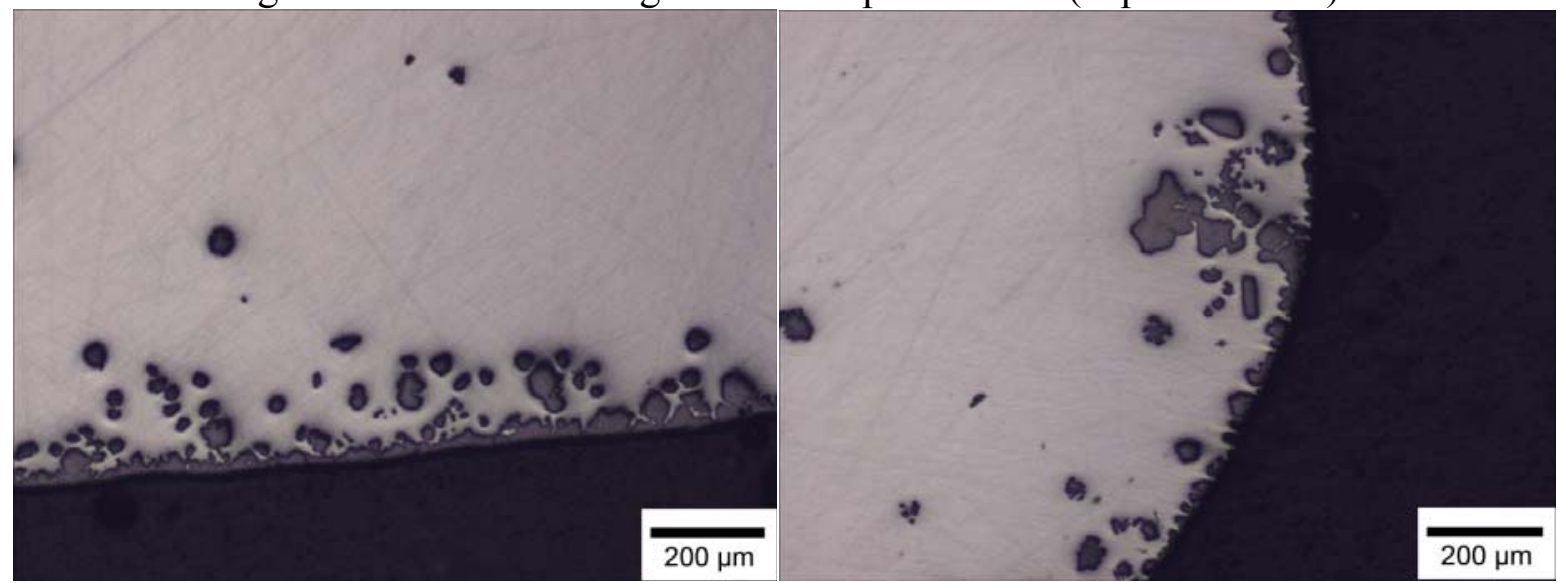

Fig.52 Optical microscope photos of inclusions in the horizontal cross section after EM separation (experiment E1)

Figure 53 shows the layer of inclusions on the cross section of the silicon ingot for experiment E2. Experiment E2 had smaller current, smaller power but the frequency was increased from 60 $\mathrm{kHz}$ to $72 \mathrm{kHz}$. Compared to the results of E1 in Figure 52, inclusions were more uniformly distributed and more dispersed for experiment E2. The average thickness of the E2 was over 200 $\mu \mathrm{m}$. The accumulation layer of the inclusions close to the crucible wall should depend on the strength of the EM force and the skin depth $\delta$ that is calculated by

$$
\delta=\sqrt{\frac{2}{\mu_{e} \sigma_{f} \omega}}
$$

where $\mu_{\mathrm{e}}$ is magnetic permeability of melt $(\mathrm{H} / \mathrm{m}), \omega$ is angular frequency $(\mathrm{rad} / \mathrm{s})$. The experiment E2 had higher frequency and lower current than the experiment E1, thus, the EM force, according to Eq.s (1) and (2), was smaller than the experiment E1. So, non-metallic particles in the layer were not as dense as E1.

The separation efficiency of inclusions by EM field depends on particle size, time, the effective magnetic flux density, separator channel size, the ratio of channel size to the skin depth, and the relative velocity between the inclusions and the fluid flow. ${ }^{[57]}$ Larger particle size, longer treatment time, larger effective magnetic flux density and smaller cross section area of the channel favor the removal of inclusions from the molten silicon. 


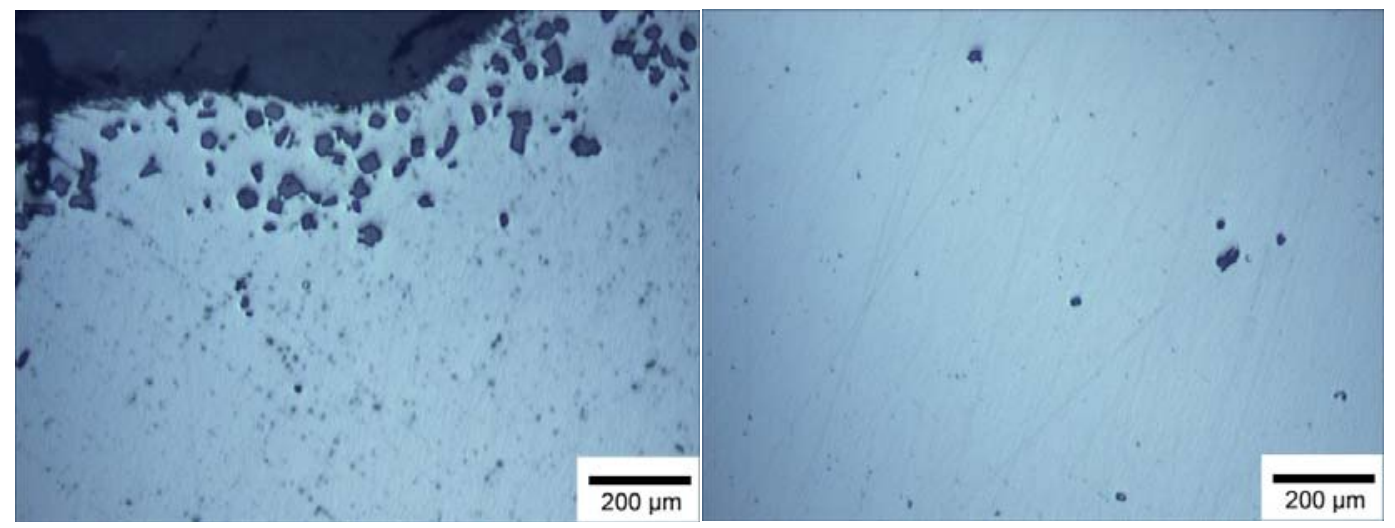

(a) In the boundary of the sample

(b) At the center region of the sample

Fig.53 Optical microscope photos of the cross section of the silicon ingot after EM purification (Experiment-E2)

\subsubsection{Summary}

Experiment results of EM separation show that the non-metallic inclusions were successfully pushed to the boundary layer of the crucible under EM force. Larger frequency and smaller current generate smaller thickness of accumulated inclusions. More detailed EM separation experiments are undergoing to investigate the factors that affect the removal efficient of inclusions from SoG-Si.

\section{Tentative Design for the Recycling of Silicon from Silicon Wastes}

The recycling of the SoG-Si top-cut scraps can be performed using the high temperature electromagnetic separation process by removing the non-metallic inclusions from the silicon.

The tentative design for the recovery of silicon from sawing slurry wastes is shown in Figure $\mathbf{5 4 .}$ The sawing slurry after several steps of centrifugal separation from CRS Company contains $45 \%$ silicon, $45 \% \mathrm{SiC}$ and $\sim 10 \%$ iron powders. Firstly, acid treatment will be performed to remove the iron powders. Then, a vacuum remelting process will be carried out to ooze the silicon from the $\mathrm{SiC}$ particles. The oozed silicon can be easily separated from the $\mathrm{SiC}$ particles. Then, the oozed silicon lumps will be remelted under electromagnetic field, and the remained small SiC particles will be pushed and removed from the silicon. The recovered and purified silicon can be used a feedstock to produce silicon wafers for solar cells.

\begin{tabular}{|l|l|}
\hline 1 & $\begin{array}{l}\text { Slurry from CRS (Product: Si } 45 \%+\mathrm{SiC} 45 \%+\mathrm{Fe} \\
10 \% \text { ) }\end{array}$ \\
\hline 2 & $\begin{array}{l}\text { Acid treatment to remove iron and drying (Product: } \\
\text { Si } 50 \%+\mathrm{SiC} 50 \% \text { ) }\end{array}$ \\
\hline 3 & $\begin{array}{l}\text { First vacuum remelting to rough separate SiC and } \\
\text { Si (Product: Si 95\% + SiC 5\%) }\end{array}$ \\
\hline 4 & $\begin{array}{l}\text { EM purification to further separate SiC from Si } \\
\text { (Product: Si 100\%) }\end{array}$ \\
\hline 5 & $\begin{array}{l}\text { - Solidification control of silicon (Product: Si ingot for } \\
\text { wafering) }\end{array}$ \\
\hline
\end{tabular}

Fig.54 The tentative design for the recovery of silicon from sawing slurry wastes 


\section{Acknowledgement}

This research is supported by Department of Energy (Award No. DE-EE0000575), the Laboratory of Green Process Metallurgy and Modeling, the Material Research Center, and the Intelligent Systems Center at Missouri University of Science and Technology. The Solar Power Industries, Inc and the CRS Reprocessing Services, Inc provided the experimental materials such as SoG silicon scraps and slurry materials. Researchers from these two companies also provided useful information on the technologies.

\section{References}

1. J. Then: http://www.zayasenergy.com/. 2010.

2. D. Sarti and R. Einhaus: Solar Energy Materials \& Solar Cells, 2002, vol. 72, pp. 27-40.

3. Solar Energy at Sandia National Laboratories, Sandia National Laboratories, Report, 1981.

4. J. Mazer: Department of Energy's Solar America Initiative (SAI). 17th Workshop on Crystalline Silicon Solar Cells and Modules: Materials and Processes: pp. 112-15, 2007.

5. Y.S. Tsuo, J.M. Gee, P. Menna, D.S. Strebkov, A. Pinov and V. Zadde: Environmentally Benign Silicon Solar Cell Manufacturing. 2nd World Conference and Exhibition on Photovoltaic Solar Energy Conversion: 1998.

6. C.P. Khattak, D.B. Joyce and F. Schmid: Production of Solar Grade (SoG) Silicon by Refining Liquid Metallurgical Grade (MG) Silicon, National Renewable Energy Laboratory, Report, 1998-1999.

7. d.W.-S. Mariska: Environmental Impact of Photovoltaic Technology. eNERGIAWorkshop on Environmental Impact/Consequences of Deployment at Scale of Alternative Renewable Energy Technologies: 2008.

8. H.A. Aulich: 2nd Solar Silicon Conference, (Munich, Germany ), 2005.

9. R.L. Billiet and H.T. Nguyen: Photovoltaic Cells from Silicon Kerf 2004.

10. D. Singh and P. Jennings: "The Outlook for Crystalline Solar Photovoltaic Technology over the Next Decade", AIP Conference Proceedings, 2007, vol. 941 (1), pp. 98-110.

11. G. Homan: "The Silicon Chain", http://www.semiconwest.org/cms/groups/public/documents/web_content/ctr_030778.pdf, 2009.

12. K. Bullis: http://www.technologyreview.com/Biztech/20702/: A Price Drop for Solar Panels. Technology Review: 2008.

13. Marketbuzz: MARKETBUZZTM 2007: ANNUAL WORLD SOLAR PHOTOVOLTAIC INDUSTRY REPORT Report, 2007.

14. J. Wohlgemuth and M. Narayanan: Large-Scale PV Module Manufacturing Using Ultra-thin Polycrystalline Silicon Solar Cells, BP Solar, Report, 2005.

15. D. Sarti and R. Einhaus: " Silicon feedstock for the multi-crystalline photovoltaic industry", Solar Energy Materials \& Solar cells, 2002, vol. 72, pp. 27-40.

16. W. Koch, A.L. Endros, D. Franke, C. Haßler, J.P. Kalejs and H.J. Moller: Bulk Crystal Growth and Wafering for PV, Handbook of Photovoltaic Science and Engineering, L. Antonio and H. Steven, eds., John Wiley \& Sons, 2003, pp. 205-54.

17. S. Nishijima, Y. Izumi, S.-I. Takeda, H. Suemoto, A. Nakahira and S.-I. Horie: "Recycling of 
abrasives from wasted slurry by superconducting magnetic separation", IEEE Transactions on Applied Superconductivity, 2003, vol. 13 (2), pp. 1596-99.

18. J. Wohlgemuth, M. Narayanan, R. Clark, T. Koval, S. Roncin, M. Bennett, D. Cunningham, D. Amin and J. Creager: "Large-scale PV module manufacturing using ultra-thin polycrystalline silicon solar cells", Conference Record of the Thirty-First IEEE Photovoltaic Specialist Conference (IEEE Cat. No. 05CH37608), 2005, pp. 1023-26.

19. N.B. Mason: "Industry Developments that Sustain the Growth of Crystalline Silicon PV Output", Proceedings of the Photovoltaic Science, Applications \& Technology Conference, (Durham UK), 2007, pp. 43-46.

20. A. Ciftja, A. Kvithyld, L. Zhang and T.A. Engh: "Removal of Inclusions from Silicon by Filtration", International conference of Silicon for the Chemical Industry VIII, (Trondheim, Norway, June 12 - 16, 2006), 2006, pp. 63-70.

21. A. Ciftja, L. Zhang, A. Kvithyld and T.A. Engh: "Purification of Solar Cell Silicon Materials Through Filtration", Rare Metals, 2006, vol. 25 (Special issue (Proceedings of International Conference on New Energy Materials- ICNEM 2006, June 27-28, 2006, Beijing)), pp. $180-85$.

22. C. Arjan, L. Zhang and T.A. Engh: "Removal of SiC and Si3N4 particles from Silicon Scrap by Form Filters", in TMS 2007 ANNUAL MEETING \& EXHIBITION:Recycling and Waste Processing: Materials Recovery from Wastes, Batteries and Co/Ni; Precious Metals Recovery; and Other NonFessrous, M. Schlesinger, R.L. Stephens and D.L. Stewart, eds.2007, pp. 67-76.

23. L. Zhang and A. Ciftja: "Recycling of solar cell silicon scraps through filtration, Part I: Experimental investigation", Solar Energy Materials \& Solar Cells 2008, vol. 92, pp. 1450-61.

24. L. Zhang, E. Øvrelid, S. Senanu, B. Agyei-Tuffour and A.N. Femi: "Nonmetallic Inclusions in Solar Cell Silicon: Focusing on Recycling of Scraps", Rewas2008: 2008 Global Symposium on Recycling, Waste Treatment and Clean Technology, (CANCUN, MEXICO), TMS, Warrendale, PA, USA, 2008, pp. 1011-26.

25. B. Sopori: National Solar Technology Roadmap: Wafer-Silicon PV, Report, 2007.

26. G. Kulia: "Nordic Renewable Energy Conference", http://www.metallkraft.no/media/4190/080513\%20presentation.pdf, 2008.

27. H. Takiguchi and K. Morita: "Sustaniability of Silicon Feedstock for a Low-carbon Society", Sustainability Sience, 2009, vol. 4, pp. 117-31.

28. K.G. Barraclough: "Waste Not, Want Not ! -A Case for Recycling Silicon Waste Powder Kerf", in www.kgbconsultingltd.com/downloads/Waste_Not_Want_Not.pdf 2006,

29. P. Mints: Phtovoltaic Manufacturer Shipemnts \& Competitive Analysis 2007/2008, Report, 2007.

30. E.A. Alsema, M.J.d. Wild-Scholten and V.M. Fthenakis: "Environmental Impacts of PV Electricity generation - a critical comparison of energy supply options", The 21st European Photovoltaic Solar Energy Conference, (Dresden, Germany), 2006.

31. L. Zhang, J. Aoki and B.G. Thomas: "Inclusion removal by bubble flotation in a continuous casting mold", Metal. \& Material Trans. B., 2006, vol. 37B (3), pp. 361-79.

32. L. Zhang and S. Taniguchi: "Fundamentals of Inclusions Removal from Liquid Steel by 
Bubbles Flotation", International Materials Reviews, 2000, vol. 45 (2), pp. 59-82.

33. R.L. Billiet and H.T. Nguyen: Photovoltaic cells from silicon kerf. vol. US20030041895 : Utility Patent Application 2003.

34. K. Sakaguchi and M. Maeda: "Decarburization of silicon melt for solar cells by filtration and oxidation", Metallurgical Transactions B (Process Metallurgy), 1992, vol. 23B (4), pp. 423-27.

35. N. Yuge, M. Abe, K. Hanazawa, H. Baba, N. Nakamura, Y. Kato, Y. Sakaguchi, S. Hiwasa and F. Aratani: "Purification of metallurgical-grade silicon up to solar grade", Progress in Photovoltaics: Research and Applications, 2001, vol. 9 (3), pp. 203-09.

36. N. Yuge, K. Hanazawa, K. Nishikawa and H. Terashima: "Removal of phosphorus, aluminum and calcium by evaporation in molten silicon", Nippon Kinzoku Gakkaishi/Journal of the Japan Institute of Metals, 1997, vol. 61 (10), pp. 1086-93.

37. W. Lee, W. Yoon and C. Park: "Purification of MetallurGical-grade Silicon in Fractional Melting Process", Journal of Crystal Growth, 2009, vol. 312 (1), pp. 146-48.

38. T.Y. Wang, Y.C. Lin, C.Y. Tai, C.C. Fei, M.Y. Tseng and C.W. Lan: "Recovery of Silicon from Kerf Loss Slurry Waste for Photovoltaic Applications", Progress in Photovoltaics: Research and Applications, 2009, vol. 17 (3), pp. 155-63.

39. Y.C. Lin, T.Y. Wang, C.W. Lan and C.Y. Tai: "Recovery of Silicon Powder from Kerf Loss Slurry by Centrifugation", pOwder Technology 2010, vol. 200, pp. 216-23.

40. H.J. Moller, L. Long, M. Werner and D. Yang: "Oxygen and carbon precipitation in multicrystalline solar silicon", Phys. Status Solidi A, 1999, vol. 171, p. 175.

41. A.C. Lifeng Zhang: "Recycling of solar cell silicon scraps through filtration, Part I: Experimental investigation", Solar Energy Materials \& Solar Cells, 2008, vol. 92, pp. 1450-61.

42. L. Zhang, E. Øvrelid, S. Senanu, B. Agyei-Tuffour and A.N. Femi: Nonmetallic Inclusions in Solar Cell Silicon: Focusing on Recycling of Scraps. REWAS 2008: 2008.

43. A.K. Soiland: Silicon for solar cells, Ph.D. Thesis Thesis, Norwegian University of Science and Technology, 2004.

44. G.H. Schwuttke, T.F. Ciszek, H.H. Yang and A. Kran: "Low cost silicon for solar energy conversion applications", IBM Journal of Research and Development, 1978, vol. 22 (4), p. 335.

45. T.F. Ciszek, G.H. Schwuttke and K.H. Yang: "Solar-grade silicon by directional solidification in carbon crucibles", IBM Journal of Research and Development, 1979, vol. 23 (3), p. 270.

46. T.F. Ciszek, G.H. Schwuttke and K.H. Yang: "Directionally solidified solar-grade silicon using carbon crucibles", Journal of Crystal Growth, 1979, vol. 46 (4), pp. 527-33.

47. T.F. Ciszek, G.H. Schwuttke and K.H. Yang: "Factors influencing surface quality and impurity distribution in silicon ribbons grown by the capillary action shaping technique (CAST) ", Journal of Crystal Growth, 1980, vol. 50 (1), pp. 160-74.

48. O.S. Fishman: "Solar Silicon Part II ", Advanced Materials \& Processes, 2008, vol. 166 (10), pp. 33-34.

49. O.S. Fishman: "Solar Silicon Part I", Advanced Materials \& Processes, 2008, (9), pp. 39-40. 
50. L. Zhang: "Recycling of Solar Cell Silicon Scraps Through Filtration, Part I: Experimental Investigation", Solar Energy Materials and Solar Cells, 2008, vol. 92 (11), pp. 1450-61.

51. A. Kolin: "An Electromagnetokinetic Phenomenon Involving Migration of Neutral Particles", Science, 1953, vol. 117 (2), pp. 134-37.

52. D. Leenov and A. Kolin: "Theory of Electromagnetophoresis. I. MagnetohydrodynamicForces Experienced by Spherical andSymmetrically Oriented Cylindrical Particles", J. Chem. Phys., 1954, vol. 22 (4), pp. 683-88.

53. K. Takahashi and S. Taniguchi: "Electromagnetic separation of nonmetallic inclusion from liquid metal by imposition of high frequency magnetic field", ISIJ Inter., 2003, vol. 43 (6), pp. 820-27.

54. F. Yamao, K. Sassa, K. Iwai and S. Asai: "Separation of inclusions in liquid metal using fixed alternating magnetic field", Tetsu-to-Hagane, 1997, vol. 83 (1), pp. 30-35.

55. V. Savolainen, J. Heikonen and J. Ruokolainen: "Simulation of Large-scale Silicon Melt Flow in Magnetic Czochralski Growth", Journal of Crystal Growth 2003, vol. 243, pp. 243-60.

56. http://www.azom.com/details.asp? ArticleID=5067.

57. D. Shu, B.D. Sun, J. Wang, T.X. Li and Y.H. Zhou: "Study of Electromagnetic Separation of Nonmetallic Inclusions from Aluminum Melt", Metall. Mater. Trans. A, 1999, vol. 30A (11), pp. 2979-88. 